\title{
GEOLOGÍA Y ESTRATIGRAFÍA DE LA HOJA 3246-II MIRAMAR, COSTA RICA
}

\author{
GEOLOGY AND STRATIGRAPHY OF THE SHEET 3246-II MIRAMAR, COSTA RICA
}

\author{
Vladimír Žáček ${ }^{1 *}$, Tomáš Vorel ${ }^{1}$, Petr $\mathrm{Kycl}^{1}$, Sofia Huapaya ${ }^{2}$, Petr Mixa ${ }^{1}$, \\ Radek Grygar ${ }^{3}$, Pavel Havlíček ${ }^{1}$, Stanislav Čech ${ }^{1}$, Petr Hrazdíra ${ }^{1}$, Václav \\ Metelka1, Josef Ševčík ${ }^{1} \&$ Zoltán Pécskay ${ }^{4}$
}

${ }^{1}$ Czech Geological Survey (Servicio Geológico Checo, CGS), Klárov 3 CZ-118 21 Praha 1, República Checa

${ }^{2}$ MINAET, Dirección de Geología y Minas, Apdo. 10104, San José, Costa Rica ${ }^{3}$ VŠB - Technical University of Ostrava, 17. listopadu 15 CZ-708 33

Ostrava-Poruba, República Checa

${ }^{4}$ Institute of Nuclear Research of the Hungarian Academy of Sciences, H-4001

Debrecen, P.O. Box 51, Hungría

*Autor para contacto: vladimir.zacek@geology.cz

(Recibido: 22/02/2012 ; aceptado: 17/12/2012)

\begin{abstract}
The oldest rocks of the Miramar sheet are represented by sediments of the Punta Carballo Formation (Miocene), which are exposed at the SW corner. However, volcanic rocks of the older Aguacate Group (MiocenePliocene) and overlying Monteverde Formation (Lower Pleistocene) dominate the area. The Pliocene to Pleistocene silicic ignimbrites and Quaternary sediments are subordinate. New K-Ar ages yielded 4,41 $\pm 0,15$ to $4,99 \pm 0,36 \mathrm{Ma}$ for the Aguacate Group and 1,71 $\pm 0,22$ to $1,77 \pm 0,11$ Ma for the Monteverde Formation. Gabrodioritic stock was newly mapped in the Aguacate Group accompanying numerous other intrusive bodies of variable composition. New K-Ar

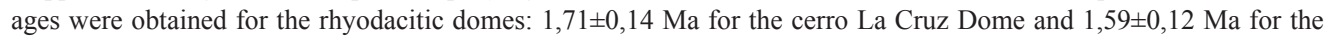
cerro San Miguel Dome. Definition of volcanic units is based on detailed petrography, XRD, microprobe and 33 new bulk-rock chemical analyses.

Keywords: geological map, Miramar, stratigraphy, K-Ar geochronology, geochemistry, Costa Rica
\end{abstract}

RESUMEN: Las rocas más antiguas de la hoja Miramar están conformadas por los sedimentos de la Formación Punta Carballo del Mioceno que afloran al SO de la hoja. Las vulcanitas del Grupo Aguacate (Mioceno-Plioceno) sobreyacidas por vulcanitas de la Formación Monteverde (Pleistoceno Inferior), representan la mayor extensión del 
mapa. En menor superficie se encuentran las ignimbritas del Plioceno hasta Pleistoceno y sedimentos del Cuaternario. Nuevas dataciones con el método K-Ar establecieron edades de 4,41 $\pm 0,15$ y 4,99 $\pm 0,36$ Ma para el Grupo Aguacate y de $1,77 \pm 0,11$ y 1,71 $\pm 0,22$ Ma para la Formación Monteverde. El Grupo Aguacate también está conformado por una serie de cuerpos intrusivos de composición variable, entre ellos un stock gabrodiorítico que fue recién mapeado y se describe por primera vez con este trabajo. Se hicieron nuevas dataciones K-Ar del domo riodacítico cerro La Cruz, cuya edad

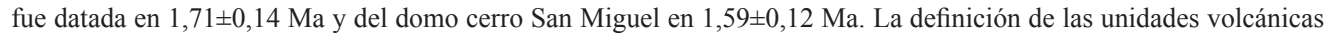
se basa en la petrografía detallada de las rocas, así como en los resultados de la difractometría de rayos X, microsonda electrónica y 33 análisis químicos.

Palabras claves: mapa geológico, Miramar, estratigrafía, dataciones geocronológicas K-Ar, geoquímica, Costa Rica.

\section{INTRODUCCIÓN}

En el año 2010, el Servicio Geológico Checo (CGS) y la Dirección de Geología y Minas (DGM), finalizaron el proyecto de investigación geológica, realizado en la región conocida como el Cinturón de oro de Costa Rica.

El levantamiento geológico estuvo a cargo de especialistas de las diferentes ramas de las geociencias y el mismo está respaldado por un trabajo de campo sistemático (2006-2009) que se realizó de acuerdo a la metodología utilizada por el CGS. Los resultados se presentaron en el informe final (Kycl et al., 2010) del proyecto, que fue entregado a la DGM. Algunos de los resultados fueron publicados - los mapas geológicos de las hojas topográficas Miramar, Chapernal y Juntas, escala 1:50 000 (Žáček et al., 2010 a-c) y tres artículos (Žáček et al. 2008, Mixa et al., 2011; Žáček et al., 2011).

Este artículo es una guía del mapa geológico de la hoja 3246-II Miramar, escala 1:50 000 (Figs. 1, 2 y 3; Žáček et al., 2010a) presentando además nuevos datos geocronológicos, mineralógicos y geoquímicos. El mapa geológico está accesible en la página web: http://www.geology. cz/mapy/miramar.pdf.

\section{METODOLOGÍA}

\section{Levantamiento geológico y muestreo}

Las campañas geológicas se realizaron durante los años 2006-2008. Fueron documentados aproximadamente 800 puntos de afloramientos, de donde también se obtuvieron muestras de rocas para los diferentes tipos de análisis realizados. Para la caracterización petrográfica se utilizaron 60 muestras, de las cuales se prepararon secciones delgadas y secciones delgadas pulidas (no cubiertas), esta última para analizarlas por microsonda electrónica. Las secciones se hicieron en los laboratorios del Servicio Geológico Checo (Czech Geological Survey - CGS) en Praga, República Checa.

\section{Microsonda electrónica}

Nueve muestras fueron analizadas por microsonda electrónica. La microsonda utilizada fue la Cameca SX-100 de la Universidad de Masaryk (MU), la cual se encuentra en el Centro de Trabajo Conjunto de la MU y CGS en Brno, República Checa. Los parámetros de análisis fueron: voltaje $15 \mathrm{kV}$, amperaje $10 \mathrm{nA}$ para feldespatos, anfíboles, piroxenos, olivinos y micas o $20 \mathrm{nA}$ para titanita, magnetita e ilmenita. Los estándares utilizados fueron: $\mathrm{Si}, \mathrm{Al}, \mathrm{K}$ - sanidina, $\mathrm{Ca}$ - andradita o titanita, Ti - titanita, $\mathrm{Cr}$ - cromita, Mn - rodonita, $\mathrm{Mg}$ - piropo, $\mathrm{Na}$ - albita, P - fluorapatita, S - barita, F - topacio, $\mathrm{Nb}$ - columbita, $\mathrm{Ta}-\mathrm{CrTa}_{2} \mathrm{O}_{6}, \mathrm{Zr}$ - zircón, $\mathrm{Zn}$ - gahnita, $\mathrm{Ni}$ - metal nativo, $\mathrm{V}$ - vanadinita, $\mathrm{Cl}-\mathrm{NaCl}$ y $\mathrm{Sr}-\mathrm{SrSO}_{4}$. Para el cálculo de los datos obtenidos se utilizó el método de Pouchou \& Pichoir (1985). Los límites de detección establecidos son: $\mathrm{Si}, \mathrm{Al}, \mathrm{Ca}, \mathrm{Cr}$ : 100-200 ppm; Mg, Na, K, Fe, Mn, V, Cl, Ti, Nb, P, S: 200-500 ppm; F, Ni, Zn: 500-1000 ppm; Ba, Ta $>1000$ ppm. Los analistas fueron Radek Škoda y Petr Sulovský. En el texto se usan las abreviaturas de minerales según Kretz (1983). El contenido 


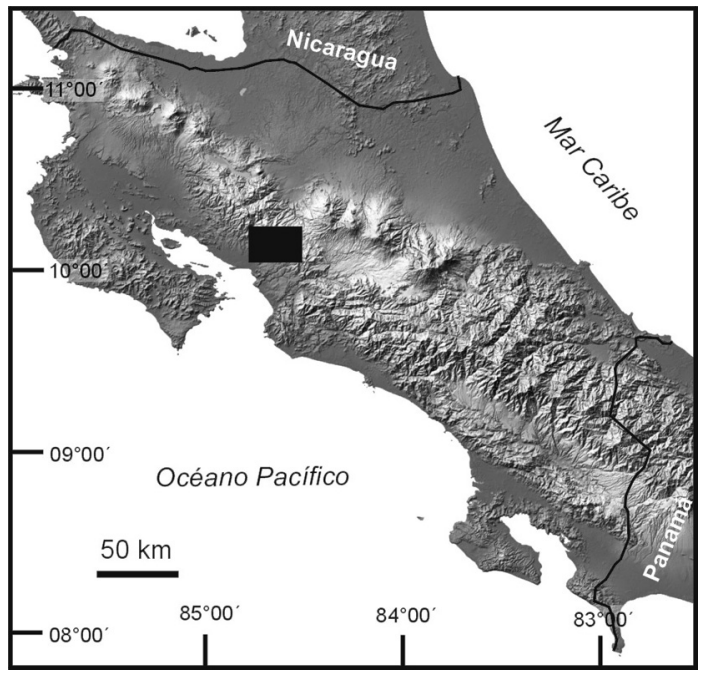

Fig. 1: Ubicación de la hoja cartográfica Miramar.

de hierro trivalente en anfíboles fue estimado según método de Holland \& Blundy (1994).

\section{Geoquímica}

Se realizaron 33 análisis químicos en los laboratorios del CGS en Praga. Fue pulverizado de 1 a $2 \mathrm{~kg}$ de muestra y se aprovechó aproximadamente $10 \mathrm{~g}$ de este material. Los óxidos principales se analizaron por el método clásico de química húmeda, los oligoelementos se determinaron por espectrometría de emisión óptica de plasma acoplado inductivamente (ICP-OES), espectrometría de rayos-X (XRF), espectrometría de absorción atómica de llama (FAAS) y los elementos de tierras raras (REE) por espectrometría de masas con fuentes de plasma acoplado inductivamente (ICP-MS). Solo cuatro muestras fueron analizadas con el método ICP-OES. Los datos fueron procesados en el programa GCDkit (Janoušek et al., 2006).

\section{Difractometría}

Para este análisis se utilizó el difractógrafo Phillips X'Pert con radiación de $\mathrm{Cu}$, ángulo de carga $2 \theta 5-75^{\circ}$, paso de carga $0,03^{\circ}$, tiempo de carga 3 $\mathrm{s}$ (según programa de cómputo ZDS-WX Search/
Match-2004 de P. Ondruš y R. Skála). Los análisis de 28 muestras fueron realizadas por la analista Irena Haladová.

\section{Dataciones K-Ar}

Con el método clásico K-Ar, se dataron 7 muestras en el Instituto de Investigaciones Nucleares (ATOMKI), Debrecen-Hungría (periodo 2007-2008). El potasio fue determinado por fotometría de llama con un búfer de $\mathrm{Na}$ y Li (patrón interno) y para el control de las mediciones se adoptaron las normas inter-laboratorio Asia 1 / 65, LP-6, HD-B1, GL-O.

El argón se extrajo de las muestras con el método "Calentamiento por inducción de alta frecuencia" ("High frequency induction heating"). Un ${ }^{38} \mathrm{Ar}$-pico se introdujo en el sistema a través de una pipeta de gas antes del inicio de la desgasificación. El Ar purificado se transportó directamente al espectrómetro de masas construido en Debrecen, Hungría. La proporción de isótopos de Ar se mide en el modo estático con un radio de $15 \mathrm{~cm}$ de sector magnético. Dalrymple \& Lanphere (1969) y Balogh (1985) describen en detalle los métodos aquí aplicados, y el cálculo de las edades se basó en constantes atómicas sugeridas por Steiger \& Jäger (1977).

\section{Susceptibilidad magnética}

Durante el trabajo de campo se procedió con la medición de la susceptibilidad magnética (SM) de las rocas volcánicas. Para la medición se utilizó un kappametro portátil KT-5 (rango 0,01$\left.999,9 \times 10^{-3} \mathrm{SI}\right)$. La magnetita fue identificada como el mineral ferromagnético predominante, con un contenido variable de $\mathrm{TiO}_{2}$ (titanomagnetita). La mayoría de las rocas volcánicas noalteradas presentaron SM significativamente alta $\left(>10,0 \times 10^{-3} \mathrm{SI}\right)$, siendo las rocas básicas la de mayor valor. Por el contrario, las rocas afectadas por la alteración hidrotermal o meteorización (laterizadas) tienen SM débil o muy baja $\left(<1,0 \times 10^{-3}\right.$ SI), lo que indica que el mineral magnético no se preservó o su volumen fue reducido. 


\section{COLUMNAESTRATIGRÁFICA}

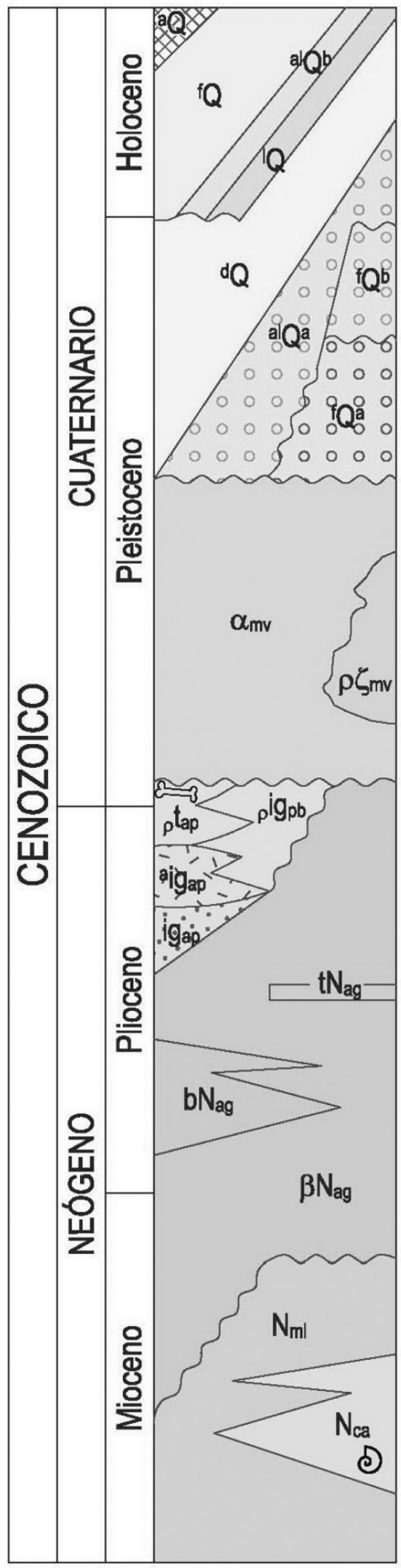

Depósitos antropogénicos ${ }^{a} Q$

Depósitos fluviales, arenas, gravas y bloques $\mathrm{f} Q$

Depósitos de abanicos aluviales, arenas, gravas y bloques ${ }^{\mathrm{al}} \mathrm{Q}^{\mathrm{b}}$

Depósitos lacustres, gravas, arenas y $\operatorname{arcillas~}^{\prime} \mathrm{Q}$

Depósitos de deslizamientos ${ }^{\mathrm{d}} \mathrm{Q}$

Depósitos de paleoabanicos aluviales, arenas, gravas y bloques con presencia de arcillas ${ }^{\text {al }} Q^{a}$

Paleoterrazas fluviales, nivel 2, arenas y gravas ${ }^{f} Q^{b}$

Paleoterrazas fluviales, nivel 1 , arenas y gravas altamente laterizadas ${ }^{\mathrm{f}} \mathrm{Q}^{\mathrm{a}}$

\section{Formación Monteverde}

Riodacita hasta andesita con biotita y anfibol (domos) $\rho \zeta_{\text {mv }}$

Andesita, andesita basáltica con brechas, lahares y tobas subordinadas $\alpha_{\mathrm{mv}}$

\section{Ignimbritas}

T.oba riolítica con biotita, unidad Alto Palomo, parte superior $\rho$ tap Ignimbrita ácida con biotita y líticos, unidad Alto Palomo, parte inferior ${ }^{\text {aigap }}$

Brecha basal (ignimbrita), unidad Alto Palomo? igap

Ignimbrita riolítica, unidad Peñas Blancas $\rho$ ig $g_{p b}$

\section{Grupo Aguacate}

Basalto, andesita basáltica (lava) con brechas subordinadas $\beta \mathrm{N}_{a g}$

Brecha andesítica tipo "brecha La Unión" con intercalaciones de lava basalto-andesítica $\mathrm{bN}_{\mathrm{ag}}$

Tobas y tobitas $\mathrm{tN}_{\mathrm{ag}}$

\section{Formación Punta Carballo}

Miembro Roca Carballo:Grauvacas, conglomerados, areniscas y lutitas calcíticas fosilíferas $\mathrm{N}_{\mathrm{ca}}$

Miembro Mata de Limón:Tobas e ignimbritas con intercalaciones de arenas fluviales $\mathrm{N}_{\mathrm{m}}$

Fig. 2: Columna estratigráfica de la hoja Miramar (según Žáček et al., 2010a). 


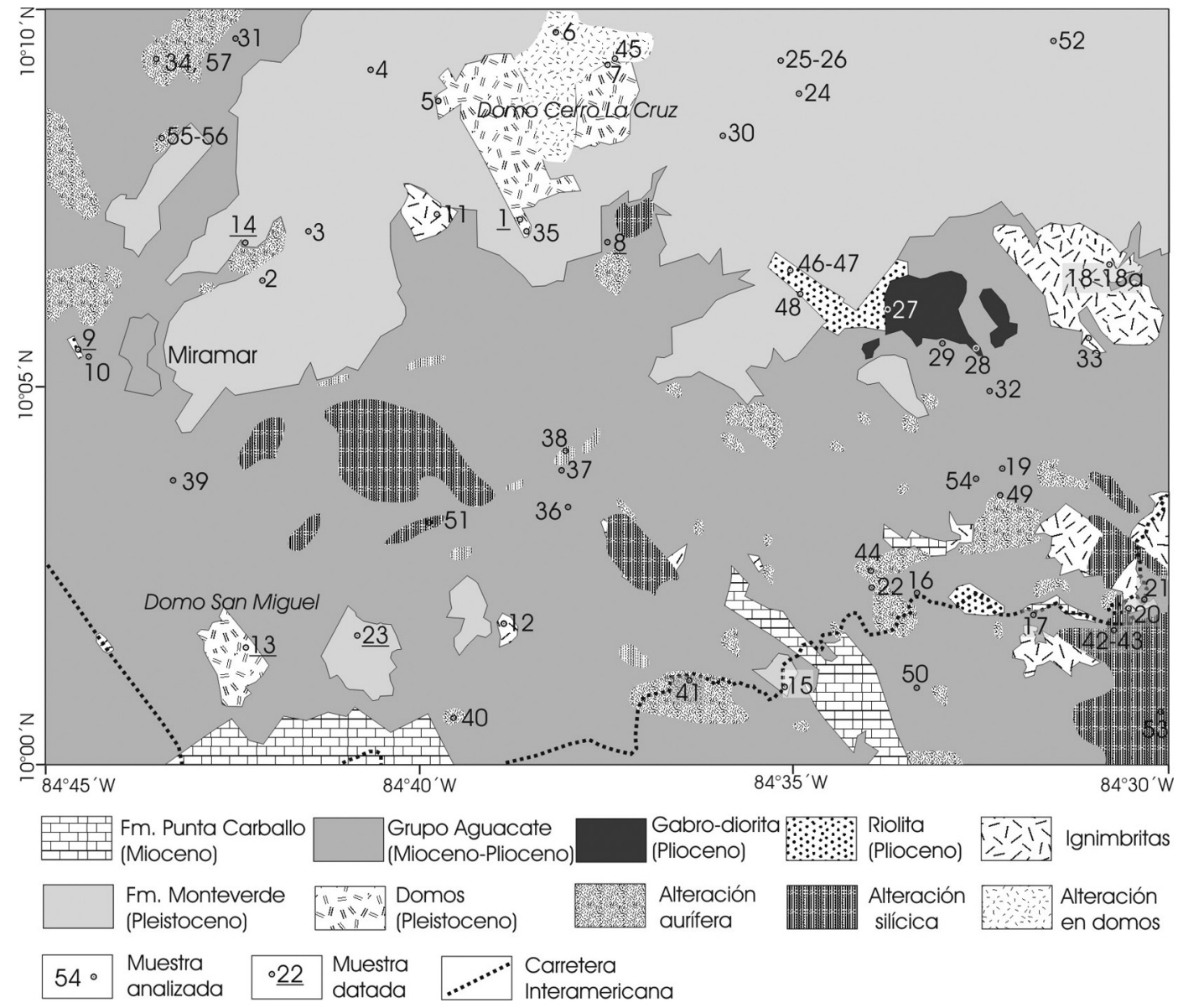

Fig. 3: Mapa geológico de la hoja Miramar (sin Cuaternario y sin la tectónica) con ubicación de las muestras estudiadas.

\section{ESTRATIGRAFÍA}

La estratigrafía está organizada desde las rocas más antiguas hacía las rocas más jóvenes. Los números que se encuentran entre paréntesis corresponden con la numeración de la columna estatigráfica del mapa geológico de la hoja Miramar publicado (Žáček et al., 2010a).

\section{Formación Punta Carballo (Mioceno Inferior- Mioceno Medio)}

Aflora en el sector sur; no obstante los afloramientos típicos se encuentran principalmente en el área de la hoja colindante (hoja Barranca escala 1:50 000). Esta formación está constituida por dos miembros principales, Mata de Limón y Roca Carballo, los cuales fueron descritos y nuevamente reclasificados por Denyer et al. (2003). En los alrededores del poblado de Río Jesús, las rocas sedimentarias del miembro Mata de Limón, se encuentran dentro de las secuencia del Grupo Aguacate.

\section{Miembro Mata de Limón (26)}

La mayor extensión de estas rocas se encuentra al sur de la hoja Miramar en la zona de Angostura, Guadalupe y fincas adyacentes, aflorando en los cortes de la Carretera Interamericana 
y en otras carreteras, también afloran cerca del pueblo Río Jesús ubicado en el cuadrante SE de la hoja.

Los depósitos del Miembro Mata de Limón provienen de ambientes continentales y están compuestos en su mayoría por material volcánico como tobas, ignimbritas y aglomerados intercalados con areniscas y limolitas, hasta gravas lentiformes de origen fluvial. En su mayoría tienen color café oscuro o café-violeta. A diferencia del Miembro Roca Carballo, no son calcáreos ni fosilíferos. Las capas individuales tienen un espesor de 0,2-1 m. A menudo tienen gradación normal, de areniscas hacia arcillas. En lentes de depósitos fluviales (tamaño 3-10 m) pueden observarse también areniscas hasta conglomerados con estratificación cruzada. Los cantos de los conglomerados son bastante ovalados, de rocas volcánicas (andesitas) y también de sedimentos (grauvacas, limolitas, lutitas y cuarzos) y normalmente con tamaños de hasta $4 \mathrm{~cm}$ (raramente hasta $20 \mathrm{~cm}$ ).

\section{Miembro Roca Carballo (25)}

Los depósitos del Miembro Roca Carballo son sedimentos calcáreos de mar somero, que transgresivamente se depositaron sobre el piso del miembro Mata de Limón. Está compuesto de areniscas y limolitas calcáreas, de color verde-gris y es significativamente fosilífero. La parte inferior de la secuencia esta formado por conglomerados de granulometría gruesa que se erosionan en formas esféricas de gran tamaño (decimétricos a métricos). El espesor de las capas de los conglomerados es de 4 a $5 \mathrm{~m}$ y el material está compuesto de clastos volcánicos bien redondeados y de fragmentos de conchas gruesas (gasterópodos, bivalvos, etc.). Presenta estratificación interna y ritmos más delgados de tamaños desde 10 a $15 \mathrm{~cm}$. El análisis del material que conforma el conglomerado mostró, que las composiciones de estos son únicamente de andesitas y andesitas basálticas, siempre con una estructura ofítica; esto demuestra la existencia de un vulcanismo andesítico antes de la deposición de las capas sedimentarias del Mioceno de la Formación Punta Carballo.
Los mejores afloramientos de este Miembro están en el cauce del río Barranca, donde se observan capas de areniscas muy fosilíferas que originan bandas de 1-1,2 m de espesor, alternando con capas de limos calcáreos y arcillas con espesores de 0,3-0,5 m. Las capas están inclinadas con ángulo de $30-40^{\circ}$ al NNO. Los fósiles encontrados fueron principalmente gasterópodos cuyas conchas se conservan enteras (tamaño 5-7 $\mathrm{cm})$ y se encuentran orientadas en todas las direcciones indicando, de esta manera, que no están en la posición original. Con menos frecuencia se observan bivalvos y sus restos, fragmentos de madera carbonizada, un erizo marino y en una capa de gran espesor, numerosas bioturbaciones. Todas estas evidencias sugieren que el mar somero (tal vez en la parte continental) dio origen al material bioclástico. Entre los gasterópodos dominan la especie Turritella altilira (Conrad) (Fig. 4) y menos abundante es la Oliva gatunensis (Tula). Según Olsson (1922) la especie Turritela altirira es típica para la Formación Gatún (Mioceno Medio hasta el Mioceno Superior) de Panamá y Costa Rica.

Otro afloramiento destacante está en un corte de camino hacia la Finca El Mango aguas arriba del río Barranca (aprox. de 1,5 km al SO de la planta hidroeléctrica Nagatac), en el flanco limitado tectónicamente. En el lugar afloran areniscas calcáreas y limolitas de color gris verde, donde son frecuentes las lumaquelas con moluscos marinos. En una capa de limolitas calcáreas, color gris oscura, de 6,5 metros de espesor, son abundantes las conchas de bivalvos Flabellipecten gatunensis (Toula) (Fig. 5). Según Woodring (1982), lo anterior es típico del Mioceno Medio.

En la Carretera Interamericana a la altura ONO del pueblo de Río Jesús, en un salto de agua, se localiza de forma aislada un área pequeña de sedimentos. En este afloramiento (de aproximadamente $20 \mathrm{~m}$ de altura) se observa, que las andesitas están tectónicamente separadas de la secuencia de limolitas y areniscas calcáreas. En calizas y calizas limolíticas se encontró especies de macro fauna, de forma abundante pero poco diversificada, representada por conchas de moluscos y gasterópodos. Los moluscos están representados por el género Cyathodonta? Unio?, (Fig. 6, Woodring 1982), 


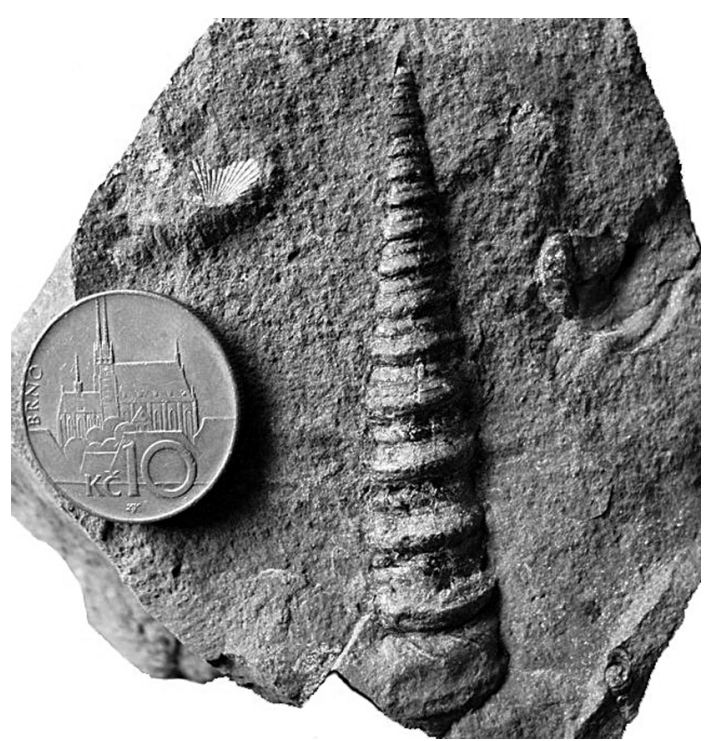

Fig. 4: Gasterópodo Turritella altilira (Conrad), Mioceno Medio en arenisca calcárea del Miembro Roca Carballo. Afloramientos en el cauce del río Barranca, Esparza. Foto Tomáš Vorel.

muestras parecida a los morfotipos del Mioceno y Plioceno Inferior de América Central. Lo interesante de este hallazgo, es que las especies mencionadas aparentemente pertenecen a fauna terrestre de agua dulce, lo que contradice a lo característico del Miembro Roca Carballo, ya que este representa un medio marino somero. Los análisis de microfauna en la hoja Miramar fueron negativos.

\section{Grupo Aguacate (Mioceno-Plioceno)}

El Grupo Aguacate es parte del antiguo arco volcánico compuesto principalmente por lavas basálticas hasta basalto-andesíticas, rocas piroclásticas, brechas y sedimentos vulcanoclásticos subordinados (Fig. 7). Está cortado por intrusiones de composición variada, como: cuerpos subvolcánicos de riolitas, dacitas, andesitas, basaltos y otras intrusiones más profundas de dioritas hasta gabros.

Este grupo se caracteriza por una intensa alteración hidrotermal que se manifiesta de diferentes tipos. En la mayoría de los casos están relacionados a zonas de fallas o intrusiones, que dan origen a una alteración hidrotermal de carácter regional. Esta última se caracteriza por la variedad multicolor que obtienen las rocas alteradas y por la presencia de vetillas y vetas de cuarzo.

En el mapa geológico, hemos clasificados 3 tipos de roca de este grupo: lava de composición basáltica hasta andesitico-basáltica $\left(\mathrm{SiO}_{2}=50,2-\right.$ $54,3 \%$ ), rocas piroclásticas o brechas basalto-andesíticas ("Brecha La Unión") y en menor cantidad tobas y sedimentos vulcanoclásticos.

En el área de la hoja Miramar, el Grupo Aguacate sobreyace la formación sedimentaria Punta Carballo. Su espesor ha sido estimado por varios autores; Madrigal (1980) lo estimó en 450 m, Kussmaul (1987) en 1100 m y Denyer \& Arias (1991) reconocen que el espesor a veces puede llegar hasta $3000 \mathrm{~m}$.

De acuerdo a más de 200 publicaciones de datos geocronológicos con el método de $\mathrm{K}-\mathrm{Ar}$, la cordillera volcánica de América Central comenzó a desarrollarse en el Mioceno Inferior alrededor de $24 \mathrm{Ma}$, pero con episodios de vulcanismo entre 16-17 Ma, 4-6 Ma y 1-2 Ma, que alternan con períodos de calma (Bellon y Tournon 1978; Amos \& Rogers, 1983; Alvarado et al., 1992; Gillot et al., 1994; Gans et al., 2002, 2003).

\section{Lavas Aguacate (22)}

Las rocas que predominan en este grupo son lavas de composición basáltica hasta andesita-basáltica. Petrográficamente son rocas masivas, de leve hasta moderada texturas porfídica (algunas lavas pueden tener amigdalas), color gris oscuro a gris negro, con fenocristales de plagioclasa de hasta $5 \mathrm{~mm}$ de longitud. Las lavas meteorizadas o alteradas pueden tener un color de gris claro a rojizo. Vista por el microscopio, la matriz que rodea a los fenocristales de plagioclasas y piroxeno es muy fina hasta afanítica. Los fenocristales están representados por plagioclasa (50-60\%), clinopiroxeno de color verde pálido, ortopiroxeno de color rosado (total de piroxenos del 20-30\%), olivino (normalmente 5-20\%) y titanomagnetita (1-4\%). A veces se observan hornblenda, clorita, biotita, calcita, relacionados con 


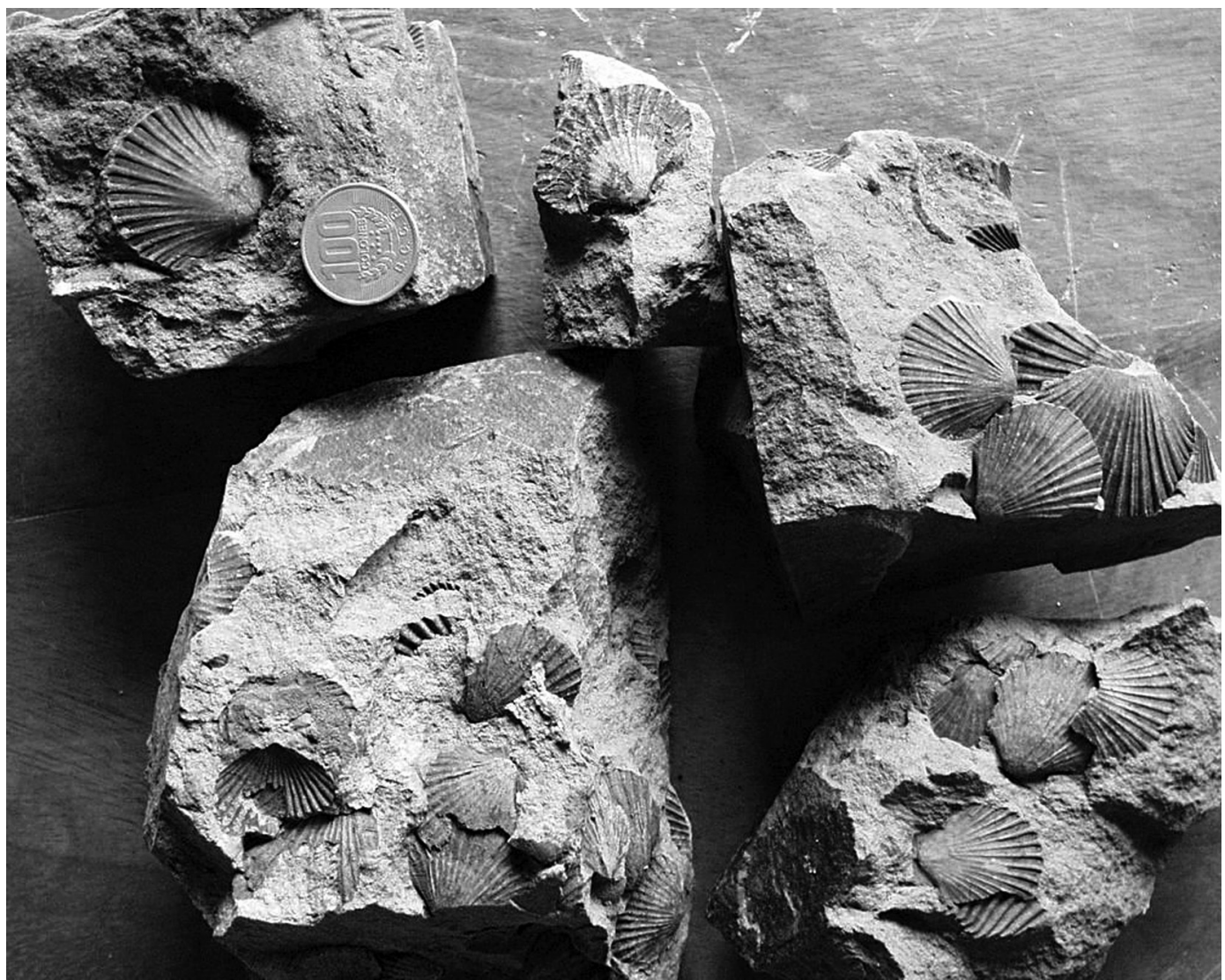

Fig. 5: Lumaquelas compuestas por bivalvos Flabellipecten gatunensis gatunensis (Tula) en capas de arenisca calcárea de Roca Carballo. Afloramientos en el cauce del río Barranca cerca de la planta hidroeléctrica Nagatac. Foto Tomáš Vorel.

alteración hidrotermal. El olivino se encuentra parcial o totalmente serpentinizado, inclusive en rocas aparentemente frescas. La susceptibilidad magnética de los basaltos y andesitas basálticas, debido al alto contenido de titanomagnetita, varía en el rango de $25-50 \times 10^{-3} \mathrm{SI}$, en las rocas alteradas es considerablemente menor.

\section{Brechas volcánicas del Grupo Aguacate (23)}

Las brechas volcánicas o los aglomerados, en su mayoría, son de composición basáltica hasta basalto-andesítica ("tipo Brecha La Unión"). Tienen espesores variables, que se alternan con diferentes capas de lavas andesíticas (también de diferentes espesores) y tobas de lapilli. Su delimitación se dificulta debido a los pocos afloramientos que se presentan en la zona y por su composición petrográfica, que es similar a las lavas basálticas y basalto-andesíticas de los alrededores. Los clastos tienen un tamaño de unos pocos milímetros hasta unos $70 \mathrm{~cm}$ (predominan los de $20 \mathrm{~cm}$ ), son angulares y subangulares. En mayor cantidad se observan clastos de andesita porfídica, menos común son los clastos de diferentes tipos de tobas. La matriz de los aglomerados también es basalto-andesítica. La dureza depende principalmente del grado de alteración hidrotermal. Las rocas no alteradas presentan mayor dureza y las alteradas como por ejemplo las que se encuentran en la mina de oro Bellavista o en los alrededores de la mina La Unión, son de dureza débil o frágil. A menudo presentan colores variados (Fig. 8). 


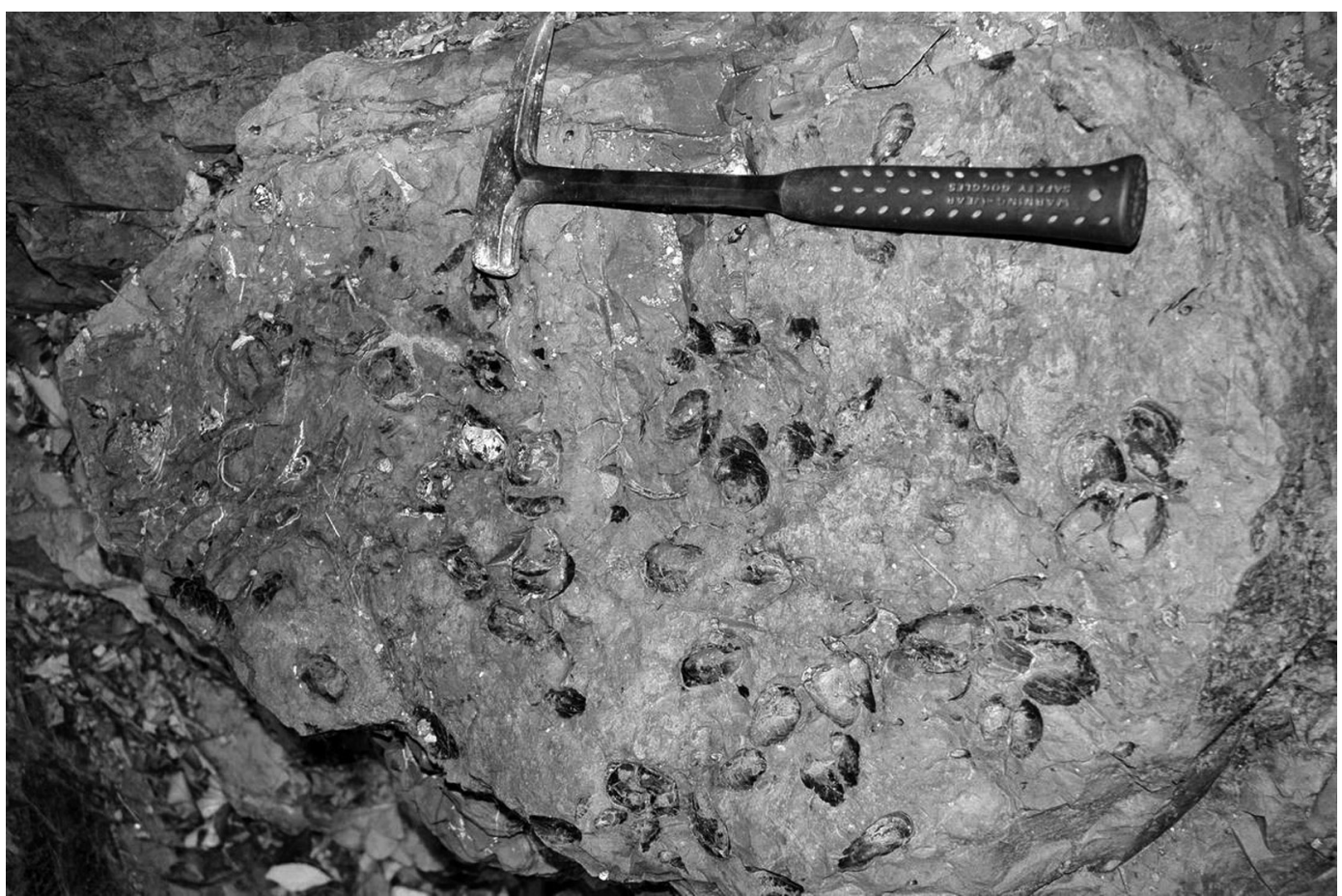

Fig. 6: Almejas probablemente del género Ciathodonta (Unio?) en pequeños lentes de sedimentos calcáreos, insertos en la Formación Aguacate. Afloramiento en la Carretera Interamericana, poblado Río Jesús. El origen se supone de agua dulce contrario al origen de la fauna marina del Miembro Roca Carballo, edad máxima estimada Mioceno-Plioceno. Foto Vladimír Žáček.

\section{Tobas y/o tobitas (22)}

Es común la presencia de tobas y/o tobitas en el Grupo Aguacate y se localizan en la parte superior cerca del contacto con la Formación Monteverde. Mayormente son de dimensiones y espesores muy pequeñas, razón por el cual no se han podido cartografiar en el mapa 1:50 000. Una intercalación significativa de un cuerpo volcanosedimentario de tobas ferrosas color café con hematita, aparece en la ladera norte del valle del río Barranca aproximadamente a $1 \mathrm{~km}$ de la planta hidroeléctrica Nagatac y aflora gracias al corte de la carretera (Cuadro 3, n 19). La matriz es de hematita opaca, aparte de ello hay acumulaciones de hematita masiva de hasta $1 \mathrm{~cm}$ de tamaño. El análisis químico de la toba-Fe, muestra que se trata principalmente de una mezcla de silicatos de aluminio hidratados (caolinita o pirofilita) y hematita $\left(36 \% \mathrm{SiO}_{2}, 29,5 \% \mathrm{Al}_{2} \mathrm{O}_{3}\right.$, el $18,6 \% \mathrm{Fe}_{2} \mathrm{O}_{3}$, los niveles de $\mathrm{Mg}, \mathrm{Ca}, \mathrm{K}, \mathrm{Na}$ por debajo del $0,2 \%$ y más del $13 \% \mathrm{H}_{2} \mathrm{O}$ ).

\section{Roca volcánica altemente alterada (21)}

En este grupo incluimos rocas volcánicas con fuerte alteración hidrotermal sobre todo con una fuerte silicificación. El protolito pudo originarse dentro de una amplia gama de composición química. Como localidad tipo tenemos los afloramientos en el cerro Pan de Azúcar, que se localiza en la hoja colindante Chapernal (1:50 000) al NO de Miramar (Žáček et al., 2010b). También afloran al este y SE de la ciudad de Miramar, principalmente entre Sábana Bonita y Mesetas Abajo. Los bloques de rocas silicificadas se encuentran dispersos en las pendientes y distantes de las zonas de origen, hasta por algunos kilómetros. Estas rocas también se presentan notablemente en formas de riscos, con morfología abrupta. Comúnmente tienen colores claros, presentan varios tonos de gris, rosado, amarillo y café claro. Son en su mayoría de grano fino o un poco porfídico y su dureza varía alternándose zonas duras (partes silicificadas) con zonas más 


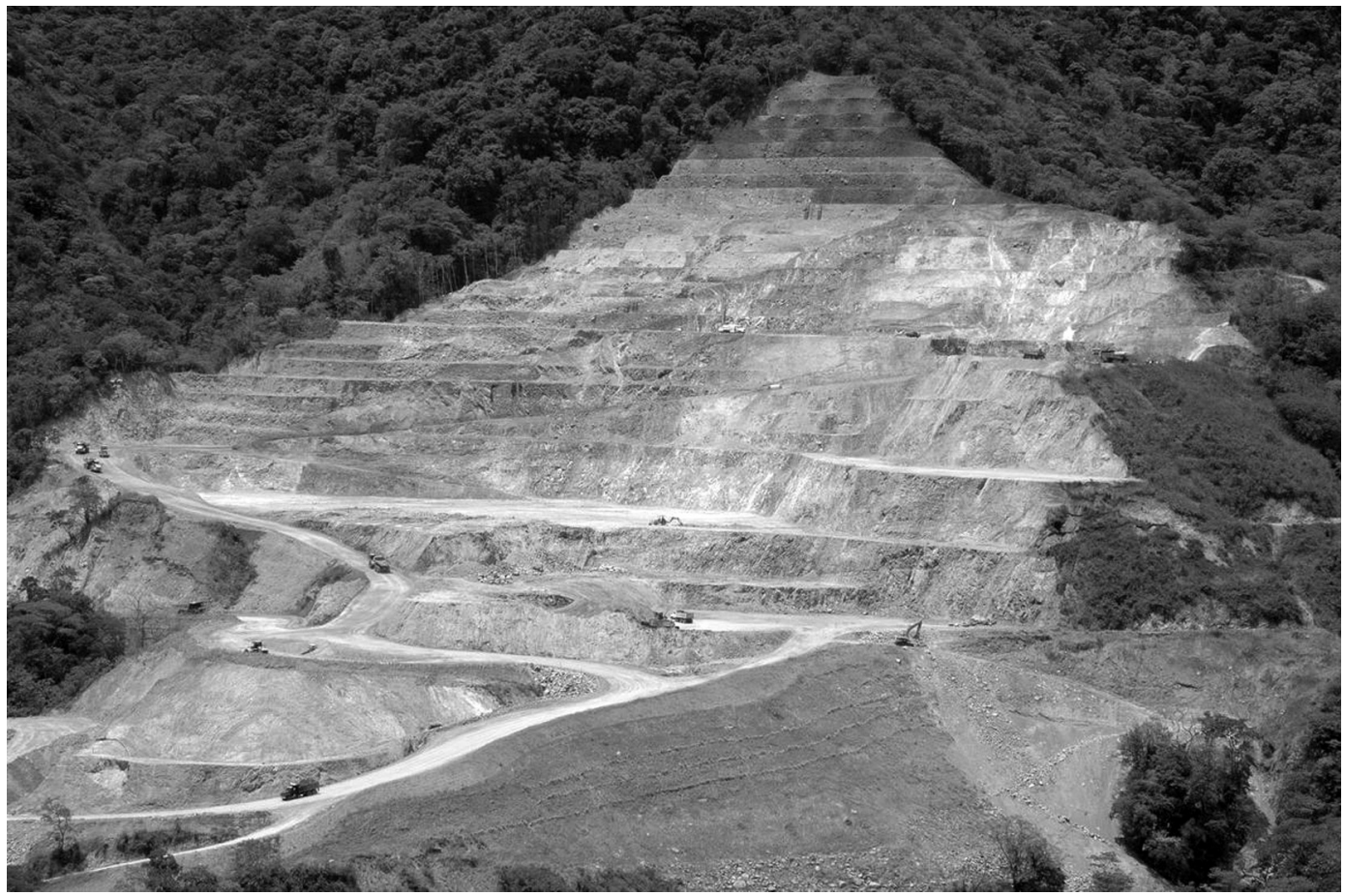

Fig. 7: Vista general de la mina Bellavista (Miramar de Puntarenas) desde la montaña opuesta al sur-este. En el borde izquierdo superior se observa el contacto tectónico oblicuo ("falla Liz ") con la Formación suprayacente Monteverde y la que está representada principalmente por lahares y en menor cantidad por lavas. La unidad subyacente Aguacate es la unidad aurífera, alterada hidrotermalmente con vetas de cuarzo y calcita. Foto Vladimír Žáček.

suaves (por lo general son zonas de brechas tectónicas silicificadas, zonas limonitizadas y arcillosas). En las secciones delgadas, generalmente se observa la matriz muy fina, solamente en algunas muestras son aparentes pseudoformas de feldespatos reemplazados por minerales secundarios. Casi siempre domina el cuarzo, para el detalle de la descripción mineralógica véase el capítulo de "Mineralogía de las rocas volcánicas". La susceptibilidad magnética es muy baja, por lo general por debajo de $0,1 \times 10^{-3} \mathrm{SI}$.

\section{Cuerpos intrusivos e hipoabisales (Mioceno- Plioceno)}

En el área formada por Grupo Aguacate, afloran cuerpos de composición química variada y de diferentes profundidades de intrusión. Se distinguen dos tipos de riolitas, diques de basalto y gabro hasta diorita.

\section{Gabro hasta diorita (20)}

El stock de gabrodiorita (gabro a diorita) aparece al SO de Piedades Sur (en un área aprox. de $3 \times 2 \mathrm{~km}$ ) intruyendo a las lavas del Grupo Aguacate. Este no ha sido datado, pero se correlaciona con una serie de cuerpos similares que están ampliamente distribuidos en las Cordilleras de Tilarán, Talamanca y en el Valle Central, los cuales fueron datados respectivamente por otros autores, obteniéndose una amplia gama de edades de alrededor de 17 hasta 3,5 Ma (Gans et al., 2002). El stock de gabrodiorita se definió a partir de la presencia de bloques (núcleos sanos) que se encuentran por todo el área indicada y la cual está altamente degradada y laterizada. No se encontraron afloramientos. Macroscópicamente son dioritas y gabros de color gris oscuro hasta negro, de grano mediano hasta grueso, muy masivos y duros. Las rocas se caracterizan también por su alta susceptibilidad magnética en el rango de 60- 


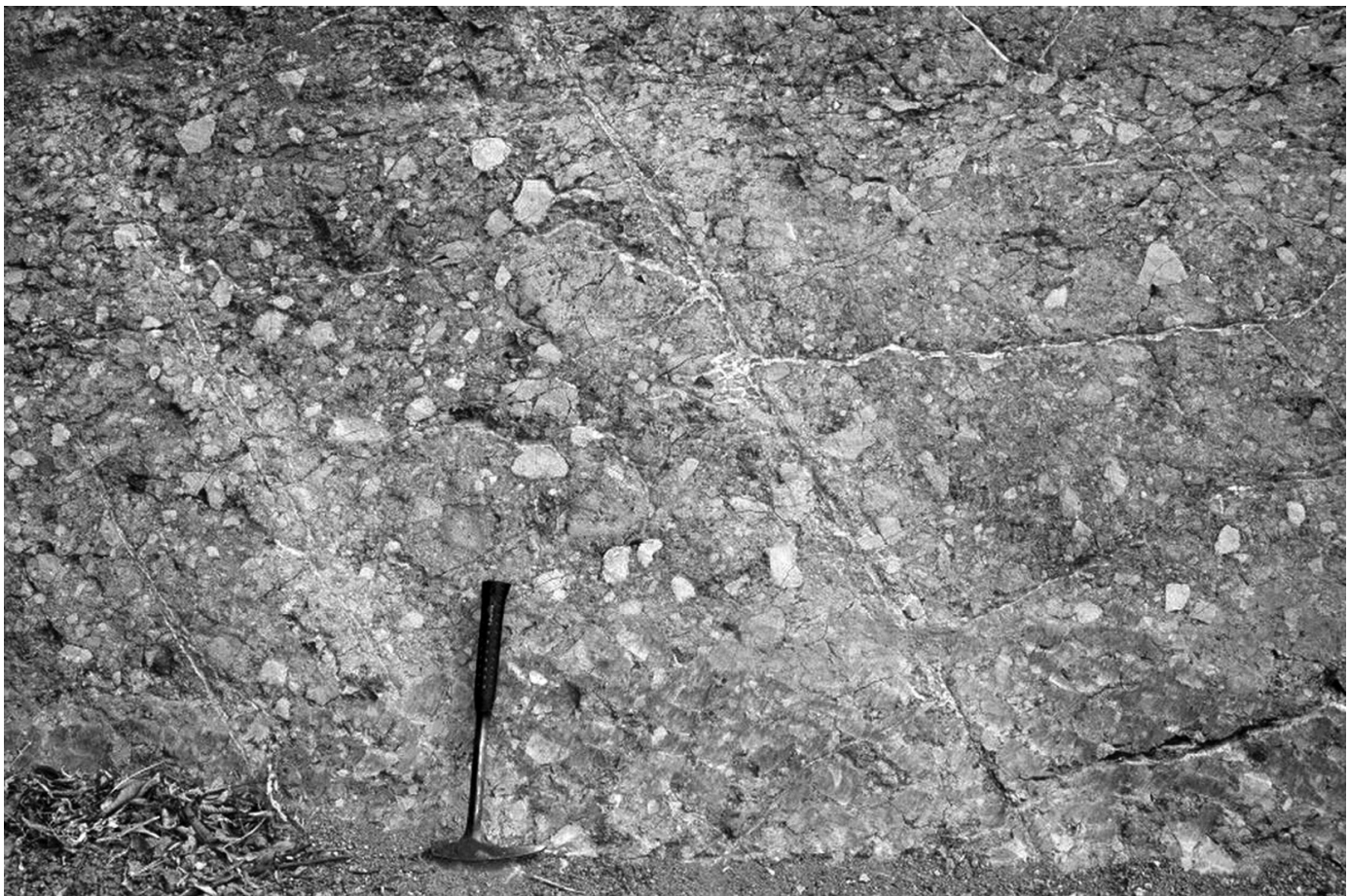

Fig. 8: Alteración hidrotermal de la "Brecha La Unión" en un corte transversal de camino a 2,5 km SO del pobladoVelásquez. Foto Vladimír Žáček.

$90 \times 10^{-3}$ SI. Petrográficamente y geoquímicamente (ver apartado "Geoquímica") se encontró una gran variedad de monzodiorita cuarzosa hasta gabro olivínico. A continuación se describen desde los más ácidos hasta los más básicos:

Monzodiorita cuarzosa (Cuadro $3, \mathrm{n}^{\circ} 27$ ) bloques identificados en una finca ubicada a $1,5 \mathrm{~km}$ al $\mathrm{S}$ de la localidad Cruzada La Laguna. La roca es de color gris, de grano mediano hasta unos 5 $\mathrm{mm}$, compuesta de plagioclasa $50 \%$, clinopiroxeno $20 \%$, cuarzo $10 \%$, actinolita secundaria (que reemplaza el piroxeno) $10 \%$, minerales opacos $4 \%$ y biotita $2 \%$.

Diorita hasta gabro, bloques encontrados en un corte de camino a $1 \mathrm{~km}$ al SO de la localidad La Guaria. De color gris oscuro casi negro, grano fino a mediano y con fenocristales de $5 \mathrm{~mm}$ de tamaño. Composición aproximada: plagioclasa $65 \%$, piroxeno $20 \%$, actinolita secundaria y epidota $10 \%$, biotita $1 \%$ y minerales opacos $4 \%$.

Gabro (Cuadro 3, $\mathrm{n}^{\circ} 28$ ), grandes bloques en el cruce de carretera a $750 \mathrm{~m}$ al S de La Guaria.
Roca de color gris oscuro a negro, de grano mediano con fenocristales de $5 \mathrm{~mm}$ de tamaño. Composición aproximada: plagioclasa $60 \%$, piroxeno $20 \%$, actinolita secundaria $10 \%$, biotita $5 \%$ y minerales opacos $5 \%$ (Fig. 9).

Gabro olivínico (Cuadro 3, $n^{\circ} 32$ ), bloques en la cuenca del río Quebrada Honda, $2 \mathrm{~km}$ al SE de La Guaria, de color negro, grano mediano, con fenocristales de plagioclasa $30 \%$ (aprox.), piroxeno $30 \%$ y de olivino completamente serpentinizado $15 \%$. El resto son en su mayoría agregados de grano fino con prevalencia de minerales secundarios como actinolita y epidota. El porcentaje de mineral opaco es alrededor del 5\%.

En la Quebrada Los Machos (La Unión, NO de la hoja Miramar) existe un afloramiento de un pequeño cuerpo intrusivo posiblemente de composición granodiorítica o de monzodiorita cuarzosa, con grandes "ojos" de cuarzo, que se extiende hasta el lado NO del río Seco (S. Kussmaul, com. oral). Es probable que este cuerpo este relacionado con el intrusivo de Guacimal (Žáček et al. 1011). 


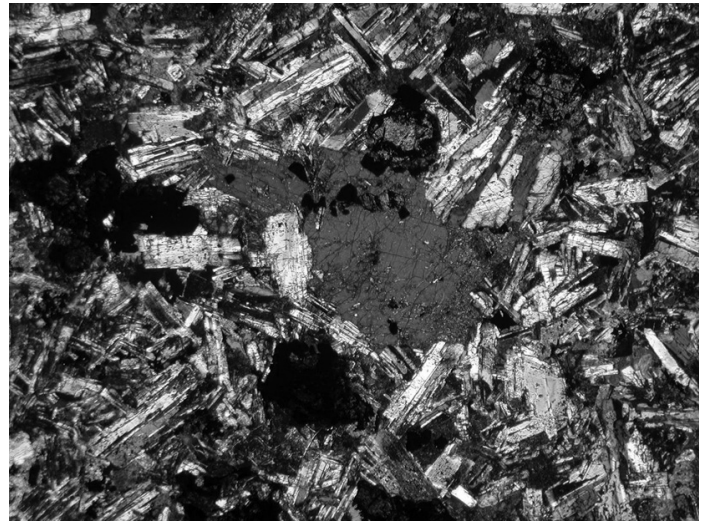

Fig: 9: Microfotografía del gabro de la localidad La Guaria (No 28, coordenadas y análisis químico véase en los cuadros 3-4). Ancho de la foto $12 \mathrm{~mm}$, polaroides X. Foto V. Žáček.

\section{Basalto (19)}

Son numerosos los diques de basalto en el Grupo Aguacate; sin embargo sus pequeñas dimensiones dificultan su representación en un mapa a escala 1:50 000. A unos $800 \mathrm{~m}$ al NO de la localidad de Laguna se localizó un dique de mayor tamaño con dimensiones de $2 \mathrm{~m}$ de espesor y con dirección de $50-60^{\circ}$, y el cual se representa en el mapa. El dique es de textura gruesa y porfídica, de color negro con fenocristales de plagioclasas idiomorfos e isométricos de 5-10 mm de tamaño (representan aprox. el 25\%) y fenocristales de olivinos serpentinizados de hasta $5 \mathrm{~mm}$. En menos cantidad contienen fenocristales de clinopiroxeno de color verde pálido que predominan sobre el ortopiroxeno. La matriz es fina holocristalina, formada por cristales delgados de plagioclasas, piroxenos y minerales opacos. A la muestra se le hizo análisis químico (Cuadro $3, \mathrm{n}^{\circ} 31$ ).

\section{Riolita de grano medio (18)}

Los cuerpos riolíticos de granulometría media aparecen cerca del poblado Cruzada La Laguna y se extienden también hacia Calle Salvador al SO de Potrerillos, lugar donde existen varias canteras. Los cuerpos tienen forma irregular de hasta $3 \times 2 \mathrm{~km}$ de superficie. Otro cuerpo de riolita aparece en la confluencia del río Barranca con el río
Barranquilla y un cuerpo más pequeño cruza la Interamericana al este de Cambronero. Los cuerpos de riolita intruyen principalmente las rocas del Grupo Aguacate. En el caso de los cuerpos más grandes en Cruzada La Laguna la situación se complica, ya que se identificó que la riolita está también en contacto con una intrusión gabrodiorítica y con la Formación Monteverde. El contacto con la Formación Monteverde es probablemente tectónico. Por otro lado no se puede determinar una relación de edad de la riolita con las intrusiones gabrodioríticas, por que el contacto entre ellas no aflora. Tampoco se pudo realizar el análisis químico de estas rocas debido a la ausencia de muestras sanas.

La riolita tiene color gris claro y granulometría media, es ligeramente porfirítica, en su mayoría muy fisurada y con desintegración en cuadrados. Generalmente presenta alteración hidrotermal, incluyendo silificación. Tiene susceptibilidad magnética muy baja en el rango de $0,05-0,17 \times 10^{-3}$ SI. La roca está conformada por fenocristales de cuarzo y principalmente de feldespatos muy alterados convertidos en una masa fina de minerales secundarios. El tamaño de los fenocristales de cuarzo o feldespatos varía de 1-4 $\mathrm{mm}$, a veces alcanzan hasta $7 \mathrm{~mm}$; sin embargo algunas muestras son de grano fino sin fenocristales. La matriz es holocristalina que consiste en un mosaico de granos de cuarzo isométricos y minerales secundarios con tamaños de 0,05-0,2 mm. Los resultados de los análisis de difractometría, aplicada a las muestras procedentes de la cantera en calle Salvador de Potrerillos, mostraron que los feldespatos originales se preservaron de manera excepcional (Cuadro 2, $\mathrm{n}^{\mathrm{o}} 46$ ). El principal mineral que se identificó fue siempre cuarzo y minerales secundarios como pirofilita, alunita, caolinita y sericita (Cuadro 2, $\mathrm{n}^{\mathrm{o}}$ 46-48).

\section{Riolita vidriosa (17)}

En en el área de la hoja Miramar se observó un pequeño cuerpo intrusivo de riolita vidriosa al oeste de la ciudad de Miramar; pero también fueron descubiertos otros pequeños cuerpos que afloran con dirección NE-SO ubicados aproximadamente a $1 \mathrm{~km}$ del límite NO del mapa (al norte 
de la localidad La Unión de Miramar) (Cuadro $\left.3, n^{\circ} 11\right)$. Esta riolita es de color blanquecina a rosada, dura, masiva y con estructura fluidal. No presenta alteración hidrotermal ya que sus feldespatos están bien conservados. La susceptibilidad magnética es baja $\left(0,1 \times 10^{-3}\right)$. La estructura microscópica es de grano fino, vítrea, levemente laminada o fluidal. La matriz es completamente desvitrificada en una mezcla de cuarzo y feldespatos de granos muy finos. Raros son los fenocristales idiomorfos (hasta $2 \mathrm{~mm}$ ) de plagioclasa y de biotita de color café oscuro significativamente pleocromática.

\section{IGNIMBRITAS (PLIOCENO SUPERIOR - PLEISTOCENO INFERIOR)}

En este trabajo se utilizará el término "ignimbrita" en el sentido genético para referirse a depósitos formados por flujos piroclásticos, ya sean soldadas o no soldadas.

En Costa Rica varios autores (p. ej. Madrigal, 1967; Alvarado \& Carr, 1993; Villegas, 1997; Vogel et al., 2006, 2007) se han dedicado a estudiarlas, los mismos las han caracterizado en diferentes tipos, han propuesto su clasificación estratigráfica y definido sus fuentes de origen. Según Gans et al. (2002) en el Valle Central y en áreas adyacentes ocurrieron muchos flujos pumíticos que están datadas en 0,$33 ; 0,49 ; 0,57 ; 0,92 ; 1,59$; 2,$1 ; 4,0$ y $6,1 \mathrm{Ma}$.

En el área de la hoja Miramar fueron encontrados varios de estos flujos en diferentes niveles estratigráficos. Su correlación es difícil, principalmente por que los afloramientos son escazos en el lugar, por lo difícil del acceso al terreno y por que algunos lugares se encuentran altamente alterados o meteorizados (laterización).

En el mapa publicado (Žáček et al., 2010a) se correlacionó, con cierta incertidumbre, estas ignimbritas (No 14-12) con la Formación Alto Palomo (datada 0,565 Ma, Vogel et al., 2004), principalmente por sus características litológicas y su textura. No obstante en la columna estratigráfica y en la leyenda del mapa, la colocamos en el Plioceno superior, entre las unidades Aguacate y Monteverde, tal como lo menciona Villegas
(2004). Esto, por que también podría tratarse de otra unidad de ignimbritas de la Cordillera de Tilarán, datadas en 6,0-1,5 Ma (Vogel et al., 2004). Aunque la posición estratigráfica de esta unidad es incierta, al menos que surgieran nuevos datos con mayor exactitud, mantenemos la estructura y numeración según la leyenda del mapa publicado (Žáček et al., 2010a).

\section{Ignimbritas ácidas - unidad no determinada (16)}

En el valle del río Barranca, entre el poblado de San Jerónimo (al N de Esparza) y la planta hidroeléctrica Nagatac se localizaron diferentes niveles de ignimbritas en su mayoría de composición dacítica y con una fuerte alteración hidrotermal. Sin embargo la relación estratigráfica entre ellas no se ha podido determinar dado a lo difícil del acceso y a la cobertura boscosa que cubre el área en mención. En el mapa con dirección de oeste a este, existen cuerpos de ignimbritas en San Jerónimo, en la confluencia del río Barranquilla y Barranca, en la desembocadura de Quebrada Llana y en las inmediaciones de la planta hidroeléctrica Nagatac. Estratigráficamente se puede tratar de flujos que se originaron durante el vulcanismo del Aguacate y Monteverde o también puede interpretarse como un cuerpo subyacente de la Formación Punta Carballo, de la parte superior de Mata de Limón, que fueron emplazadas por fallas tectónicas hacia el Grupo Aguacate.

\section{Ignimbrita riolítica, unidad Peñas Blancas (15)}

Al noreste del poblado de Peñas Blancas, aflora un cuerpo ignimbrítico caracterizado como flujo de cenizas de composición riolítica, de gran espesor, con un área de 1,3 km de largo y $0,7 \mathrm{~km}$ de ancho. Parte de este cuerpo ignimbrítico se encuentra cubierto por depósitos de deslizamientos tal como se ha descrito en Flores et al. (2001). El ángulo de inclinación es de $30^{\circ}$ hacia el sur hasta el SO. El espesor excede de unas pocas decenas de metros, incluso según Villegas (1997) afirma que pueden tener entre 200-300 m. La unidad subyacente es el Grupo Aguacate, 
pero no es observable un contacto directo. El contacto superior de esta unidad tampoco pudo ser definido como directo; sin embargo por su litología, probablemente se trate de la Formación Monteverde. En la base de la ignimbrita hay una capa de varios metros de espesor de toba volcánica de color café oscuro con clastos de $1-3 \mathrm{~cm}$ de tamaño.

La ignimbrita es poco hasta medianamente soldada, sin estratificación, de grano fino, color gris-blanco, con fragmentos de piedra pómez blanca porosa y líticos angulares de andesita con un tamaño de 1-5 cm. La muestra estudiada consta de una matriz fina hasta vítrea que representa aproximadamente el $40 \%$, pómez colapsados con tamaños de 0,5-15 mm que constituyen otro $40 \%$ y líticos de diferentes composiciones el 3\%. El resto representan fenocristales de plagioclasa $15 \%$, hornblenda $1 \%$, biotita $3 \%$ y titanomagnetita $1 \%$. Además contienen zircón y apatita como minerales accesorios.

\section{Ignimbritas de Las Musas, Bajo Barrantes y Catarata, unidad Alto Palomo (14-12)}

Desde el centro de Piedades Sur y en la localidad de Catarata (ambos del cantón de San Ramón), aparecen ignimbritas y tobas ácidas en un área de aprox. $5 \times 3 \mathrm{~km}$. También afloran en algunas concesiones mineras (canteras) ubicadas en las localidades de Las Musas y Cataratas. La base de la ignimbrita está formada por lavas básicas del Grupo Aguacate, el contacto está muy bien expuesto, como p. ej. en la cantera Las Musas.

En el mapa geológico se definió 3 tipos de ignimbritas: brecha basal, ignimbrita con biotita y clastos, toba y cenizas volcánicas riolíticas.

La litología observada corresponde con la parte superior de la Formación Alto Palomo llamada Palmitos, que también se caracteriza por la presencia de distintas gradaciones, la presencia de biotita y de una zona de acumulación de cenizas de lapilli en las caídas co-ignimbríticas. Según Villegas (2004), la capa de ignimbritas tiene un espesor entre $20-100 \mathrm{~m}$ e inicialmente aparecen en un área de $900 \mathrm{~km}^{2}$. La fuente, según el mismo autor, fue la caldera de Chocosuela.

\section{Brecha basal (ignimbrita) (14)}

Aflora solamente en el cañón del valle del río Barranca entre Bajo Matamoros al norte y en menor cantidad en la desembocadura del río Piedras (Fig. 10). Es una ignimbrita de color gris o rojizo oscuro, con clastos centímetros hasta $1 \mathrm{~m}$, de composición andesítica hasta dacitica, no alterada, muy bien soldada sin estratificación. Su espesor es de varias decenas de metros. Se diferencia de las brechas del Grupo Aguacate por su fuerte soldadura, por estar sana y por la ausencia de alteración. Puede determinarse como una secuencia basal de ignimbritas; sin embargo no se puede descartar que se trate de otra unidad.

\section{Ignimbrita ácida con biotita y líticos, unidad Alto Palomo, parte inferior (13)}

Los mejores afloramientos se encuentran en el tajo (cantera) Las Musas y en las caídas de agua ubicadas en el balneario con el mismo nombre, lugar por donde cruza la quebrada Catarata. La roca es gris hasta rosa, muy bien soldada, muy vidriosa con fragmentos líticos blancuzcos y angulares de varios centímetros, y abundantes fiammes de color negro.

Microscópicamente presenta una textura vitroclástica donde predomina una matriz no recristalizada. La matriz se compone de fragmentos de vidrio y fiammes (pómez comprimi-

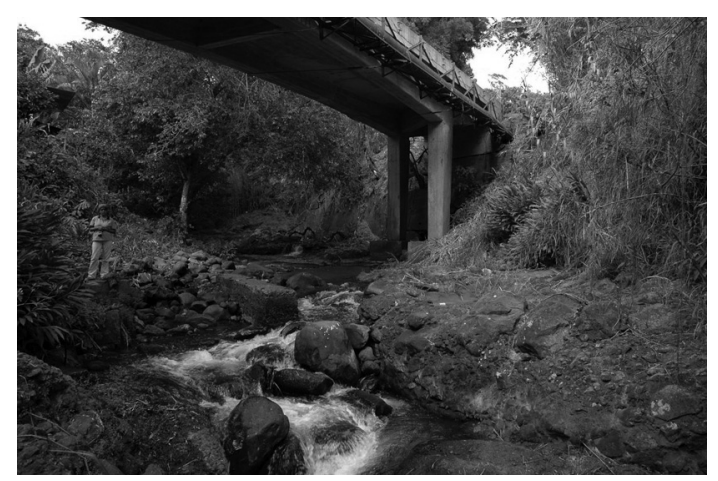

Fig. 10: Aglomerado de andesitas muy bien soldadas, que aparecen bajo del puente del río San Pedro y forman una catarata de $20 \mathrm{~m}$ de altura en la confluencia con el río Barranca. Probablemente el aglomerado forma probablemente la base de las ignimbritas de la unidad Alto Palomo. Foto V. Žáček. 


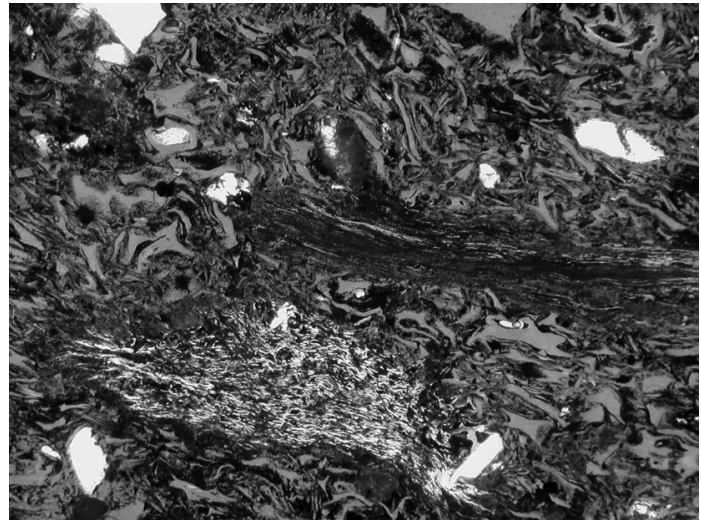

Fig. 11: Microfotografía de la ignimbrita del tajo Las Musas. Con abundante pómez comprimido (fiamme) y fragmentos de vidrio al lado de los fenocristales de Pl y Bt. Ancho de foto $12,5 \mathrm{~mm}$. Foto Vladimír Žáček.

do) hasta de varios centímetros de tamaño (Fig. 11). Los fragmentos de fenocristales de cuarzo y menos abundante de feldespatos, hacen aprox. un $25 \%$ de la composición mineral de la roca. La biotita es de color café oscura (aprox. 4\%), con tablas de hasta $2 \mathrm{~mm}$, menos frecuente es el anfíbol verde (alrededor del 1\%) de hasta $1 \mathrm{~mm}$. Los líticos son piedras pómez u otras rocas ácidas en su mayoría con tamaños de hasta $5 \mathrm{~cm}$, algunas de grano fino, otras vítreas, a veces con fenocristales feldespáticos. La susceptibilidad magnética de la ignimbrita en el tajo Las Musas varía entre $5,7-8,8 \times 10^{-3} \mathrm{SI}$.

Otro lugar donde afloran ignimbritas parecidas que se correlacionan con Alto Palomo, es en la esquina SE de la hoja Miramar, principalmente a lo largo de la Carretera Interamericana, entre las localidades de Río Jesús y Constancia. La posición estratigráfica de los flujos no es muy clara, principalmente por que la roca está afectada por una fuerte alteración y meteorización. La única ignimbrita no alterada, de color gris rosa, con una matriz isotrópica vítrea y con unos líticos de hasta $5 \mathrm{~cm}$, aflora en una cantera cerca de la mina Moncada. No se puede descartar la posibilidad de que estas rocas sean más antiguas, principalmente por el fuerte hidrotermalismo que tipifica a las rocas del Grupo Aguacate; también ha sido muy difícil su clasificación, básicamente por el alto grado de descomposición de las rocas que no son las idóneas para los análisis respectivos.

\section{Toba riolítica con biotita, unidad Alto Palomo, parte superior (12)}

Una secuencia estratificada de tobas claras hasta grises que consideramos como una capa superior de la unidad Alto Palomo, afloran en las localidades de Piedades Sur, San Miguel y Bajo de los Barrantes (localidad representativa por el hallazgo de restos de mamíferos del Pleistoceno). Las tobas son de color blanquecino o amarillento, están subhorizontalmente estratificadas hasta laminadas, en algunas capas hay acumulaciones de clastos de pómez de 1-5 $\mathrm{mm}$ con gradación (graded bedding) (Fig. 12) y en otras capas se acumulan lapilli de acreción hasta $1 \mathrm{~cm}$ de tamaño (Fig. 13), además la roca contiene biotita macroscópica y minerales opacos accesorios. Microscópicamente contiene una proporción variable de fenocristales y fragmentos de feldespatos, cuarzo, anfíbol, biotita, pero prevalece una matriz fina hasta vítrea. La susceptibilidad magnética oscila entre $0,3-2,7 \times 10^{-3}$ SI. Geoquímicamente se determinó que es de composición riolítica hasta dacítica.

Los contactos de las unidades no están bien expuestos y una clara relación entre la Formación Monteverde y estas ignimbritas, no se ha podido encontrar. Alvarado (1986) indica que en las capas suprayacentes de estas tobas aparecen andesitas hasta basaltos erosionados y de difícil correlación litoestratigráfica, que podrían ser de la Formación Motenverde. También Villegas (1997) pone a la unidad estratigráfica Alto Palomo junto con las ignimbritas de Peñas Blancas, entre Aguacate y Monteverde. Más tarde este mismo, Villegas (2004), asigna a la Formación Alto Palomo una edad de Pleistoceno Medio, más joven que la Formación Monteverde.

Con respecto a la estratigrafía paleontológica de Bajo de los Barrantes, esta ha ya sido descrita en la literatura (Valerio, 1939; Segura, 1942, 1963; Alvarado, 1986, Lucas et al., 1997). 


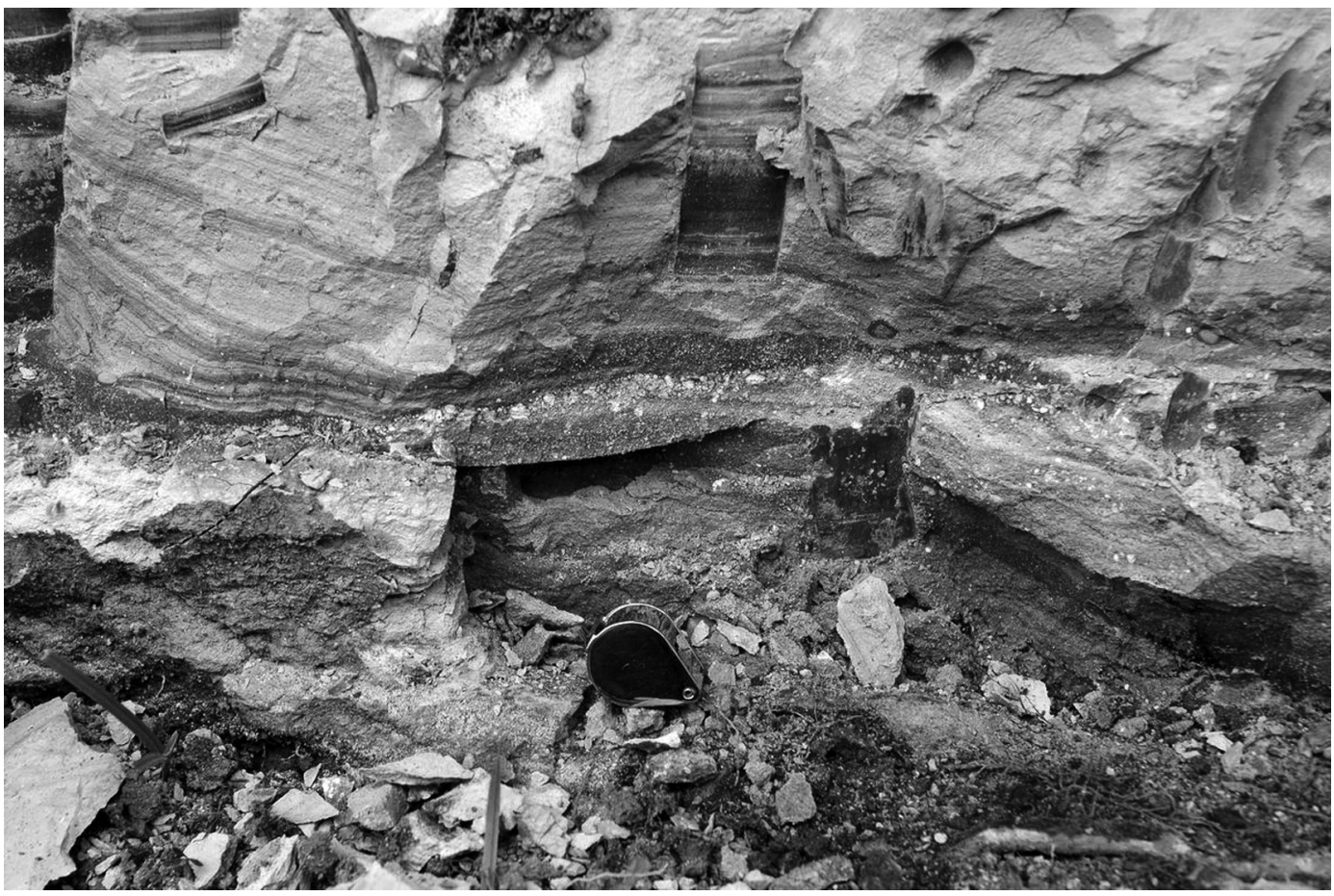

Fig. 12: Nivel de clastos de pómez entre las capas de ceniza tobáceas de composición riolítica, carretera entre Bajo Matamoros y San Miguel (cuadro 3, 4, No 18). Foto Vladimír Žáček.

\section{FORMACIÓN MONTEVERDE (PLEISTOCENO INFERIOR)}

En el área mapeada, la Formación Monteverde forma grandes superficies, especialmente en las cimas de la Cordillera de Tilarán. Ocupa la parte norte montañosa del mapa donde aparece principalmente en altitudes superiores a 1000 m.s.n.m. En los alrededores de Miramar o de Esparza de Puntarenas, se encuentra en forma de relictos de flujos de lavas, en altitudes más bajas. Estratigráficamente es la unidad más joven y es discordante al Grupo Aguacate (Cháves \& Sáenz, 1974). De los perfiles geológicos en la hoja Miramar se deduce que en algunos lugares su espesor sobrepasa los $500 \mathrm{~m}$.

Litológicamente está conformada por lavas andesíticas hasta andesita-basálticas no alteradas, en menor cantidad hay rocas piroclásticas (brechas y tobas) y localmente importante son los depósitos de lahares (Fig. 14).

Las rocas de la Formación Monteverde y del subyacente Grupo Aguacate son muy similares y es muy difícil diferenciar el contacto entre sí. No obstante los criterios que se utilizaron para distinguir a la unidad más joven fueron: la posición (zonas altas) y geomorfología, la presencia de las lavas fluidales y vítreas, ausencia de rocas intrusivas salvo domos, ausencia de alteraciones hidrotermales, vetas de cuarzo y criterios geoquímicos.

\section{Andesita, andesita basáltica con brechas, lahares y tobas subordinadas (11)}

Las lavas andesíticas (o lavas de composición andesita-basáltica), son las rocas que predominan en la Formación Monteverde; basaltos no fueron encontrados. También aparecen capas de brechas volcánicas, tobas y lahares. En el cerro Azahar ( $1610 \mathrm{~m}$ ) ubicado en el cuadrante NE de la hoja Miramar zona más alta de la región, predominan solo andesitas.

Las lavas (andesitas y andesitas basálticas) están sanas, son masivas, de color gris oscuro has- 


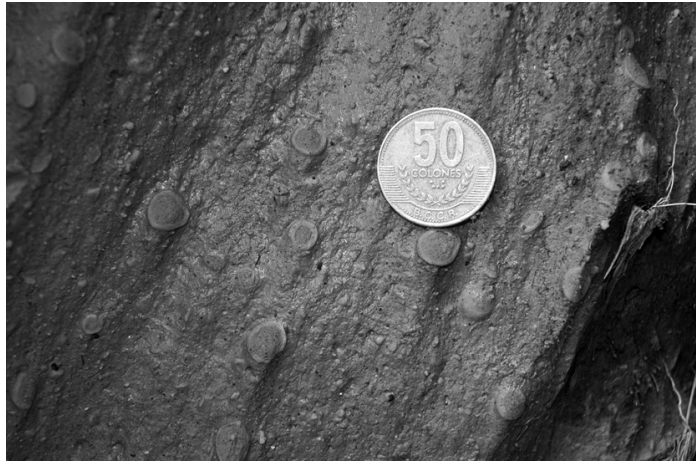

Fig. 13: Lapilli de acreción en una toba riolítica de la localidad de San Miguel, cerca de Bajo de Los Barrantes (cuadro 3, 4, No 18). Foto Vladimír Žáček.

ta casi negras, ligeramente porfídicas, compuesta de fenocristales de plagioclasa y piroxenos (20$50 \%$ ), y de una matriz fina a veces con estructuras fluidales. El tamaño de los fenocristales de plagioclasas alcanza hasta $4 \mathrm{~mm}$ y el de los piroxenos hasta $3 \mathrm{~mm}$. La matriz es de grano fino, holocristalina, sin la presencia de vidrio y compuesto de los mismos minerales que conforman los fenocristales. La cantidad de plagioclasa se estima de 50 a $70 \%$, parte de ellas se manifiestan en forma de fenocristales y la otra parte como matriz, La proporción de piroxenos es de $30-40 \%$; los ortopiroxenos y clinopiroxenos se encuentran en cantidades fluctuantes. El olivino está presente en las andesitas basálticas en cantidades hasta $5 \%$ y está parcial o totalmente serpentinizado. El mineral opaco es la magnetita y debido a su alto contenido en la andesita y basalto-andesítico (2-4\%), estas rocas alcanzan una susceptibilidad magnética de $25-50 \times 10^{-3}$ SI. Raramente se encuentra biotita y como mineral accesorio es común apatita. Las muestras de andesitas obtenidas de las localidades del Socorro y Zapotal, presentan una textura vesicular rellenas de clorita y probablemente alunita.

Lahares, aparecen principalmente en la base de la Formación Monteverde y forman capas no estratificadas, poco consolidadas, compuestas de una mezcla caótica de clastos y bloques de varios tamaños angulares hasta subangulares $\mathrm{y}$ de composición andesítica. Además de la mina Bellavista, lugar donde se encontró el mejor afloramiento, pueden ser vistos al sur del poblado
Laguna y están muy bien expuestos en los caminos entre los poblados de Zapotal y Barranquilla (Fig. 14) al NE de la hoja cartográfica Miramar. Probablemente existen más depósitos de estos; sin embargo por la cobertura vegetal y la laterización no se pueden distinguir o diferenciarse.

\section{Riodacita hasta andesita con biotita y anfíbol (domos) (10)}

\section{Domo cerro La Cruz}

En el sector norte de la hoja cartográfica, a unos $10 \mathrm{~km}$ al NE de la ciudad de Miramar, aparece un cuerpo aproximadamente de $4 \times 4 \mathrm{~km}$ de área, compuesto de rocas volcánicas ácidas con una amplia zona de alteración hidrotermal, conocido en la literatura como el domo o el antiguo centro volcánico cerro La Cruz (Fig. 15). En las inmediaciones de este centro volcánico afloran lavas y rocas piroclásticas probablemente de la Formación Monteverde. Los contactos son en parte tectónicos y en parte intrusivos, por lo general están muy alterados y oscurecidos por la laterización y la intensa alteración hidrotermal. En algunos lugares la riodacita encierra xenolitos de andesita (de la Formación Monteverde) de tamaños de 1-20 cm. En el domo cerro La Cruz se encontró rocas con una amplia gama de composición andesítica hasta riodacítica predominando las riodacitas. En todas las rocas hay presencia de fenocristales de anfíbol y biotita, mientras que los piroxenos están ausentes. La susceptibilidad magnética se midió en el rango de $5-10 \times 10^{-3} \mathrm{SI}$.

Las rocas de composición riodacítica son de color gris claro, amarillento o rosado, de grano mediano, porfídicas y con matriz mas o menos fluidal. Los fenocristales de plagioclasa, biotita y anfíbol son de hasta $5 \mathrm{~mm}$ de tamaño. A veces la roca tiene un aspecto plutónico por su alto contenido de fenocristales idiomórficos de plagioclasa, por esta razón se supone que se trata de una facie subvolcánica más profunda.

A nivel microscópico está compuesta de fenocristales de plagioclasa prismática (25-35\%), de anfíbol pleocróico de color verde olivo a café oscuro $(5-10 \%)$ y de biotita café oscuro muy pleocróica (1-5\%). Los minerales opacos están presentes 


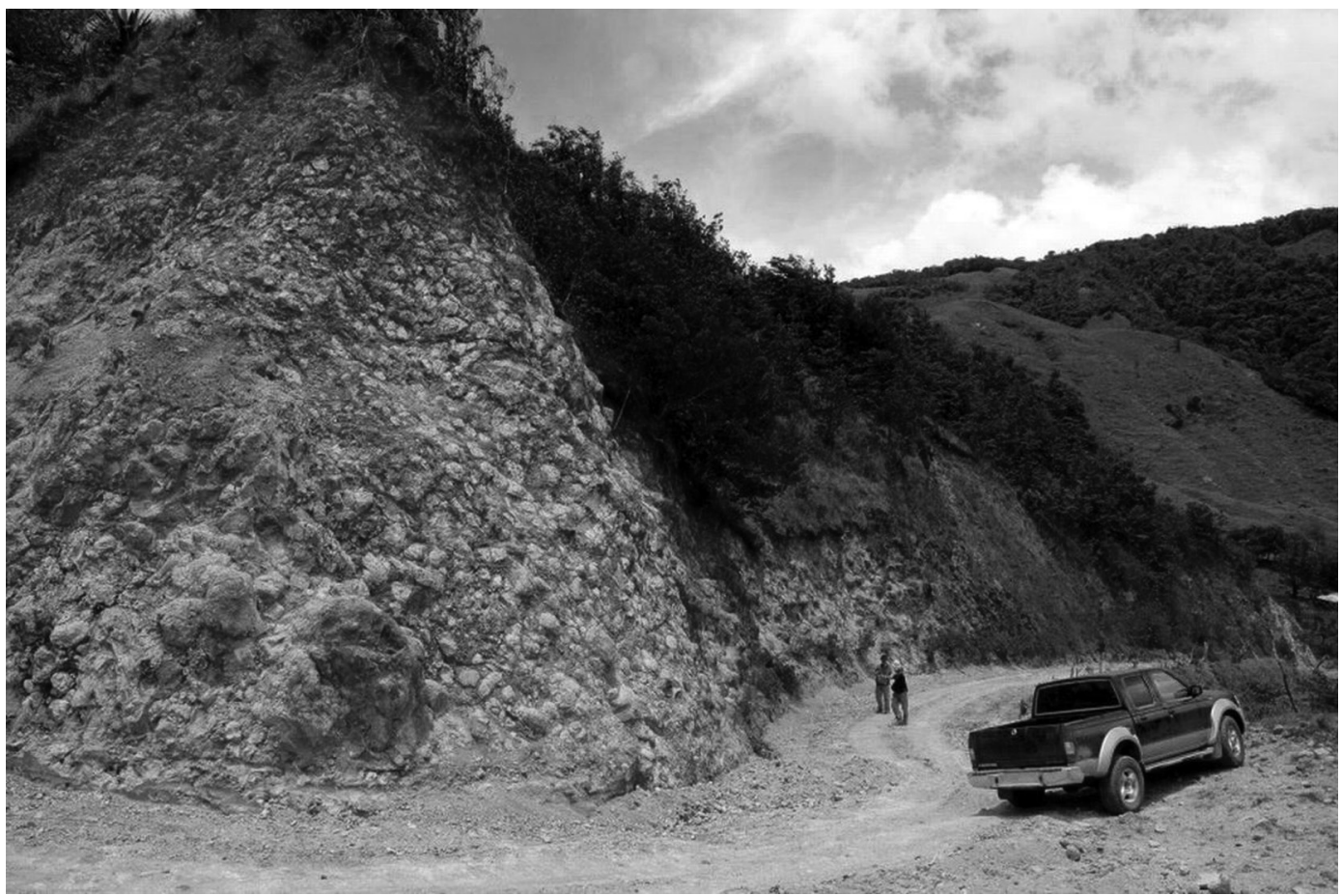

Fig. 14: Lahar compuesto de grandes bloques de andesita subangulares en una matriz poco compacta, aflora en las rutas entre los pueblos Zapotal y Barranquilla. Foto Vladimír Žáček.

en cantidades de $1-2 \%$. La matriz vítrea originaria $(45-60 \%)$ está completamente devitrificada en esferulitas de calcedonia con una estructura radial de 0,1-1,5 mm de diámetro. Entre las esferas hay material fino, ligeramente anisotrópico y el vidrio no se conservó. Según la difractometría aplicada a dos muestras de riodacitas (Cuadro 3, No 1, 5) se confirmó que además de los minerales mencionados también hay feldespato potásico, abundante tridimita, en menor cantidad cristobalita y el cuarzo está ausente.

\section{Domo cerro San Miguel}

Forma un cerro del mismo nombre que se eleva al SE de la hoja Miramar. Se trata de un cuerpo rectangular que cubre un área de aproximadamente $1,5 \times 2,5 \mathrm{~km}$ y corta a vulcanitas del Grupo Aguacate, formando un domo con pequeñas coladas de lava. La roca dominante es la dacita anfíbol-biotítica de color gris pálido a rosado, de grano medio, ligeramente porfídica, con fenocristales de plagioclasa de color blanco o incolora y anfíbol negro visible macroscópicamente.

A menudo la estructura de la roca es fluidal y en los afloramientos se separan en forma de tablas o láminas. No están muy afectadas por la alteración, solo se pudo distinguir una débil caolinización. Microscópicamente la roca es porfídica, con matriz fluidal y estructura esferulítica. La dacita se compone de fenocristales prismáticos, bien desarrollados, de plagioclasa con tamaño de 0,2-4 $\mathrm{mm}$ (20-30\%), de anfíbol idiomórfico de hasta 3 $\mathrm{mm}$, color café hasta verdes (aprox. 8-10\%) y de cristales de biotita (2-7\%). La proporción del mineral opaco es aprox. de 2-3\%. El resto (50-60\%) es una matriz de color café oscuro opaco, que se formó originalmente de vidrio y que en gran medida recristalizó en mosaico de esferulitas de "calcedonias", con diámetro de 0,1-1 mm. Otra parte de la matriz y en menor cantidad es microcristalina compuesta principalmente por aparentes tridimita y cristobalita (Fig. 16). 


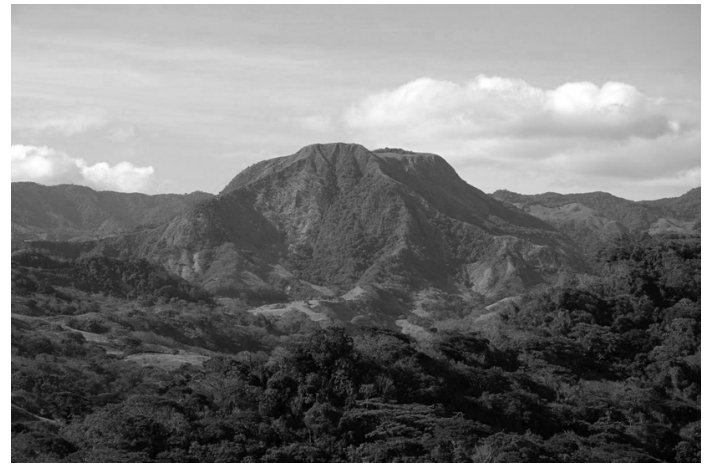

Fig. 15: Cerro La Cruz, que forma el borde oriental del gran domo riodacítico. Vista desde el SE del pueblo de El Salvador. Foto Vladimír Žáček.

\section{TOBA ARENOSA DE COLOR CAFÉ CLARO (PLEISTOCENO SUPERIOR - HOLOCENO) (7)}

Relictos de depósitos vulcanoclásticos más jóvenes, se conservan en el sector noreste de la región estudiada, entre los poblados de Bajo La Paz y Piedades Norte, a un nivel de 1100-1550 m.s.n.m. Todo este sector está conformado por rocas volcánicas de la Formación Monteverde, las cuales se encuentran muy laterizadas (las lateritas pueden alcanzar hasta varios metros de espesor).

Las tobas arenosas se conservaron en planicies laterizadas, las que ya han sido erosionadas; por esta razón y por su poca resistencia mecánica, no es posible observar afloramientos naturales de esta roca. Solo se pueden ver en zanjas o excavaciones a lo largo del camino.

En un perfil laterítico de $4 \mathrm{~m}$ de altura, se localizó una capa de tobas con un espesor de 1-2 $\mathrm{m}$ acupando la parte media y superior del perfil.

La roca no es laminada, es deleznable, liviana, de color café claro y parecida a una arenisca. Raras veces se pudo encontrar fragmentos de plantas carbonizadas. En los diferentes afloramientos estudiados, la roca presenta una susceptibilidad magnética que varía de $8-12 \times 10^{-3} \mathrm{SI}$.

En sección delgada se puede ver el tamaño del grano que es subangular, de 0,1-1 mm, sin estratificación aparente. El reconocimiento de los minerales es difícil debido a la fuerte meteorización ("limonitización").
La difractometría identificó gibbsita, cuarzo, magnetita, cristobalita y en cantidades más pequeñas olivino, plagioclasa, feldespato potásico y hematita (Cuadro 2). Con el análisis se comprobó que el hierro y los hidróxidos de aluminio secundarios son dominantes (gibbsita al lado de limonita amorfa) y son el resultado de la meteorización; mientras que otros minerales son relictos de la composición original (olivino, feldespato) y de los minerales resistentes a la meteorización (magnetita, cuarzo). La fuente de origen de las tobas, se supone de la actividad eruptiva de los volcanes Poás o Platanar en el Pleistoceno tardío hasta el Holoceno (G. Alvarado y R. Mora, com. oral).

\section{CUATERNARIO NO VOLCÁNICO (PLEISTOCENO-HOLOCENO)}

Se diferenciaron varios tipos de depósitos cuaternarios, desde el Holoceno hasta Pleistoceno inferior, algunos de ellos ya han sido mapeados anteriormente (p.ej. Denyer et al., 2003) y correlacionados con la Formación Esparza; no obstante genéticamente aún no han sido divididos. Por esta razón clasificamos a estos depósitos según su origen en: depósitos de deslizamientos, sedimentos fluviales, conos de deyección, acumulaciones de paleo-abanicos aluviales y también dos niveles de paleoterrazas. Las relaciones estratigráficas y edad se muestran en la figura 2.

\section{Paleoterrazas fluviales, nivel 1 , arenas y gra- vas altamente laterizadas (9)}

Un amplio sistema de paleoterrazas se ubica en los alrededores de Marañonal, Esparza y San Jerónimo, al sur de la hoja. La posición morfológica de las paleoterrazas es clara; sin embargo sucede lo contrario con la identificación de la composición litológica y la estimación de los espesores, dado a la fuerte laterización que afecta hasta profundidades de 3 a $4 \mathrm{~m}$. Solamente en zanjas situadas en los alrededores de las planicies, empiezan a aparecer niveles de gravas con una litología muy variada. Dominan 


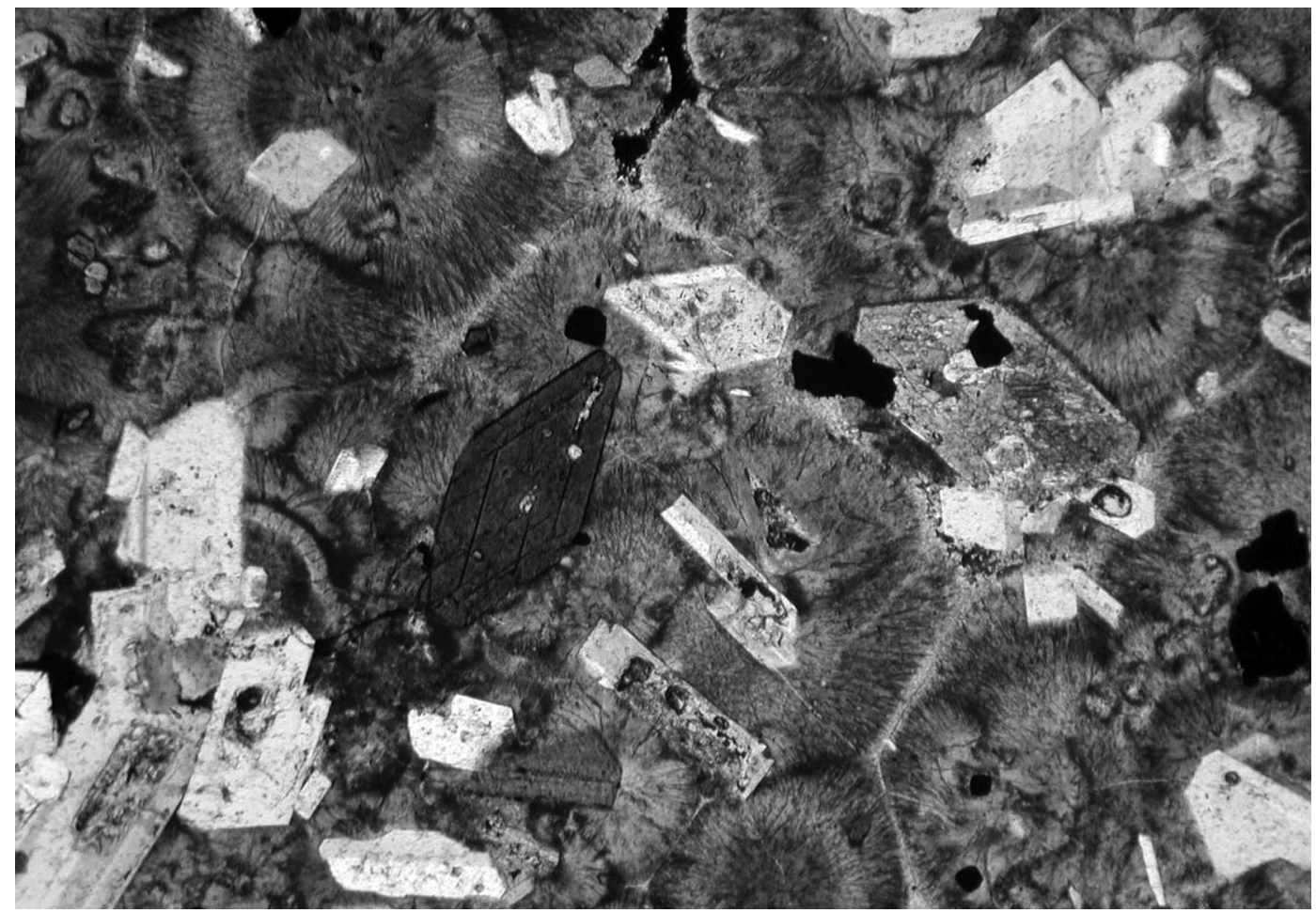

Fig. 16: Microfotografía de una dacita anfíbol-biotitíca (cuadro 3, 4, No 13) del cerro San Miguel datada en 1,59 Ma. Coordenadas y análisis químico véase en el cuadro 3 y 4 . Ancho de foto $3,3 \mathrm{~mm}$, polaroides //. Foto V. Žáček.

andesitas porfídicas, en menor cantidad dacitas de color gris, e ignimbritas. Otros materiales pero también de importancia son los cantos de rocas silicificadas de colores claros que son más resistentes a la meteorización. El tamaño predominante de los clastos varían entre 5-20 $\mathrm{cm}$ pero hay bloques de andesitas de hasta 50 $\mathrm{cm}$. Salvo las rocas silicificadas, estas se encuentran altamente laterizadas. Los cantos y bloques presentan descomposición tipo cebo1la. El espesor de los depósitos fluviales sobre el río Barranca se puede estimar de 5-10 m, tal vez más. Estas terrazas se correlacionan con el Pleistoceno Inferior, dado los niveles de elevación de las terrazas (más de $100 \mathrm{~m}$ sobre el lecho actual), el grado de meteorización del material clástico y sus características en general.

\section{Paleoterrazas fluviales, nivel 2, arenas y gravas (8)}

Son niveles de paleoterrazas de menor extensión, que se encuentran de 15 a 20 m por encima del lecho actual del río Barranca y se localizan a unos $3 \mathrm{~km}$ al NO de Angostura. Se distingue por un notable nivel morfológico. Son gravas hasta arenas gruesas muy parecidas a los sedimentos fluviales de caudales recientes. La edad probablemente corresponda al Pleistoceno Medio hasta Superior.

\section{Depósitos de deslizamientos (6)}

Los depósitos de deslizamientos están conformados por material clástico (clastos y bloques de hasta varios metros de diámetro) de rocas vol- 
cánicas principalmente andesitas y dacitas, están caóticamente mezcladas con una matriz arcillosa o de fragmentos líticos y por lo general saturados de agua (Fig. 17). Sus espesores pueden alcanzar hasta varias decenas de metros. Por el tamaño de los bloques se supone que el material es de largo transporte, en algunos casos de varios kilómetros de distancia como p.ej. los gigantescos deslizamientos en Peñas Blancas y San Antonio cerca del cerro La Cruz.

\section{Depósitos de paleoabanicos aluviales, arenas, gravas y bloques con presencia de arcillas (5)}

Estos depósitos alcanzan superficies relativamente grandes y aparecen al SO de la hoja Miramar, pero principalmente se encuentran en la hoja colindante "Chapernal". Se manifiestan en formas morfológicas alargadas y elevadas (lomas) hasta $30 \mathrm{~m}$ de altura. Los depósitos actuales están representados por relictos de erosión de los antiguos conos de deyección (Pleistoceno), modelados en el Holoceno, por caudales de aguas recientes. El espesor de estas acumulaciones es variable y pueden alcanzar varias decenas de metros. Litológicamente se trata de depósitos de grava constituidos por cantos rodados con prevalencia de andesitas laterizadas mezcladas con una matriz de arena fina o arcilla laterítica. Típico es la fuerte meteorización laterítica y una altura mayor con respecto al nivel de los lechos de los ríos actuales.

\section{Depósitos lacustres, gravas, arenas y arcillas (4)}

Depósitos lacustres se ubican en la parte NO del territorio estudiado y están relacionados principalmente con las depresiones (lagunas) de la superficie, en áreas de deslizamientos. Están formados de arcillas y arenas, mezcladas con fragmentos de rocas más grandes cuya fuente de material son los propios deslizamientos. Un mayor alcance tiene en las Peñas

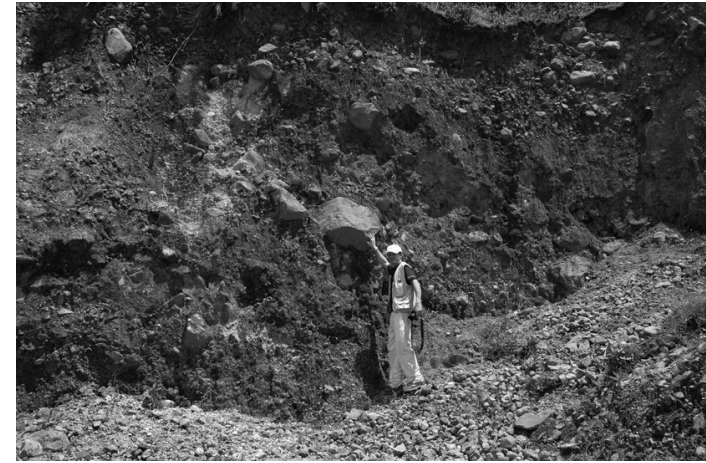

Fig. 17: Depósito de deslizamiento en el poblado San Antonio de San Ramón al sur del cerro Azahar. Foto V. Žáček.

Blancas, finca La Laguna o en los alrededores de las localidades de Barranquilla y Zapotal.

\section{Depósitos de abanicos aluviales, arenas, gra- vas y bloques (3)}

Los depósitos recientes (Holoceno) de conos de deyección están relacionados a las corrientes de aguas más torrentosos de la región y se localizan principalmente, en la desembocadura de los valles hacia la llanura. Las acumulaciones más importantes se encuentran al sur de Peñas Blancas, al lado de la finca La Laguna y en la desembocadura de la quebrada Jiménez hacia el río Barranca, cerca del puente de San Jerónimo. Litológicamente, los depósitos consisten de materiales gruesos, en su mayoría de rápido transporte (gravas de inundación con bloques de rocas), que dependiendo de la distancia del recorrido pueden ser de menos a mas retrabajados.

\section{Depósitos fluviales, arenas, gravas y bloques (2)}

Los sedimentos fluviales forman bancos de material que rellenan los cauces de los ríos, especialmente en aquellos de mayor flujo y dimensiones como son p.ej. el río Barranca, Barranquilla, Naranjo, Ciruelas y La Paz. La 
red fluvial en su mayoría es de edad cuaternaria (Holoceno) y al SO de la hoja Miramar (desde Cuatro Cruces de Miramar) bordeando la línea de costa, los ríos cortan los depósitos de antiguos conos de deyección del Pleistoceno. Probablemente el de mayor antigüedad es el río Barranca, ya que según los cortes observados, estas terrazas se sitúan a un nivel de más de 100 $\mathrm{m}$ sobre el lecho reciente del cauce y conservan aún las formas de sus flujos primarios, posiblemente del Pleistoceno Inferior.

Litológicamente, los depósitos fluviales están compuestos principalmente de gravas hasta arenas gruesas, sobre todo con cantos y bloques de semi hasta bien redondeados, compuestos de diferentes rocas volcánicas principalmente andesitas, basaltos y brechas.

Una situación anómala ocurre aguas arriba del río Jabonal, que a pesar de ubicarse en una zona alta de la región (1300 m.s.n.m.) de mucha laterización y con una alta precipitación, típica del bosque nuboso, se forman meandros de aguas tranquilas. Una de las terrazas con mayor extensión aparece en el cauce del río Barranca al norte de Marañonal (Esparza), donde alcanzan dimensiones de hasta $1,1 \mathrm{~km}$ de ancho.

\section{Depósitos antropogénicos (Holoceno) (1)}

En la región estudiada el principal depósito de este tipo se encontró en la mina de oro "Bellavista" en Miramar de Puntarenas. Se trata de la escombrera de este proyecto minero, compuesta principalmente de rocas estériles. Después de los deslizamientos que ocurrieron en el año 2007 debido a las altas precipitaciones que azotaron el país, las operaciones de extracción y recuperación de oro fueron suspendidas, limitándose únicamente las labores a la recuperación ambiental de la mina.

Otras escombreras y depósitos de lamas de menor tamaño se ubican en las antiguas explotaciones de la Mina Unión y la Mina Moncada, las mismas no pudieron dibujarse a una escala 1:50 000 por ser muy pequeña.

\section{K-AR DATACIONES}

En el Cuadro 1 se sintetizan los resultados de cada una de las muestra, con sus respectivas ubicaciones en coordenadas geográficas y composición mineralógica. De igual forma, los análisis geoquímicos y mineralógicos de las mismas se resumen en los Cuadros 2-4 y en los capítulos siguientes de Geoquímica y Mineralogía.

Del Grupo Aguacate se dataron dos muestras, una de basalto (Cuadro $1, \mathrm{n}^{\circ} 8$ ) y otra de riolita vidriosa (Cuadro $1, \mathrm{n}^{\circ}$ ) ) que intruye basaltos del mismo grupo. Los resultados dieron edades de 4,99 ( \pm $0,6)$ Ma para el basalto y de 4,41 $( \pm 0,15)$ Ma para la riolita que corresponden al Plioceno Inferior. Por otro lado, con el método U-Pb se dataron circones de los granitos de Guacimal (hoja Juntas), resultan-

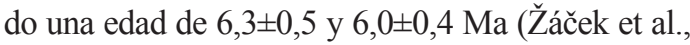
2011). Dicho granito también intruye las lavas del Grupo Aguacate, lo que indica que la edad de esta unidad alcanza en algunos lugares más de $6 \mathrm{Ma}$.

De la Formación Monteverde fueron datadas dos muestras de andesita basáltica (Cuadro 1, $\mathrm{n}^{\circ}$ 14) una del tajo Bellavista otra de la Finca Mirón ubicada cerca de Esparza (Cuadro 1, n 23). Los resultados de ambas muestras fueron muy parecidos: $1,77( \pm 0,11)$ y $1,71( \pm 0,25 \mathrm{Ma})$.

Una muestra de riolita del domo cerro $\mathrm{La}$ Cruz (Cuadro 1, $\left.\mathrm{n}^{\circ} 1\right)$ dio la edad de 1,13 $( \pm 0,06$ Ma) para toda la roca y de $1,71( \pm 0,14 \mathrm{Ma})$ para la biotita y anfíbol que fueron separados, esta se considera la edad más confiable.

De la biotita separada de una muestra de dacita del domo cerro San Miguel (Cuadro 1, ${ }^{\circ} 13$ ), se obtuvo una edad de 1,59 ( $\pm 0,12 \mathrm{Ma})$, que confirmó junto con las lavas de la Fm. Monteverde una edad del Pleistoceno Inferior y una relación genética con el cuerpo del cerro La Cruz.

Por último se dató una toba ácida con restos de macrofauna de la localidad tipo „Bajo Barrantes" (Cuadro 1, n 18a), los resultados fueron erróneos debido a un bajo contenido de $\mathrm{K}$ y Ar en la roca. Aunque la edad resultante fue de 2,6 ( \pm $1,8) \mathrm{Ma}$, este resultado no puede ser considerado como confiable, dada la gran diferencia con lo que actualmente se encuentra establecido. 


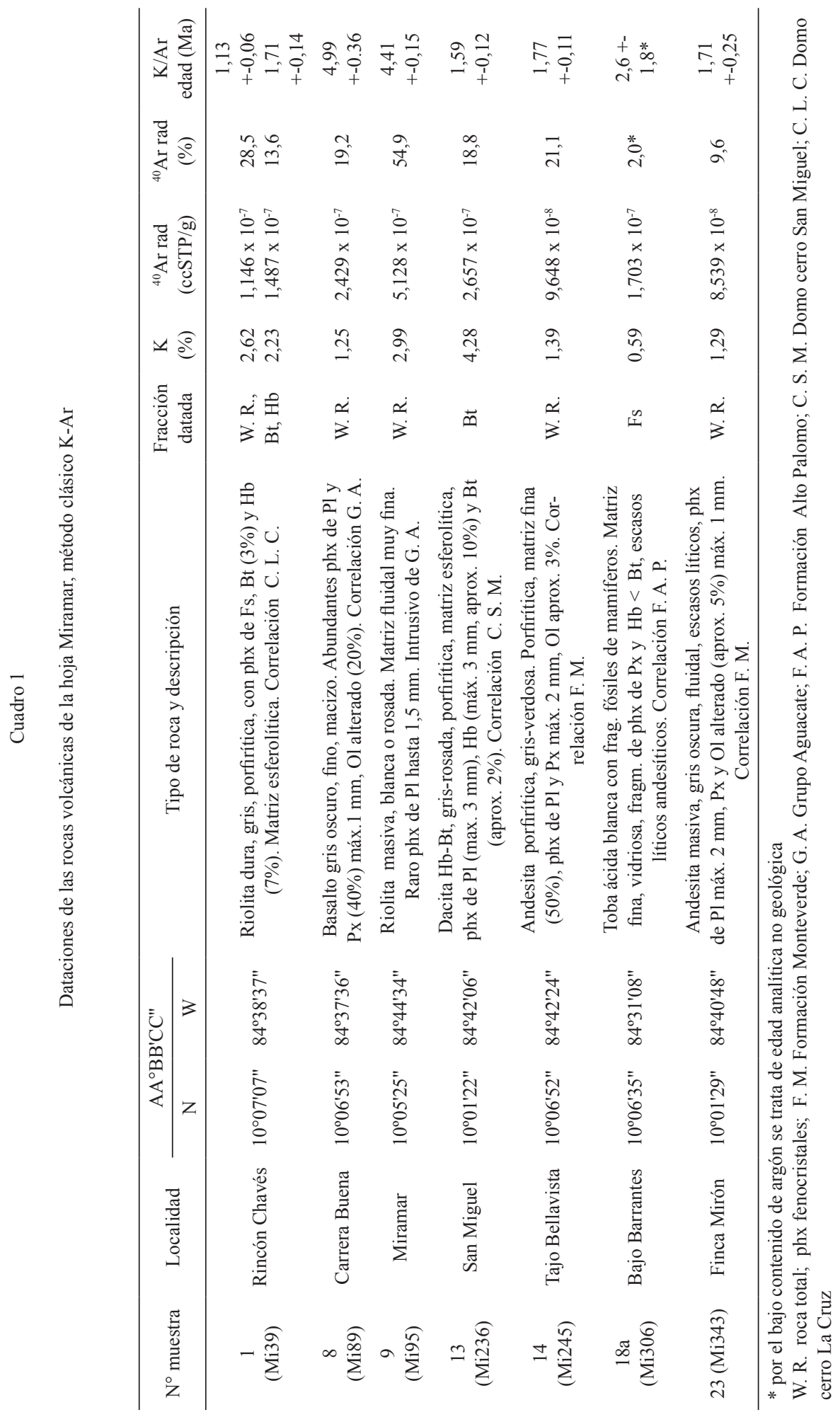




\section{MINERALOGÍA DE LAS ROCAS VOLCÁNICAS}

Por microsonda electrónica se analizaron 9 muestras de rocas volcánicas para determinar la composición química de los minerales (Fig. 18 a-d), también se hicieron análisis químicos de las mismas y algunas de ellas fueron datadas por el método K-Ar (véase Cuadros 1, 3-4). Con el método de difractometría se analizaron otras 28 muestras de rocas alteradas y varios minerales como zeolitas, sulfatos, etc. (véase Cuadro 2); además por microscopía fueron examinadas 80 secciones delgadas.

\section{Lavas del Grupo Aguacate}

Fueron consideradas dos muestras de lava: a) basalto (Cuadro $3, n^{\circ} 8$ ) andesita basáltica (Cuadro 3, $\mathrm{n}^{\circ}$ 10). Ambas muestras contienen plagioclasa básica, clinopiroxeno y ortopiroxeno (predominante), olivino y titanomagnetita subordinada. La muestra de basalto (Cuadro $3, \mathrm{n}^{\circ} 8$ ) además contiene biotita y calcita como minerales accesorios secundarios. La Plagioclasa se trata de labradorita hasta bytownita $\left(\mathrm{An}_{66-88}\right)$ con un elevado contenido de $\mathrm{SrO}(0,2-0,3 \%)$ pero pobre en $\mathrm{BaO}(0,0 \%)$, muestra zonación y su basicidad disminuye hacia el borde.

Clinopiroxeno, se presenta como $\mathrm{Fe}-$ diópsido, $X_{\mathrm{Mg}}=\mathrm{Mg} /(\mathrm{Mg}+\mathrm{Fe})=0,70-0,86$ con un valor elevado de $\mathrm{Al}_{2} \mathrm{O}_{3}(2,6-4,4 \%)$, bajo en $\mathrm{Na}_{2} \mathrm{O}$ $(0,3-0,4 \%)$.

Ortopiroxeno, se presenta como Fe-enstatita, $\left(\mathrm{X}_{\mathrm{Mg}}=0,60-0,74\right)$, con valores elevados de $\mathrm{Al}_{2} \mathrm{O}_{3}$ $(0,7-1,4 \%)$ y $\mathrm{CaO}(1,6-4,6 \%)$.

Olivino, se trata de forsterita, $\mathrm{X}_{\mathrm{Mg}}=0,85$ 0,89 con valores elevados de $\mathrm{CaO}(0,17-0,24 \%)$, $\mathrm{MnO}(0,22-0,44 \%)$ y $\mathrm{NiO}(0,08-0,21 \%)$. Hacia la margen del grano, tiende a aumentar débilmente el contenido de $\mathrm{Mg}$.
Ti-magnetita (serie ulvöspinel-magnetita), es el único mineral opaco en las muestras estudiadas. Contiene 11-15\% $\mathrm{TiO}_{2}$ y también altos valores de $\mathrm{Al}_{2} \mathrm{O}_{3}(\sim 2 \%), \mathrm{MgO}(0,2-1,9 \%), \mathrm{V}_{2} \mathrm{O}_{3}(0,8-1,1 \%)$, $\mathrm{MnO}(0,3-0,5 \%)$ y $\mathrm{ZnO}(0,2-0,4 \%)$.

Biotita, Mg-dominante $\left(\mathrm{X}_{\mathrm{Mg}}=0,85\right)$, rica en $\mathrm{TiO}_{2}(3,7-5,6 \%)$ y $\mathrm{F}(\sim 5,5 \%)$.

\section{Lavas Monteverde}

Se analizó una muestra (Cuadro $3, \mathrm{n}^{\circ} 2$ ).

La plagioclasa está significativamente zona$\mathrm{da}$, se trata de oligoclasa-labradorita ácida $\left(\mathrm{An}_{15}\right.$ $\left.{ }_{52}\right)$, la basicidad y el contenido de $\mathrm{BaO}(0,08-$ $0,55 \%)$ descienden hacia el borde y el contenido de $\mathrm{SrO}(\sim 0,23 \%)$ no varía.

Ortopiroxeno, se presenta como Fe-enstatita, ligeramente zonada (disminución de $\mathrm{Al}$, ascenso de Ca con dirección al borde del grano), $\mathrm{X}_{\mathrm{Mg}}=\mathrm{Mg}$ $/\left(\mathrm{Mg}^{+} \mathrm{Fe}^{2+}\right)=0,70-0,77$ con $\left.\mathrm{Al}_{2} \mathrm{O}_{3} 0,9-1,1 \%\right)$ y $\mathrm{MnO}$ (alrededor de $0,7 \%)$ y $\mathrm{CaO}(1,4-1,9 \%)$.

Clinopiroxeno, se presenta como Fe-diópsido, $\mathrm{X}_{\mathrm{Mg}}=0,67-0,76, \mathrm{Al}_{2} \mathrm{O}_{3}=1,8-4,1 \%, \mathrm{TiO}_{2}=0,4-$ $1,0 \%, \mathrm{Na}_{2} \mathrm{O}=0,3-0,5 \%$. Hacia el borde de los granos crece en $\mathrm{Al}$ y disminuye en $\mathrm{X}_{\mathrm{Mg}}$.

Olivino, corresponde a la Fe-forsterita, $\mathrm{X}_{\mathrm{Mg}}=$ $0,79-0,82$, contiene $0,13-0,15 \% \mathrm{CaO}, 0,38-0,47 \%$ $\mathrm{MnO}$ y $0,11-0,23 \% \mathrm{NiO}$.

Ti-magnetita, contiene alrededor de $6 \%$ $\mathrm{TiO}_{2}$ y valores significativos de $\mathrm{Al}_{2} \mathrm{O}_{3}$ (alrededor de $1,9 \%), \mathrm{MgO}(1,2 \%), \mathrm{MnO}(0,5 \%), \mathrm{y}_{2} \mathrm{O}_{5}$ $(0,66 \%)$.

Ilmenita es un mineral accesorio poco frecuente que contiene $\sim 0,9 \% \mathrm{MnO}$ y $\sim 1,95 \% \mathrm{MgO}$.

\section{Los domos riodacíticos}

Se investigó una muestra de dacita (Cuadro $3, n^{\circ} 1$ ) del cerro La Cruz (también datada, método K-Ar). La roca está compuesta de fenocristales 
Cuadro 2

Resultados de los análisis con difractometría de las rocas y minerales

\begin{tabular}{|c|c|c|c|c|c|c|c|c|c|}
\hline \multirow{2}{*}{$\begin{array}{c}\mathrm{N}^{\circ} \\
\text { muestra }\end{array}$} & \multicolumn{2}{|c|}{$\mathrm{AA}^{\circ} \mathrm{BB}^{\prime} \mathrm{CC} "$} & \multirow{2}{*}{$\begin{array}{c}\text { Roca, } \\
\text { alteración }\end{array}$} & \multirow{2}{*}{ U. C } & \multirow{2}{*}{ Localidad } & \multirow{2}{*}{$\begin{array}{l}\text { Tipo } \\
\text { Alt. }\end{array}$} & \multicolumn{3}{|c|}{ Composición } \\
\hline & $\mathrm{N}$ & W & & & & & Mayor \% & Menor \% & Raro \\
\hline $\begin{array}{c}5 \\
(\mathrm{Mi} 68)\end{array}$ & $10^{\circ} 08^{\prime} 42^{\prime \prime}$ & $84^{\circ} 39^{\prime} 47^{\prime \prime}$ & $\begin{array}{c}\text { Amdesita } \\
\text { con } \mathrm{Hb} \text { y Bt }\end{array}$ & $\begin{array}{l}\text { C. L. } \\
\text { C. }\end{array}$ & Río Jabonal & sana & $\mathrm{Pl}, \mathrm{Sa}$ & $\mathrm{Hb}$ & $\begin{array}{c}\text { Bt, ?Crs } \\
\text { ?Di }\end{array}$ \\
\hline $\begin{array}{c}6 \\
(\mathrm{Mi} 73)\end{array}$ & $10^{\circ} 09^{\prime} 42^{\prime \prime}$ & $84^{\circ} 38^{\prime} 14^{\prime \prime}$ & $\begin{array}{l}\text { Roca al- } \\
\text { terada }\end{array}$ & $\begin{array}{l}\text { C. L. } \\
\text { C. }\end{array}$ & Barranquilla & (ii-b) & $\begin{array}{l}\text { Natro-Aln, } \\
\text { Trd }\end{array}$ & Kln & ?Qtz \\
\hline $\begin{array}{c}9 \\
(\mathrm{Mi} 95)\end{array}$ & $10^{\circ} 05^{\prime} 25^{\prime \prime}$ & $84^{\circ} 44^{\prime} 34^{\prime \prime}$ & $\begin{array}{l}\text { Riolita vid- } \\
\text { riosa sana }\end{array}$ & Int. & Miramar & (ii-a) & Qtz & $\mathrm{Sa}, \mathrm{Pl}$ & Mnt \\
\hline $\begin{array}{c}12 \\
(\mathrm{Mi2} 20)\end{array}$ & $10^{\circ} 01^{\prime} 51^{\prime \prime}$ & $84^{\circ} 38^{\prime} 53^{\prime \prime}$ & $\begin{array}{l}\text { Roca ácida } \\
\text { A(ii-a) }\end{array}$ & Ig. & $\begin{array}{c}\text { Sn. } \\
\text { Jerónimo }\end{array}$ & (i-a) & Trd, Sa, Pl & Crs & Kln \\
\hline $\begin{array}{c}34 \\
(\mathrm{Mi29b})\end{array}$ & $10^{\circ} 09^{\prime} 23^{\prime \prime}$ & $84^{\circ} 43^{\prime} 31^{\prime \prime}$ & Zeolita & G. A. & La Unión & (i-a) & $\begin{array}{l}\text { Heulandita- } \\
\text { Ca/estilbita }\end{array}$ & Qtz, Cal & \\
\hline $\begin{array}{c}35 \\
(\mathrm{Mi39})\end{array}$ & $10^{\circ} 07^{\prime} 07^{\prime \prime}$ & $84^{\circ} 38^{\prime} 37^{\prime \prime}$ & $\begin{array}{l}\text { Riolita con } \\
\mathrm{Hb} \text { y Bt }\end{array}$ & $\begin{array}{l}\text { C. L. } \\
\text { C. }\end{array}$ & Rnc. Chaves & sana & $\operatorname{Trd}$ & $\mathrm{Pl}$ & $\mathrm{Bt}, \mathrm{Hb} ? \mathrm{Or}$ \\
\hline $\begin{array}{c}36 \\
(\mathrm{Mi} 212)\end{array}$ & $10^{\circ} 03^{\prime} 24^{\prime \prime}$ & $84^{\circ} 38^{\prime} 01^{\prime \prime}$ & $\begin{array}{l}\text { Roca al- } \\
\text { terada }\end{array}$ & $\begin{array}{l}? \mathrm{G} . \\
\text { A. }\end{array}$ & $\begin{array}{c}\text { Sn. } \\
\text { Jerónimo }\end{array}$ & (ii-a) & Qtz & Nacrita-2M2 & \\
\hline $\begin{array}{c}37 \\
(\mathrm{Mi213})\end{array}$ & $10^{\circ} 03^{\prime} 51^{\prime \prime}$ & $84^{\circ} 38^{\prime} 07^{\prime \prime}$ & $\begin{array}{l}\text { Roca al- } \\
\text { terada }\end{array}$ & G. A. & $\begin{array}{c}\text { Sn. } \\
\text { Jerónimo }\end{array}$ & (ii-a) & Qtz & Kln & ?Ant \\
\hline $\begin{array}{c}38 \\
(\mathrm{Mi2} 215)\end{array}$ & $10^{\circ} 04^{\prime} 04^{\prime \prime}$ & $84^{\circ} 38^{\prime} 06^{\prime \prime}$ & $\begin{array}{l}\text { Bloque } \\
\text { silícico }\end{array}$ & G. A. & $\begin{array}{c}\text { Sn. } \\
\text { Jerónimo }\end{array}$ & (ii-a) & Qtz & & \\
\hline $\begin{array}{c}39 \\
(\mathrm{Mi} 223)\end{array}$ & $10^{\circ} 03^{\prime} 48^{\prime \prime}$ & $84^{\circ} 43^{\prime} 20^{\prime \prime}$ & $\begin{array}{l}\text { Bloque } \\
\text { silícico }\end{array}$ & G. A. & Sn. Isidro & (ii-a) & Qtz & $\begin{array}{c}\text { Huangita, } \\
\text { Anh }\end{array}$ & \\
\hline $\begin{array}{c}40 \\
(\mathrm{Mi} 260)\end{array}$ & $10^{\circ} 00^{\prime} 31^{\prime \prime}$ & $84^{\circ} 39^{\prime} 34^{\prime \prime}$ & $\begin{array}{l}\text { Roca al- } \\
\text { terada }\end{array}$ & G. A. & Esparza & (i) & Qtz & $\mathrm{K} \ln , \mathrm{Ms}$ & $? \mathrm{Sa}$ \\
\hline $\begin{array}{c}41 \\
(\mathrm{Mi2} 283)\end{array}$ & $10^{\circ} 01^{\prime} 112$ & $84^{\circ} 36^{\prime} 22^{\prime \prime}$ & $\begin{array}{l}\text { Roca al- } \\
\text { terada }\end{array}$ & G. A. & Angostura & (i) & Qtz & Ms(sericita) & \\
\hline $\begin{array}{c}42 \\
(\mathrm{Mi310a})\end{array}$ & $10^{\circ} 01^{\prime} 52^{\prime \prime}$ & $84^{\circ} 30^{\prime} 41^{\prime \prime}$ & eflorescencia & G. A. & Río Jesús & (iii) & $\begin{array}{l}\text { Halotrichita } \\
\text { - pickerin- } \\
\text { gita }\end{array}$ & & \\
\hline $\begin{array}{c}43 \\
(\mathrm{Mi} 310 \mathrm{~b})\end{array}$ & $10^{\circ} 01^{\prime} 52^{\prime \prime}$ & $84^{\circ} 30^{\prime} 41^{\prime \prime}$ & $\begin{array}{l}\text { Roca al- } \\
\text { terada }\end{array}$ & G. A. & Río Jesús & (ii-a) & Qtz & $\operatorname{Prl}, \mathrm{K} \ln , \mathrm{Aln}$ & ?Ant \\
\hline $\begin{array}{c}44 \\
(\mathrm{Mi329})\end{array}$ & $10^{\circ} 02^{\prime} 37^{\prime \prime}$ & $84^{\circ} 33^{\prime} 52^{\prime \prime}$ & eflorescencia & G. A. & $\begin{array}{l}\text { P.H.. Na- } \\
\text { gatac }\end{array}$ & (i) & Malaquita & Qtz, Chl & \\
\hline $\begin{array}{c}45 \\
(\mathrm{Mi359})\end{array}$ & $10^{\circ} 09^{\prime} 18^{\prime \prime}$ & $84^{\circ} 37^{\prime} 28^{\prime \prime}$ & $\begin{array}{l}\text { Roca al- } \\
\text { terada }\end{array}$ & $\begin{array}{l}\text { C. L. } \\
\text { C. }\end{array}$ & Zapotal & (ii-b) & Trd & & $\begin{array}{c}\mathrm{K} \ln , ? \mathrm{Crs}, \\
\text { ?Ant }\end{array}$ \\
\hline $\begin{array}{c}46 \\
\text { (Mi371a) }\end{array}$ & $10^{\circ} 06^{\prime} 30^{\prime \prime}$ & $84^{\circ} 35^{\prime} 02^{\prime \prime}$ & $\begin{array}{l}\text { Riolita } \\
\text { alterada }\end{array}$ & Int. & Potrerillos & (ii-a) & Qtz & Aln, $\operatorname{Prl}, \mathrm{K} \ln$ & $\begin{array}{l}\text { Ms (ser- } \\
\text { icita), Or }\end{array}$ \\
\hline $\begin{array}{c}47 \\
(\mathrm{Mi} 371 \mathrm{~b})\end{array}$ & $10^{\circ} 06^{\prime} 30^{\prime \prime}$ & $84^{\circ} 35^{\prime} 02^{\prime \prime}$ & $\begin{array}{l}\text { Riolita } \\
\text { alterada }\end{array}$ & Int. & Potrerillos & (ii-a) & Qtz & $\begin{array}{l}\text { Prl, Ms (ser- } \\
\text { icita), Aln }\end{array}$ & \\
\hline
\end{tabular}


Cuadro 2 (continuación)

Resultados de los análisis con difractometría de las rocas y minerales

\begin{tabular}{|c|c|c|c|c|c|c|c|c|c|}
\hline \multirow{2}{*}{$\begin{array}{c}\mathrm{N}^{\circ} \\
\text { muestra }\end{array}$} & \multicolumn{2}{|c|}{$\mathrm{AA}^{\circ} \mathrm{BB}^{\prime} \mathrm{CC}^{\prime \prime}$} & \multirow{2}{*}{$\begin{array}{l}\text { Roca, } \\
\text { alteración }\end{array}$} & \multirow{2}{*}{ U. C } & \multirow{2}{*}{ Localidad } & \multirow{2}{*}{$\begin{array}{l}\text { Tipo } \\
\text { Alt. }\end{array}$} & \multicolumn{3}{|c|}{ Composición } \\
\hline & $\mathrm{N}$ & W & & & & & Mayor \% & Menor \% & Raro \\
\hline $\begin{array}{c}48 \\
\text { (Mi389) }\end{array}$ & $10^{\circ} 06^{\prime} 14^{\prime \prime}$ & $84^{\circ} 35^{\prime} 01^{\prime \prime}$ & $\begin{array}{l}\text { Riolita } \\
\text { alterada }\end{array}$ & Int. & $\begin{array}{l}\text { Calle Sal- } \\
\text { vador }\end{array}$ & (ii-a) & Qtz & Aln & $\begin{array}{l}\text { sericita, } \\
\text { ?natroal- } \\
\text { unita }\end{array}$ \\
\hline $\begin{array}{c}49 \\
\text { (Mii406) }\end{array}$ & $10^{\circ} 03^{\prime} 40^{\prime \prime}$ & $84^{\circ} 32^{\prime} 12^{\prime \prime}$ & $\begin{array}{l}\text { Vetitas en } \\
\text { basalto }\end{array}$ & G. A. & $\begin{array}{l}\text { P.H.. Na- } \\
\text { gatac }\end{array}$ & (i) & Qtz & Chl & \\
\hline $\begin{array}{c}50 \\
(\mathrm{Mi} 451)\end{array}$ & $10^{\circ} 00^{\prime} 51^{\prime \prime}$ & $84^{\circ} 33^{\prime} 17^{\prime \prime}$ & Zeolita & G. A. & Cambronero & (i-a) & $\begin{array}{c}\text { Estilbita } \\
\text { (desmin.) }\end{array}$ & Qtz & ?Pg \\
\hline $\begin{array}{c}51 \\
(\mathrm{Mi} 473)\end{array}$ & $10^{\circ} 03^{\prime} 11^{\prime \prime}$ & $84^{\circ} 39^{\prime} 51^{\prime \prime}$ & $\begin{array}{l}\text { Roca al- } \\
\text { terada }\end{array}$ & G. A. & $\begin{array}{l}\text { Mesetas } \\
\text { Arriba }\end{array}$ & (Ii-a) & Prl & $\mathrm{K} \ln$ & $\begin{array}{c}\text { ?Crs, Anl, } \\
\text { Sa }\end{array}$ \\
\hline $\begin{array}{c}52 \\
\text { (Mi1370) }\end{array}$ & $10^{\circ} 09^{\prime} 38^{\prime \prime}$ & $84^{\circ} 31^{\prime} 32^{\prime \prime}$ & $\begin{array}{l}\text { Toba arenosa } \\
\text { meteorizada }\end{array}$ & $\begin{array}{l}? \mathrm{~V} . \\
\mathrm{P} .\end{array}$ & $\mathrm{La} \mathrm{Paz}$ & (iv) & Gbs & Qtz, Or, Pl & $\begin{array}{c}\text { Mag, Ol, } \\
\text { Hem }\end{array}$ \\
\hline $\begin{array}{c}53 \\
\text { (Mi1376) }\end{array}$ & $10^{\circ} 00^{\prime} 41^{\prime \prime}$ & $84^{\circ} 39^{\prime} 04^{\prime \prime}$ & $\begin{array}{c}\text { Roca al- } \\
\text { terada }\end{array}$ & G. A. & Río Jesús & (ii-a) & $\begin{array}{l}\text { Qtz, Prl, } \\
\text { Aln, Kln }\end{array}$ & Hem, Or & \\
\hline $\begin{array}{c}54 \\
(\mathrm{APOF})\end{array}$ & $10^{\circ} 03^{\prime} 40^{\prime \prime}$ & $84^{\circ} 32^{\prime} 12^{\prime \prime}$ & Zeolita & G. A & $\begin{array}{l}\text { P.H.. Na- } \\
\text { gatac }\end{array}$ & (i-a) & $\begin{array}{l}\text { Clinopti- } \\
\text { lolita } \mathrm{Ca} / \\
\text { heulandita }\end{array}$ & $\begin{array}{c}\text { Mnt, Al-Di, } \\
\mathrm{Ab}\end{array}$ & \\
\hline $\begin{array}{c}55 \\
(\mathrm{TM} 34 \mathrm{c})\end{array}$ & $10^{\circ} 08^{\prime} 18^{\prime \prime}$ & $84^{\circ} 43^{\prime} 26^{\prime \prime}$ & $\begin{array}{c}\text { Sulfato } \\
\text { naranja en } \\
\text { zona de } \\
\text { piritización }\end{array}$ & G. A. & Tajo Alto & $\begin{array}{l}\text { (i), } \\
\text { (iii) }\end{array}$ & $\begin{array}{l}\text { Al-copi- } \\
\text { apita }\end{array}$ & $\begin{array}{c}\text { Coquimbita, } \\
\text { Qtz }\end{array}$ & \\
\hline $\begin{array}{c}56 \\
\text { (TM34f) }\end{array}$ & $10^{\circ} 08^{\prime} 18^{\prime \prime}$ & $84^{\circ} 43^{\prime} 26^{\prime \prime}$ & $\begin{array}{l}\text { Andesita } \\
\text { alterada }\end{array}$ & G. A. & Tajo Alto & (i) & $\operatorname{Prl}$ & Qtz, Kln & \\
\hline $\begin{array}{c}57 \\
\text { (Mi29a) }\end{array}$ & $10^{\circ} 09^{\prime} 23^{\prime \prime}$ & $84^{\circ} 43^{\prime} 31^{\prime \prime}$ & Zeolita & G. A. & La Unión & (i-a) & Estilbita & & \\
\hline
\end{tabular}

U. C. unidad correlacionable, G. A. Grupo Aguacate, C. L. C. domo Cerro la Cruz, Int. intrusivo, Ig. ignimbrita, V. P. volcán Platanar

de plagioclasa, anfíbol y biotita y de una matriz microcristalina compuesta de tridimita, feldespato potásico y en menos cantidad cristobalita.

Plagioclasa, muestra una leve zonación y está representada por la andesina, $\left(\mathrm{An}_{38-43}\right)$ con un valor de $\mathrm{SrO} 0,16-0,23 \%$ y baja en $\mathrm{BaO}(<0,07 \%)$.

Anfíbol, con débil zonación, se trata de magnesio-hornblenda (según Leake et al., 1997) con crecimiento de $\mathrm{Na}$ y Al hacia el borde del grano, salvo un anillo marginal estrecho que es de origen secundario: ( $\mathrm{Si}=6,64-6,99 \mathrm{apfu}, \mathrm{X}_{\mathrm{Mg}}=0,75-0,77$, $\left.(\mathrm{Na}+\mathrm{K})_{\mathrm{A}}=0,17-0,33 \mathrm{apfu}\right)$, con elevados valores de $\mathrm{TiO}_{2}=1,0-1,9 \%, \mathrm{MnO}=0,39-0,74 \%$ y muy pobre en $\mathrm{F} \mathrm{y} \mathrm{Cl}(<0,1 \%)$.

Biotita, es rica en magnesio $\mathrm{X}_{\mathrm{Mg}}=0,63-0,64$, rica en $\mathrm{TiO}_{2}(4,1-4,2 \%)$ y pobre en flúor $(0,17-0,24 \%)$.
Ti-magnetita, $\left(5,3 \% \mathrm{TiO}_{2}\right)$ es el mineral opaco dominante que es la causa del aumento de la susceptibilidad magnética de las rocas $\left(5-10 \times 10^{-}\right.$ $\left.{ }^{3}\right)$. Además contiene entre $1-1,6 \% \mathrm{Al}_{2} \mathrm{O}_{3}, \mathrm{MnO}$ y $\mathrm{MgO}$ y $0,2-0,3 \% \mathrm{ZnO}_{\text {y }} \mathrm{V}_{2} \mathrm{O}_{5}$.

Ilmenita, es mineral escaso y contiene 1,1$1,3 \%$ de $\mathrm{MnO}$ y $\mathrm{MgO}$.

\section{Riolita vidriosa}

Fue analizada la muestra Mi95 (Cuadro 3, ${ }^{\circ}$ 9, también datada por el método K-Ar). La roca es maciza y muy fina, su matriz está completamente devitrificada en una mezcla de cuarzo y feldespatos de granos muy finos. Raros son los 
Cuadro 3

Característica y ubicación (coordenadas geográficas) de las muestras utilizadas para el análisis geoquímico

\begin{tabular}{|c|c|c|c|c|c|}
\hline \multirow{2}{*}{ muestra } & \multicolumn{2}{|c|}{$\mathrm{AA}^{\circ} \mathrm{BB}^{\prime} \mathrm{CC}^{\prime \prime}$} & \multirow{2}{*}{ Localidad } & \multirow{2}{*}{ Tipo de roca } & \multirow{2}{*}{ U. C. } \\
\hline & $\mathrm{N}$ & $\mathrm{W}$ & & & \\
\hline 1 (Mi39) & $10^{\circ} 07^{\prime} 07^{\prime}$ & $84^{\circ} 38^{\prime} 37^{\prime \prime}$ & Rincón Chaves & Riolita & C. L. C. \\
\hline $2(\mathrm{Mi} 45)$ & $10^{\circ} 06^{\prime} 30^{\prime \prime}$ & $84^{\circ} 41^{\prime} 58^{\prime \prime}$ & Miramar & Andesita bas. & F. M. \\
\hline 3 (Mi47) & $10^{\circ} 06^{\prime} 55^{\prime \prime}$ & $84^{\circ} 41^{\prime} 33^{\prime \prime}$ & Peñas Blancas & Andesita bas. & F. M. \\
\hline 4 (Mi53) & $10^{\circ} 09^{\prime} 13^{\prime \prime}$ & $84^{\circ} 40^{\prime} 34^{\prime \prime}$ & Río Jabonal & Andesita & F. M. \\
\hline 5 (Mi68) & $10^{\circ} 08^{\prime} 42^{\prime \prime}$ & 84.39 .47 .9 & Río Jabonal & $\begin{array}{c}\text { Andesita con } \mathrm{Hb} \\
\mathrm{y} \mathrm{Bt}\end{array}$ & C. L. C. \\
\hline $6(\mathrm{Mi} 73)$ & $10^{\circ} 09^{\prime} 42^{\prime \prime}$ & $84^{\circ} 38^{\prime} 14^{\prime \prime}$ & Barranquilla & Roca alterada & C. L. C. \\
\hline 7 (Mi75) & $10^{\circ} 09^{\prime} 19^{\prime \prime}$ & $84^{\circ} 37^{\prime} 35^{\prime \prime}$ & Barranquilla & Dacita & C. L. C. \\
\hline 8 (Mi89) & $10^{\circ} 06^{\prime} 53^{\prime \prime}$ & $84^{\circ} 37^{\prime} 36^{\prime \prime}$ & Carrera Buena & Basalto & G. A. \\
\hline 9 (Mi95) & $10^{\circ} 05^{\prime} 25^{\prime \prime}$ & $84^{\circ} 44^{\prime} 34^{\prime \prime}$ & Miramar & Riolita & G. A. \\
\hline 10 (Mi96) & $10^{\circ} 05^{\prime} 21 "$ & $84^{\circ} 44^{\prime} 31^{\prime \prime}$ & Miramar & Andesita bas. & G. A. \\
\hline 11 (Mi98) & $10^{\circ} 07^{\prime} 17^{\prime \prime}$ & $84^{\circ} 39^{\prime} 50^{\prime \prime}$ & Peñas Blancas & Ignimbrita & U. P. B. \\
\hline $12(\mathrm{Mi} 220)$ & $10^{\circ} 01^{\prime} 51^{\prime \prime}$ & $84^{\circ} 38^{\prime} 53^{\prime \prime}$ & San Jerónimo & Ignimbrita & G. A.? \\
\hline $13(\mathrm{Mi} 236)$ & $10^{\circ} 01^{\prime} 22^{\prime \prime}$ & $84^{\circ} 42^{\prime} 06^{\prime \prime}$ & Cerro San Miguel & Dacita & C. S. M. \\
\hline $14(\mathrm{Mi} 245)$ & $10^{\circ} 06^{\prime} 52^{\prime \prime}$ & $84^{\circ} 42^{\prime} 24^{\prime \prime}$ & Tajo Bellavista & Andesita bas. & F. M. \\
\hline 15 (Mi288) & $10^{\circ} 01^{\prime} 00^{\prime \prime}$ & $84^{\circ} 35,08^{\prime \prime}$ & $\begin{array}{l}\text { Angostura (In- } \\
\text { teram.) }\end{array}$ & Andesita & F. M. \\
\hline $16(\mathrm{Mi} 297)$ & $10^{\circ} 02^{\prime} 14^{\prime \prime}$ & $84^{\circ} 33^{\prime} 24^{\prime \prime}$ & $\begin{array}{l}\text { Cambronero } \\
\text { (Inter.) }\end{array}$ & Andesita bas. & G. A. \\
\hline $17(\mathrm{Mi302})$ & $10^{\circ} 02^{\prime} 03^{\prime \prime}$ & $84^{\circ} 31^{\prime} 47^{\prime \prime}$ & $\begin{array}{l}\text { Río Jesús (In- } \\
\text { teram.) }\end{array}$ & Basalto & G. A. \\
\hline $18(\mathrm{Mi} 305)$ & $10^{\circ} 06^{\prime} 38^{\prime \prime}$ & $84^{\circ} 30^{\prime} 47^{\prime \prime}$ & Bajo Barrantes & Toba ácida & F. A. P.? \\
\hline 19 (Mi307) & $10^{\circ} 03^{\prime} 57^{\prime \prime}$ & $84^{\circ} 32^{\prime} 12^{\prime \prime}$ & P. H Nagatac & Toba con hematita & G. A. \\
\hline $20(\mathrm{Mi} 312)$ & $10^{\circ} 02^{\prime} 01^{\prime \prime}$ & $84^{\circ} 30^{\prime} 33^{\prime \prime}$ & $\begin{array}{l}\text { Río Jesús (In- } \\
\text { teram.) }\end{array}$ & Ignimbrita & F. A. P.? \\
\hline $21(\mathrm{Mi} 316)$ & $10^{\circ} 02^{\prime} 11^{\prime \prime}$ & $84^{\circ} 30^{\prime} 20^{\prime \prime}$ & $\begin{array}{l}\text { Constancia (In- } \\
\text { teram.) }\end{array}$ & Basalto & G. A. \\
\hline $22(\mathrm{Mi326})$ & $10^{\circ} 02^{\prime} 16^{\prime \prime}$ & $84^{\circ} 33^{\prime} 57^{\prime \prime}$ & Fn. Piedra Blanca & Basalto & G. A. \\
\hline 23 (Mi343) & $10^{\circ} 01^{\prime 2} 29^{\prime \prime}$ & $84^{\circ} 40^{\prime} 48^{\prime \prime}$ & Finca Mirón & Andesita bas. & F. M \\
\hline 24 (Mi355) & $10^{\circ} 08^{\prime} 52^{\prime \prime}$ & $84^{\circ} 34^{\prime} 54^{\prime \prime}$ & Río San Pablo & Andesita & F. M. \\
\hline 25 (Mi357) & $10^{\circ} 09^{\prime} 14^{\prime \prime}$ & $84^{\circ} 35^{\prime} 12^{\prime \prime}$ & Cerro Azahar & Andesita & F. M. \\
\hline $26(\mathrm{Mi357b})$ & $10^{\circ} 09^{\prime} 14^{\prime \prime}$ & $84^{\circ} 35^{\prime} 12^{\prime \prime}$ & Cerro Azahar & Andesita & F. M \\
\hline $27(\mathrm{Mi365})$ & $10^{\circ} 05^{\prime} 60^{\prime \prime}$ & $84^{\circ} 33^{\prime} 43^{\prime \prime}$ & $\begin{array}{l}\text { Cruzada La } \\
\text { Laguna }\end{array}$ & Monzodiorita & S. P. \\
\hline $28(\mathrm{Mi395})$ & $10^{\circ} 05^{\prime} 30^{\prime \prime}$ & $84^{\circ} 32^{\prime} 34^{\prime \prime}$ & La Guaria & Gabro & S. P. \\
\hline $29(\mathrm{Mi398})$ & $10^{\circ} 05^{\prime} 29^{\prime \prime}$ & $84^{\circ} 33^{\prime} 54^{\prime \prime}$ & Tablones & Basalto & G. A. \\
\hline $30(\mathrm{Mi} 432)$ & $10^{\circ} 08^{\prime} 20^{\prime \prime}$ & $84^{\circ} 35^{\prime} 18^{\prime \prime}$ & Socorro & Andesita & F. M. \\
\hline 31 (TM44) & $10^{\circ} 09^{\prime} 29^{\prime \prime}$ & $84^{\circ} 42^{\prime} 21^{\prime \prime}$ & $\begin{array}{l}\text { Laguna (La } \\
\text { Unión) }\end{array}$ & Basalto & G. A \\
\hline
\end{tabular}


Cuadro 3 (continuación)

Característica y ubicación (coordenadas geográficas) de las muestras utilizadas para el análisis geoquímico

\begin{tabular}{|c|c|c|c|c|c|c|}
\hline \multirow{2}{*}{$\mathrm{N}^{\circ}$} & \multirow{2}{*}{ muestra } & \multicolumn{2}{|c|}{$\mathrm{AA}^{\circ} \mathrm{BB}^{\prime} \mathrm{CC}^{\prime \prime}$} & \multirow{2}{*}{ Localidad } & \multirow{2}{*}{ Tipo de roca } & \multirow{2}{*}{ U. C. } \\
\hline & & $\mathrm{N}$ & $\mathrm{W}$ & & & \\
\hline \multicolumn{2}{|c|}{32 (TM126) } & $10^{\circ} 04^{\prime} 56^{\prime \prime}$ & $84^{\circ} 32^{\prime} 20^{\prime \prime}$ & La Guaria & Gabro & S. P. \\
\hline \multicolumn{2}{|c|}{33 (Mi1322) } & $10^{\circ} 05^{\prime} 34^{\prime \prime}$ & $84^{\circ} 31^{\prime} 05^{\prime \prime}$ & Las Musas & Ignimbrita & F. A. P.? \\
\hline
\end{tabular}

U. C. Unidad correlacionable, G. A. Grupo Aguacate, F. M. Formación Monteverde,

C. S. C. Domo cerro La Cruz, C. S. M. Domo cerro San Miguel, F. A. P. Formación Alto Palomo,

S. P. Stock Piedades Sur, U. P. B. Unidad Peñas Blancas

fenocristales idiomorfos (hasta $2 \mathrm{~mm}$ ) tanto de la plagioclasa casi homogénea $\left(\mathrm{An}_{43-45}\right)$ con elevada concentración de $\mathrm{SrO}(0,3 \%)$, y de la biotita $\left(\mathrm{X}_{\mathrm{Mg}}=0,67\right)$, la cual es rica en $\mathrm{TiO}_{2}(3,3 \%)$ y flúor $(3,6-3,9 \%)$.

\section{Ignimbrita riolítica, unidad Peñas Blancas}

Se consideró una muestra para el análisis (Cuadro 3, no 11). La roca está compuesta principalmente de una matriz vítrea, de fragmentos de líticos de diferentes tipos y fenocristales de plagioclasa $15 \%$, biotita $3 \%$, hornblenda $1 \%$, titanomagnetita $1 \%$ y minerales accesorios como zircón y apatita.

Plagioclasa, casi sin zonación y se trata de andesina ácida $\left(\mathrm{An}_{31}\right)$.

Anfíbol, está presente como magnesiohornblenda rica en hierro trivalente $(\mathrm{Si}=6,55-6,99$ apfu, $\mathrm{X}_{\mathrm{Mg}}=0,75-0,77, \mathrm{Fe}^{3+}=0,41-0,62 \mathrm{apfu}$, $\mathrm{Fe}^{2+}=0,92-1,06 \mathrm{apfu},(\mathrm{Na}+\mathrm{K})_{\mathrm{A}}(0,23-0,45 \mathrm{apfu})$, con valores elevados de $\mathrm{TiO}_{2}(1,3-2,0 \%)$ y $\mathrm{MnO}$ $(0,52-0,66 \%)$, pobre en $\mathrm{Cl}$ y $\mathrm{F}=(<0,2 \%)$.

Biotita, Mg-dominante $\left(\mathrm{X}_{\mathrm{Mg}}=0,64\right)$, rica en $\mathrm{TiO}_{2}(4,6-4,7 \%)$ y $\mathrm{BaO}(1,35 \%)$, también pobre en flúor $(0,17-0,24 \%)$.

Ti-magnetita, predomina entre los minerales opacos y es la causante del aumento de la susceptibilidad magnética $\left(5,3 \times 10^{-3}\right)$ de la roca. El mineral contiene 4,5\% de $\mathrm{TiO}_{2}, 1-1,5 \%$ de óxidos de $\mathrm{Al}$, $\mathrm{Mn}, \mathrm{Mg}$ y alrededor de $0,3 \%$ de óxidos de $\mathrm{Zn}$ y V. Granos de gran tamaño de Ti-magnetita, presentan formas de aguja o finos listones de Mn-ilmenita.

\section{Rocas alteradas}

En el mapa geológico se distinguen tres tipos de alteración hidrotermal y además zonas de intensa laterización:

i) alteración hidrotermal aurífera con vetas de cuarzo

ii) alteración hidrotermal silícica, caolinítica y alunítica (no aurífera)

iii) piritización

iv) laterización

La alteración hidrotermal se presenta exclusivamente en las rocas volcánicas y cuerpos intrusivos del Grupo Aguacate, mientras que en la Formación Monteverde está ausente (salvo las alteraciones alrededor del domo cerro La Cruz).

Con el análisis de las rocas alteradas utilizando difractometría, se identificó una gran variedad de minerales secundarios como: albita, alunita, analcima, anatasa, anhidrita, barita, beidellita, calcita, clorita, clinoptilolita (o heulandita), cuarzo, diaspora, dickita, epidota, feldespato potásico, gibbsita, hematita, illita, "limonita", huangita, malaquita, montmorillonita, nacrita, natroalunita, pirita, pirofilita, sericita y estilbita (véase Cuadro 2). Es importante mencionar que no se encontró prehnita ni rodocrocita tal como fue indicado por Laguna $(1983,1984)$ y Cigolini $\&$ Chaves (1986). También fueron identificados sulfatos supergénicos formados a partir de la descomposición de la pirita: yeso, pickeringitahalotriquita, aluminocopiapita, jarosita, coquimbita y melanterita. 

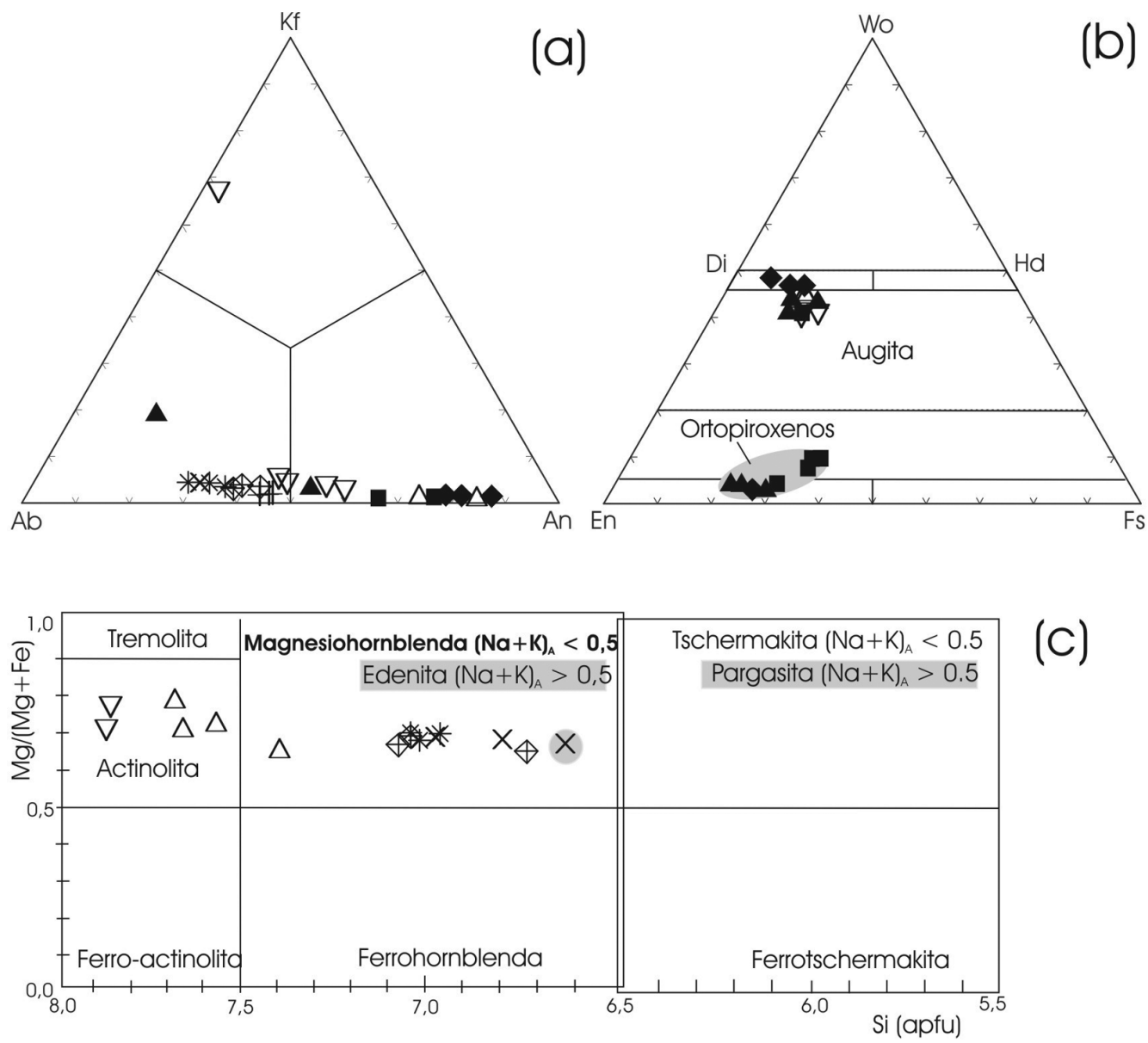

(c)

(d)

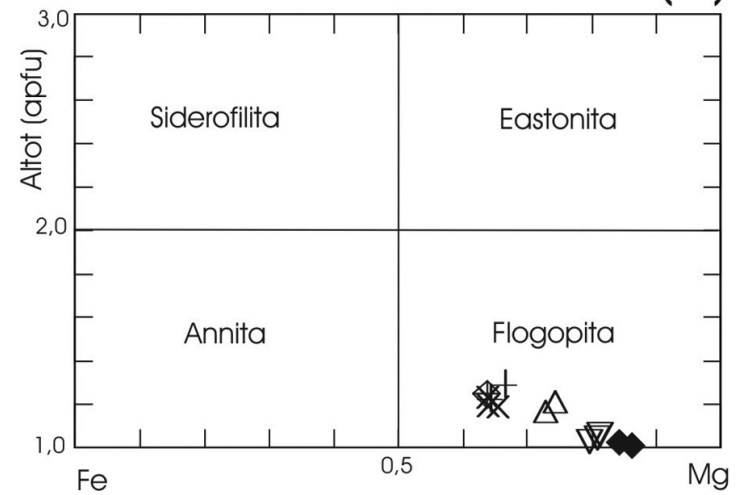

$\oplus$ Mi39 Dacita, lava, domo Cerro La Cruz

- Mi45 Andesita bas., lava, Fm. Monteverde

- Mi89 Basalto, lava, Grupo Aguacate

+ Mi95 Riolita vidriosa, intrusivo

- Mi96 Basalto, lava, Grupo Aguacate

X Mi98 Ignimbrita, Unidad Peñas Blancas

$\nabla$ Mi365 Monzodiorita, stock Piedades Sur

$\triangle$ Mi395 Gabro, stock Piedades Sur

* Mi1320 lgnimbrita, Las Musas

Fig. 18: Diagramas de clasificación de feldespatos (a), piroxenos (a), anfíboles (c) y „biotitas“(d). La clasificación de anfíboles según Leake et al. (1997). 


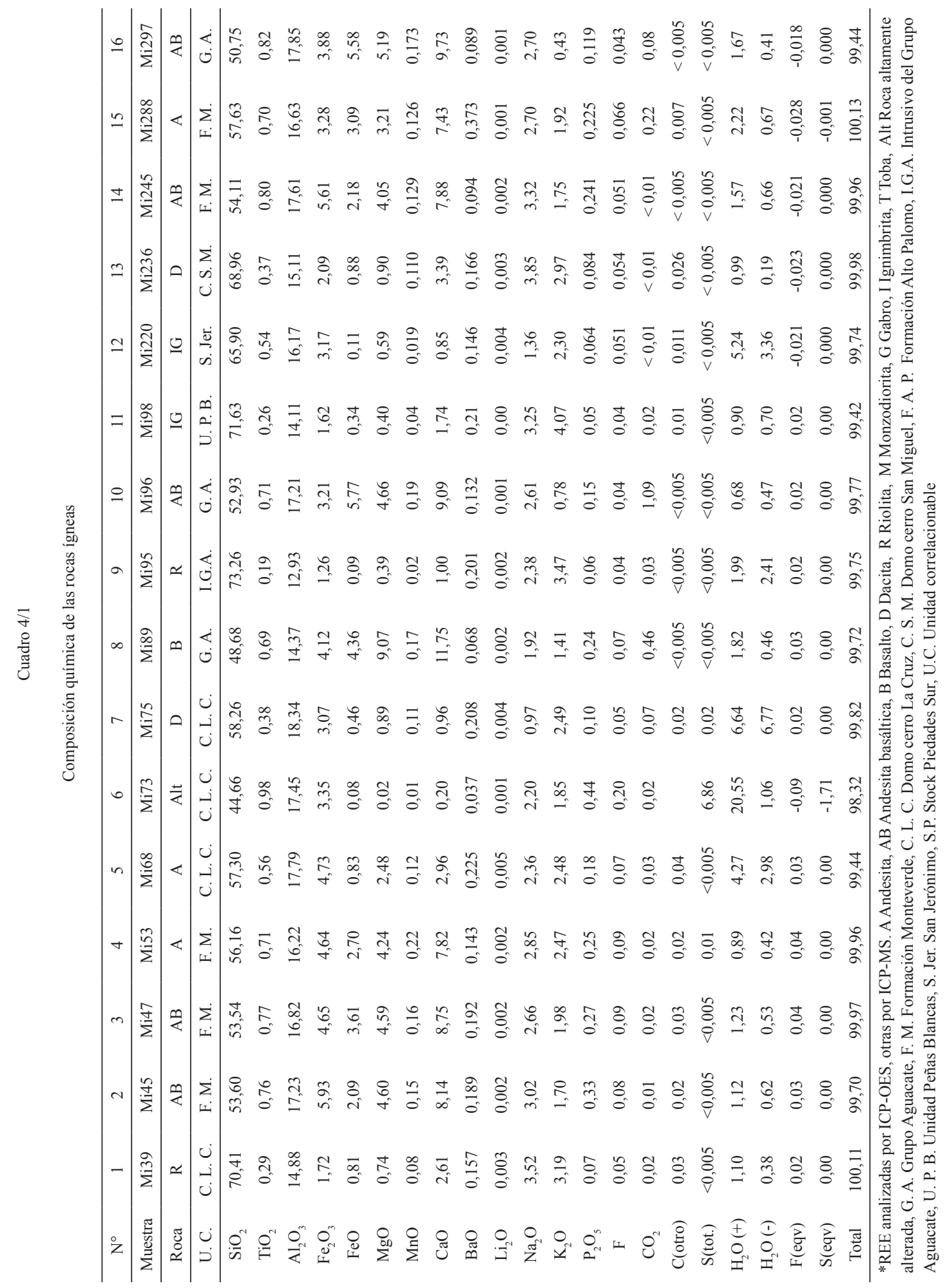




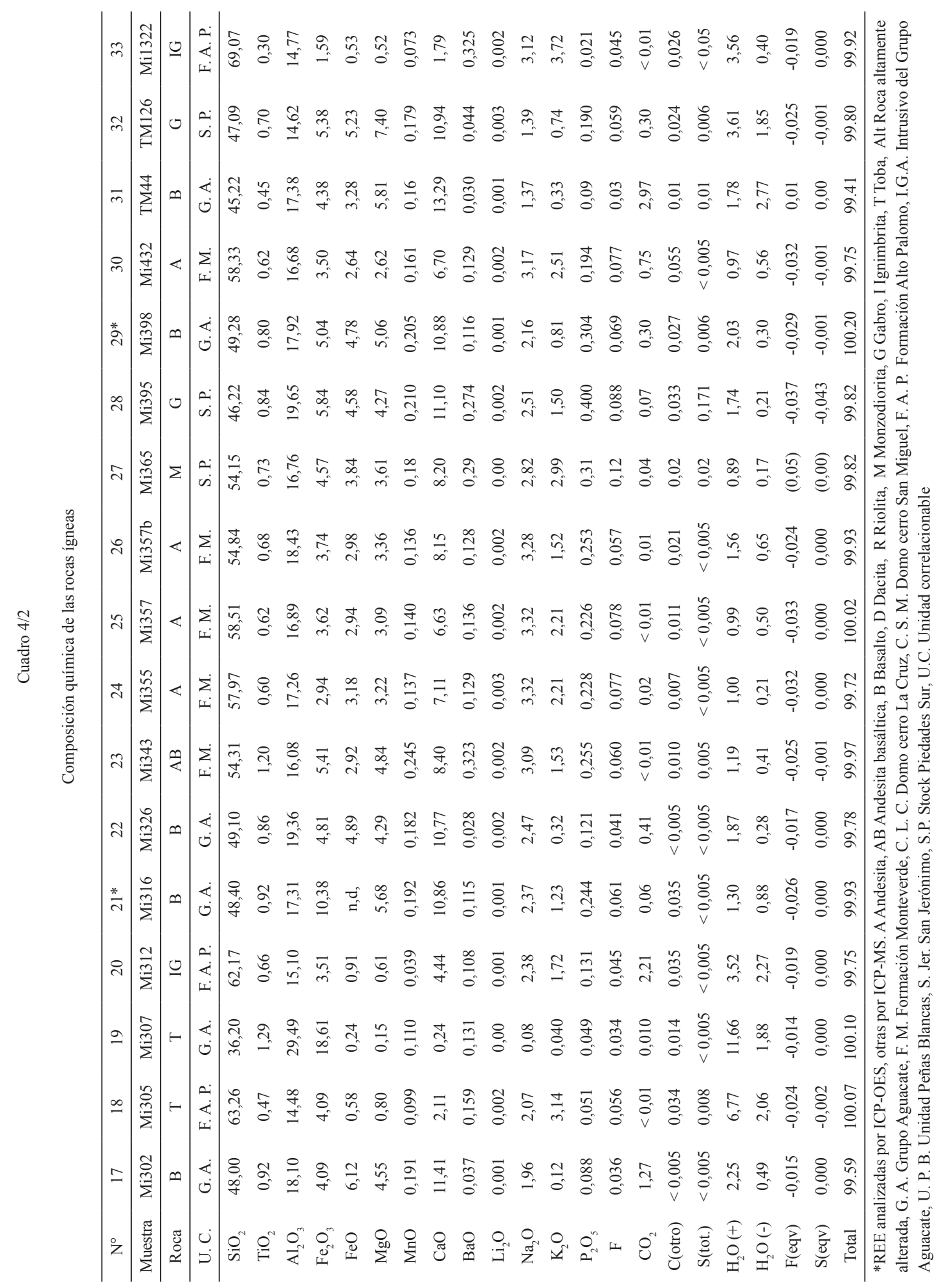




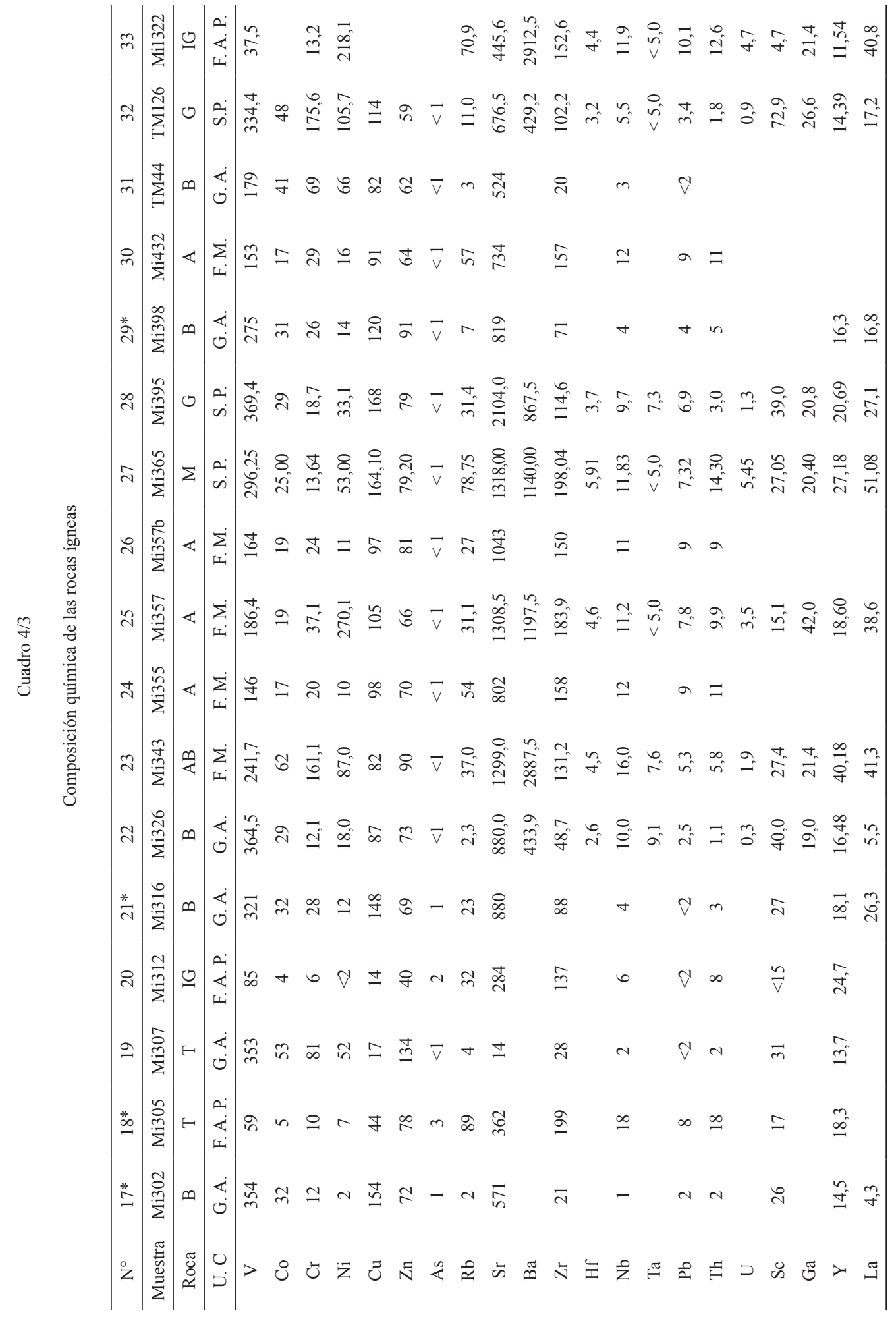




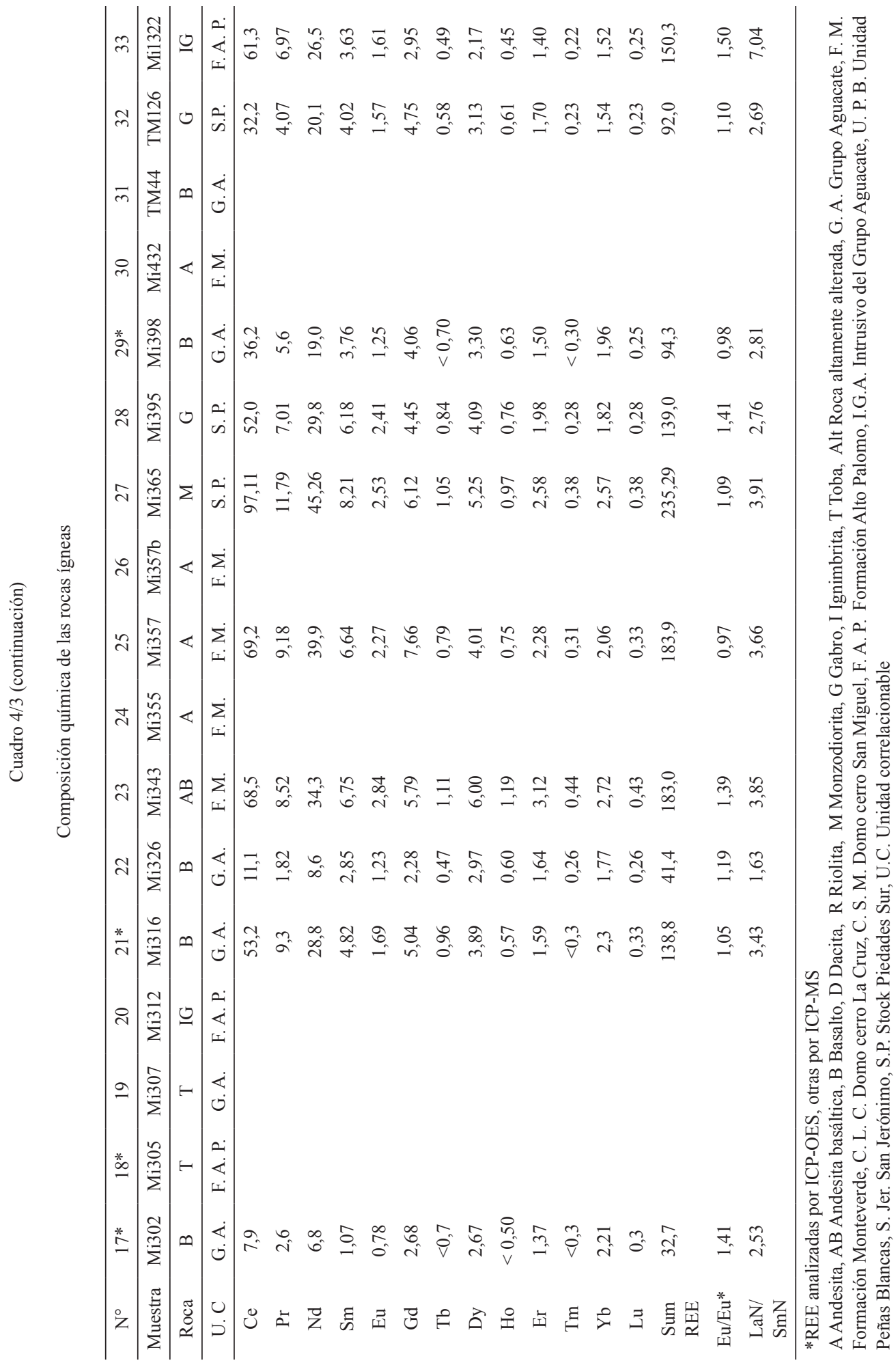




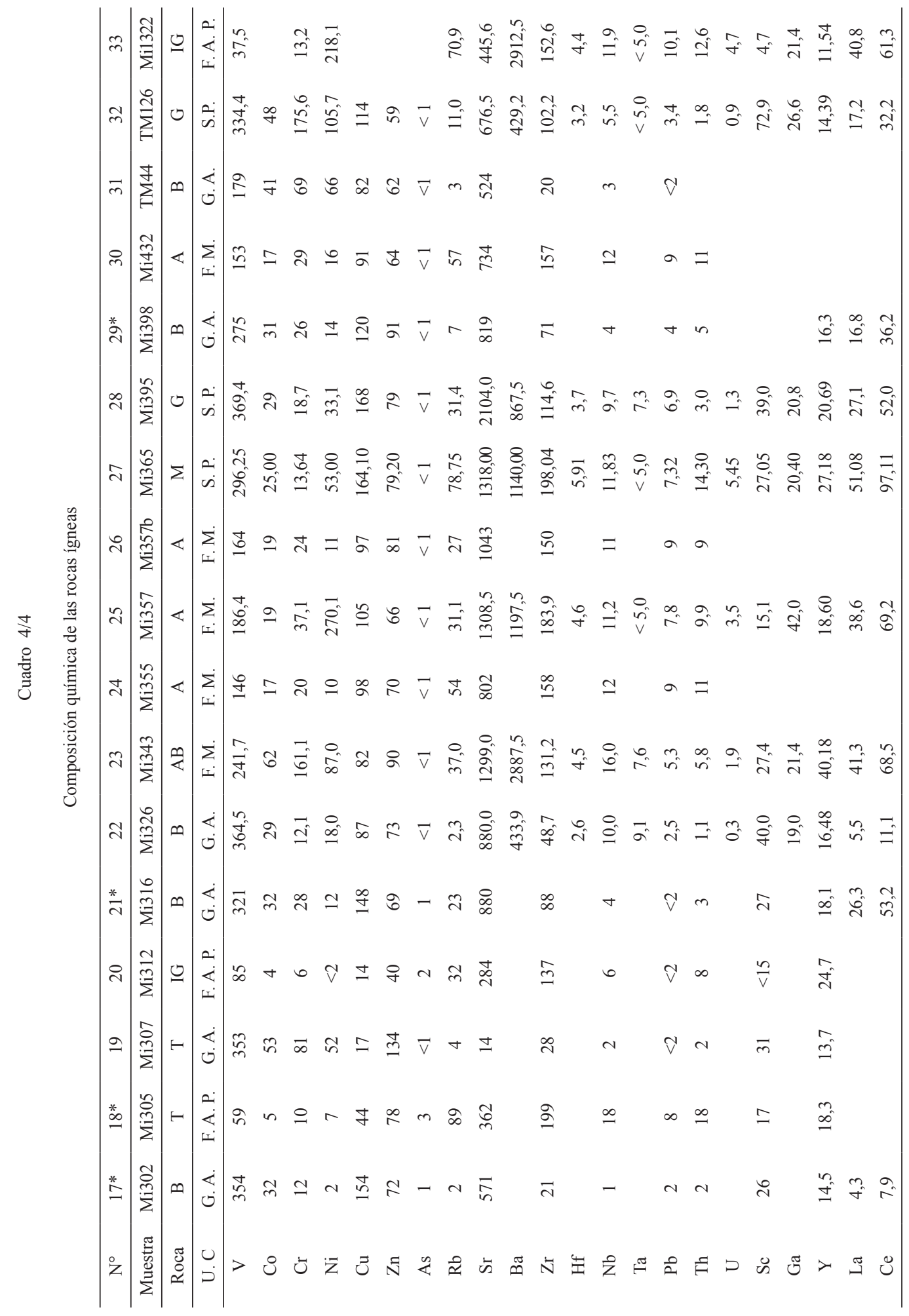




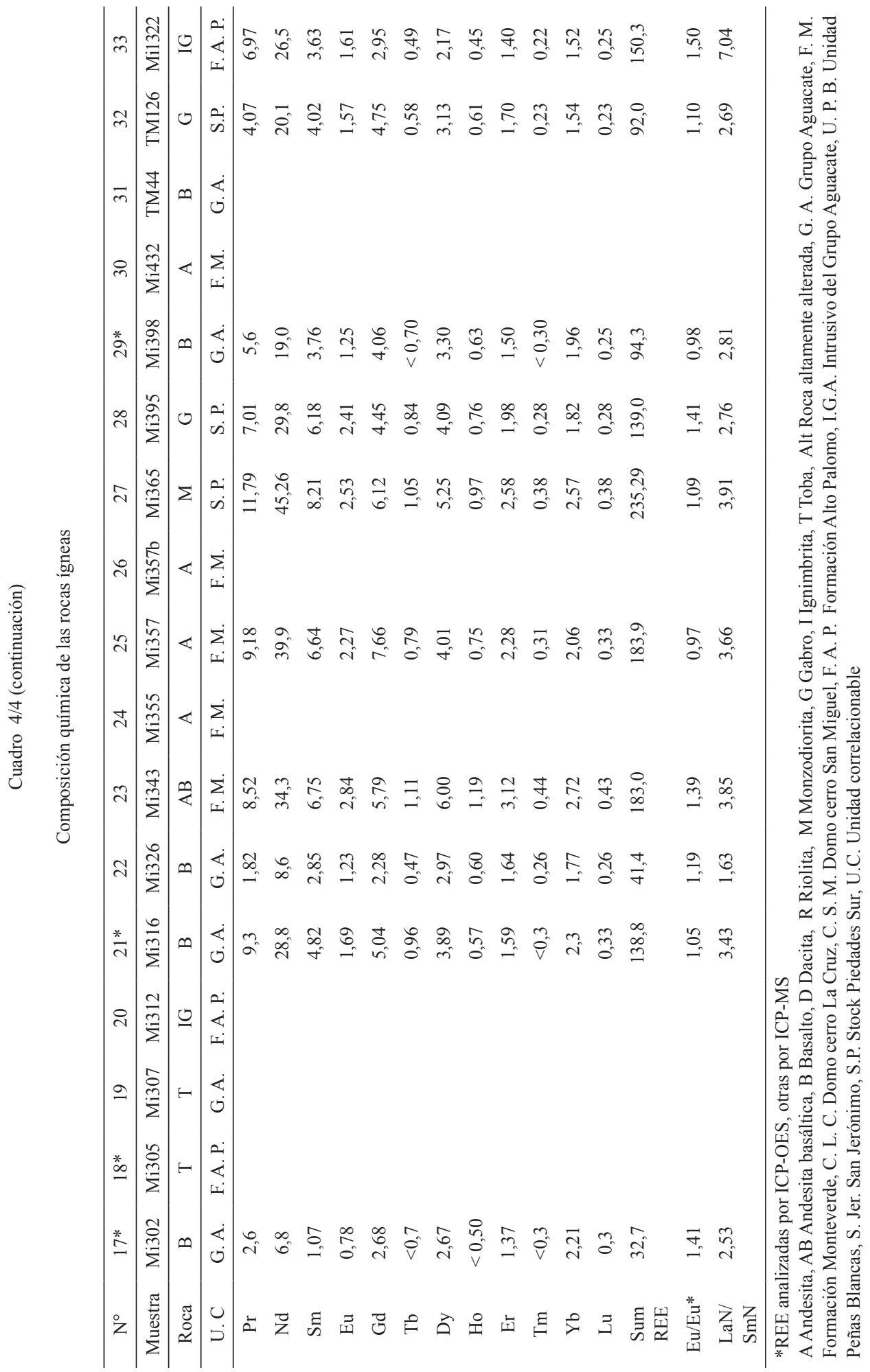




\section{i) Alteración hidrotermal aurífera con vetas de cuarzo}

Grandes áreas formadas por rocas volcánicas del Grupo Aguacate son afectados por alteracíón hidrotermal relacionada con la mineralización aurífera. Este tipo de alteración fue muy bien identificada a principios del siglo XIX por prospectores de oro. Las zonas más grandes de alteración se ubican básicamente cerca de la ciudad de Miramar y del poblado La Unión, a lo largo de la Carretera Interamericana al este de Macacona, en las laderas y valle del río Barranca, en los alrededores de la planta hidroeléctrica Nagatac donde hay minas abandonadas y en la zona donde se encuentra la mina Chassoul.

Las características principales de este tipo de alteración, es una variada tonalidad de colores (especialmente el verde), un cambio rápido de la intensidad de alteración y la presencia de vetas y/o vetillas de cuarzo. Con menos frecuencia aparecen vetas de calcita y zonas de piritización. Por lo general las vetitas y vetas de cuarzo presentan cavidades colmatadas de cristales también de cuarzo. Los minerales característicos asociados al cuarzo son: calcita, clorita, K-feldespato (adularia), albita, barita, epidota, pirita, caolinita, illite/ esmectita, varias zeolitas y sericita. Los minerales metalíferos primarios de las vetas auríferas son: pirita y As-pirita, arsenopirita, calcopirita, esfalerita, galena, marcasita, menos abundante son acantita, pirargirita, greenockita, covellita, bornita y casiterita. El único mineral aurífero es el oro (electrum) con concentraciones de plata que oscilan entre $30-42 \%$. Otros minerales identificados fueron "limonita", anglesita y cerusita. Los datos de minerales metálicos provienen principalmente del distrito minero de Las Juntas, (Mixa et al., 2011).

Según Cigolini \& Chaves (1986) la temperatura que dio origen a la alteración regional fue de 200-250 ${ }^{\circ} \mathrm{C}$, esto concuerda con los nuevos datos obtenidos del estudio de inclusiones fluidas en cuarzo, del distrito minero de Abangares, en donde se estimó que la temperatura de los procesos de mineralización aurífera se produjo entre los 150$290{ }^{\circ} \mathrm{C}$ (Mixa et al., 2011).

i-a) Zeolitas, este tipo de alteración que contiene una cantidad significativa de zeolitas fue reconocido como un subtipo de la alteración aurífera. Se encuentra en una franja de unos $6 \mathrm{~km}$ de an- cho y $12 \mathrm{~km}$ de largo, con dirección NO-SE desde las cercanías de la localidad de El Salvador (norte del mapa), y se extiende hacia los alrededor de la confluencia del río Jesús María y río Agua Agria (sur este del mapa). Se identificaron estilbita y clinoptilolita. La estilbita es muy abundante en andesitas y rocas piroclásticas que se encuentran en el camino entre el río Jesús María y la quebrada Obispo, donde se observó cristales perfectos y vetitas hasta $5 \mathrm{~cm}$ asociados con cristales de cuarzo y clorita (Cuadro 2, $\mathrm{n}^{\circ}$ 50). Las mismas zeolitas también son abundantes en la vertiente norte del río Barranca al lado de la planta hidroeléctrica Nagatac y en las cuencas de los ríos: Las Vueltas, quebrada Guapinol y Potrerillos. En La Unión se identificaron estilbita (radial) y heulandita-Ca (agregados exfoliables y cristales), así como calcita y cuarzo (Cuadro 2, $n^{\circ} 34,35$ ).

\section{ii) Alteración hidrotermal silícica, caolinítica y alunítica (no aurifera)}

ii-a) Rocas volcánicas altamente alteradas. Un área importante conformada por rocas volcánicas del Grupo Aguacate, presenta una fuerte alteración hidrotermal, principalmente con alto grado de silicificación (ver también apartado de estratigrafía, No 21). Las rocas presentan colores variados, a veces se encuentran totalmente descompuestas a material arcilloso y a veces silicificadas y duras. Casi siempre predomina el cuarzo microcristalino (en algunas muestras sólo se identificó cuarzo) acompañado de caolinita, nacrita, sericita, en algunos casos pirofilita, alunita, natroalunita y en otros analcima, anhidrita y huangita, siendo este último mineral un raro $\mathrm{Ca}$ miembro del grupo de la alunita (Cuadro 2, $\mathrm{n}^{\circ}$ 39). Al contrario de la alteración aurífera no hay presencia de vetas de cuarzo ni de calcita, tampoco tienen clorita ni adularia.

ii-b) Las alteraciones en los domos riodacíticos. En los alrededores del cerro La Cruz (domo), un área extensa de varios $\mathrm{km}^{2}$ se encuentra fuertemente alterada. Es la única alteración de tipo hidrotermal que afecta las rocas de la Formación Monteverde. Estas rocas son de color claro hasta café oscuro, con texturas masivas (silicificadas) 
de grano fino, con zonas de brecha o zonas blancas de material más o menos suave. Los minerales dominantes son cuarzo, tridimita, natroalunita y caolinita, a veces y en pocas cantidades cristobalita y probablemente anatasa (Cuadro $2, n^{\circ} 6$ ). En algunos lugares aparece también una intensa piritización. La presencia de tridimita y cristobalita indica que sus protolitos fueron riodacitas del propio domo.

\section{iii) Piritización}

Muy intensa con sulfatos secundarios recientes (Cuadro 2, $\mathrm{n}^{\circ} 42,55$ ) fue observada cerca de los puentes de la quebrada Zamora y del Río Seco en La Unión. También en las riberas de la quebrada Palmital, al sur del cerro La Cruz, y ampliamente en los alrededores del pueblo de Río Jesús y Constancia al SE de la hoja.

\section{iv) Laterización}

La intensidad de la laterización esta determinada principalmente por la altitud, las precipitaciones y la morfología del terreno (Alán, 1983). La extensión actual representa relictos de denudación preservada en las zonas planas. La zona lateritizada más grande se localiza en el sector norte del área de estudio a unos 1200-1500 m.s.n.m., que afecta exclusivamente a las rocas de la Formación Monteverde hasta varios metros de profundidad. Rocas primarias aparecen sólo como núcleos sanos. Con difractometría se identificaron caolinita (con un bajo grado de cristalización), montmorillonita, hematita, luego gibsita y un poco de cuarzo.

\section{GEOQUÍMICA DE LAS ROCAS ÍGNEAS}

\section{Introducción}

Las características generales de las muestras con sus respectivas ubicaciones (coordenadas geográficas) se pueden observar en el Cuadro 3. Los datos analíticos se presentan en el Cuadro 4 y la composición química en los diagramas geoquímicos estándares de las figuras 19 a-d, 20 a-f.
La caracterización geoquímica de las rocas volcánicas de Costa Rica desde el Neógeno hasta el Cuaternario, ha sido estudiada por muchos autores. Sin embargo consideramos que los datos proporcionados por Kussmaul et al. (1994) describen de manera más completa las características geoquímicas de estas. Las lavas y rocas piroclásticas son un producto de la evolución del arco volcánico primitivo, originado de un vulcanismo y magmatismo toleítico, que durante el Neógeno se transformaron en un arco continental y originó magmas y lavas calco-alcalinas (principalmente de química andesítica y dacitica). Los basaltos y algunas andesitas basálticas son producto de la fusión parcial del manto. Algunas variaciones geoquímicas son probablemente el resultado de la cristalización fraccionada y mezcla de magmas. La génesis es discutida en detalle en una publicación de Kussmaul et al. (1994).

En resumen, las rocas volcánicas que conforman la hoja Miramar pueden ser descritas como subalcalinas con una tendencia de diferenciación toileítica hasta calco-alcalina. Parte de las muestras (la mayoría lavas de la Fm. Monteverde, dacitas y algunas ignimbritas) se ubican en el subgrupo de rocas calco-alcalinas con alto contenido de $\mathrm{K}$. No se encontraron rocas completamente alcalinas. La basicidad de acuerdo al diagrama TAS es amplia y varía de basalto hasta la riolita. Las lavas de las unidades Aguacate y Monteverde son metaalumínicas, la dacita intrusiva hasta riolitas e ignimbritas son la mayoría peralumínicas. Las lavas primitivas del Aguacate, las cuales son pobres en $\mathrm{K}$ corresponden geoquímicamente con la serie de arco de islas primitivo. Geoquímicamente las más fraccionadas son las lavas de la Fm. Monteverde y las rocas de los domos dacíticos. A diferencia de las rocas del Grupo Aguacate las ignimbritas silícicas (así como los domos de riodacita y las rocas de la Fm. Monteverde) se caracterizan por sus elevadas concentraciones de $\mathrm{K}, \mathrm{Rb}$ y $\mathrm{Zr}$, mientras que son más pobres en $\mathrm{Mg}, \mathrm{P}, \mathrm{Ca}, \mathrm{Fe}$ y Sr. La mayoría de rocas estudiadas muestran una anomalía positiva de europio, que puede significar la presencia de cumulados de plagioclasa básica en el cámara magmática. Al contrario, los granitos del Intrusivo de Guacimal muestran una anomalía negativa significativa de Eu (Žáček et al., 2011). 

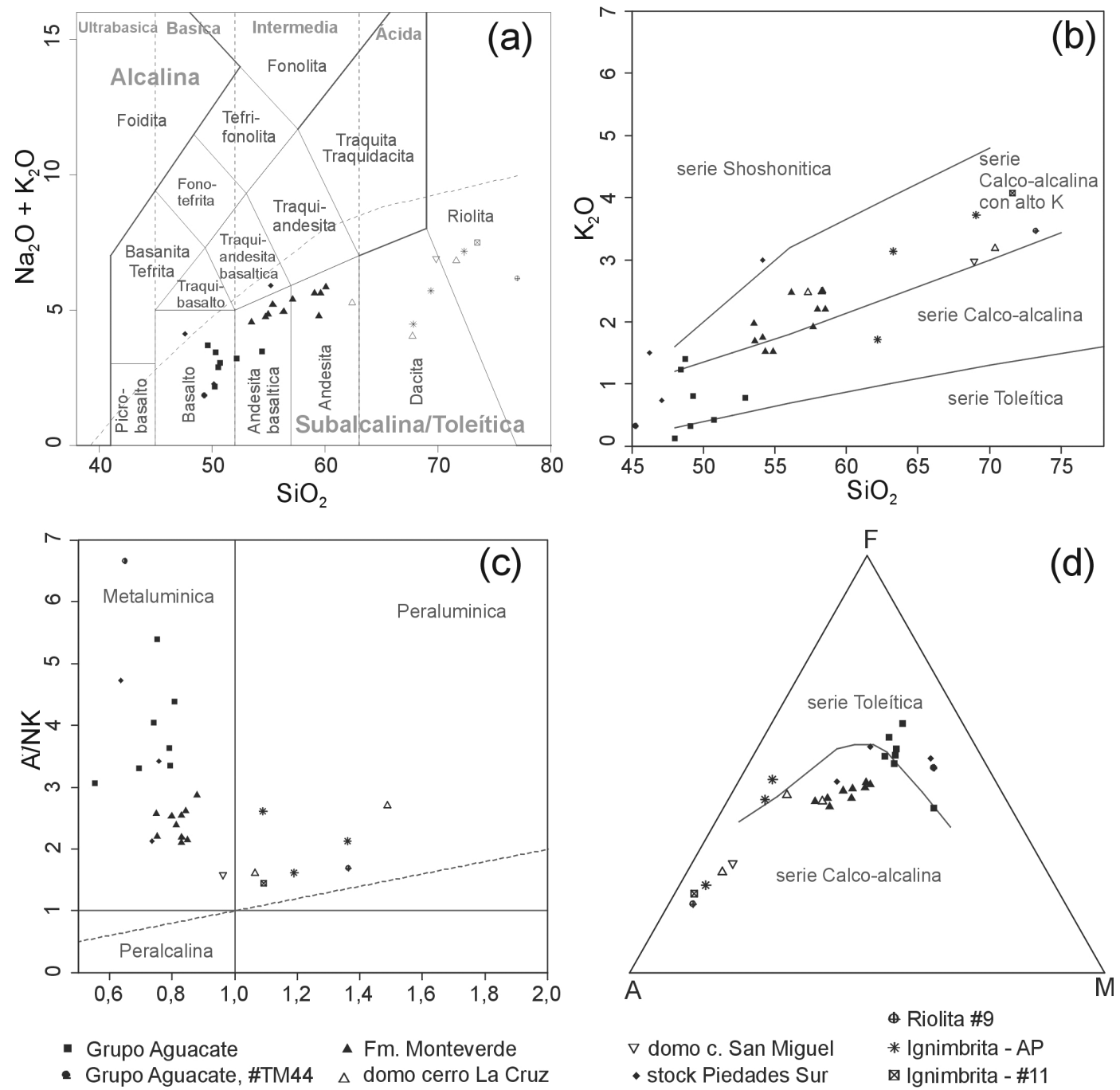

Fig. 19 a-d: Diagramas de clasificación geoquímica, a. Diagrama de clasificación TAS según Le Bas et al. (1986). Linea discriminatoria entre las series alcalinas y subvolcánicas, según Irvine \& Baragar (1971), b. diagrama $\mathrm{SiO}_{2}$ vs. $\mathrm{K}_{2} \mathrm{O}$ por Peccerillo \& Taylor (1976), c. diagrama de clasificación AFM de Irvine \& Baragar (1971), d. diagrama de clasificación A/ CNK vs. A / NK (Shand, 1943)

\section{Lavas del Grupo Aguacate}

Se analizaron 7 muestras de lavas (Cuadro $\left.3-4, n^{\circ} 8,10,16,17,21,22,29\right)$ y una muestra de dique de basalto (Cuadro $4, \mathrm{n}^{\circ} 31$ ). Las lavas son poco diferenciadas, desde basaltos hasta andesitas basálticas y presentan valores entre $48,0-52,9 \%$ $\mathrm{SiO}_{2}, 14,4-19,4 \% \mathrm{Al}_{2} \mathrm{O}_{3}, 0,69--0,92 \% \mathrm{TiO}_{2}, 4,3-$ $5,8 \% \mathrm{MgO}, 0,12-1,4 \% \mathrm{~K}_{2} \mathrm{O}, 0,08-0,30 \% \mathrm{P}_{2} \mathrm{O}_{5} \mathrm{y}$ $0,03-0,13 \% \mathrm{BaO}$. En el diagrama $\mathrm{SiO}_{2}$ vs. $\mathrm{K}_{2} \mathrm{O}$ la mayoría de lavas del Grupo Aguacate coinciden en la serie toleítica hasta calco-alcalina, mientras que en el diagrama AFM demuestran una clara tendencia toleítica.

Las lavas presentan valores altos de $\mathrm{Sr}$ (490-880 ppm) y bajos de Rb (1-30 ppm), Zr (20-93 ppm), Nb (1-10 ppm), Th (1,1-7,4 ppm) y U (0,3-2,2 ppm). La sumatoria $\Sigma$ REE oscila entre 33-140 ppm, la anomalía de europio no es significativa con tendencia positiva $\left(\mathrm{Eu} / \mathrm{Eu}^{*}=\right.$ $0,96-1,41)$ y la proporción entre $\mathrm{Nd}_{\mathrm{N}} / \mathrm{Sm}_{\mathrm{N}}$ es baja de 1,63-3,58. 

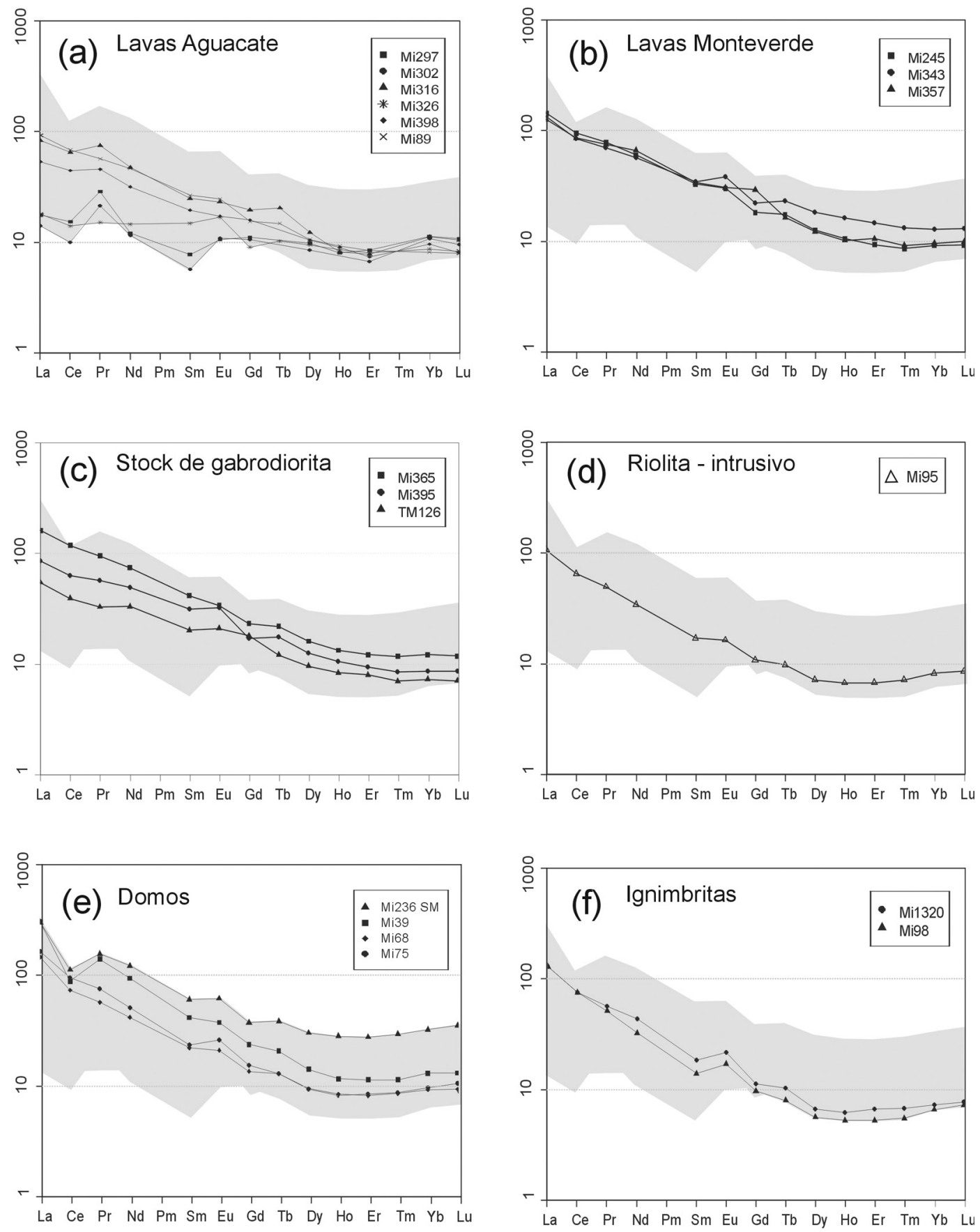

Fig 20 a-f: Distribución de las tierras raras normalizados por condritas según Boynton (1984). 
Dentro del rango de basaltos "normales" se tiene la muestra Mi326 de la finca Piedra Blanca (Cuadro 3-4, $\mathrm{n}^{\circ}$ 22) que es una roca poco diferenciada y el diagrama REE manifiesta una morfología plana.

También dentro del rango de basaltos y andesitas basálticas pobres en K se identifican dos muestras de basaltos toleíticos: una de la localidad de Carrera Buena (Cuadro 4, n 8) y la otra tomada al lado de la Carretera Interamericana, cerca de la localidad de Río Jesús (Cuadro 4, n 21). Esta última es más rica en potasio $\left(1,2-1,4 \% \mathrm{~K}_{2} \mathrm{O}\right)$ y en el diagrama $\mathrm{K}_{2} \mathrm{O}$ vs. $\mathrm{SiO}_{2}$ se refleja en el límite de la serie calco-alcalina con la serie calco-alcalina con alto contenido de potasio. En comparación con las lavas convencionales del Aguacate, estas son más ricas en $\mathrm{Rb}$ (19,5-23 ppm), Zr (88-93 ppm) y $\mathrm{Nb}$ (4-38 ppm).

La muestra $n^{\circ} 31$ (TM44) proviene de un dique basáltico (Cuadro 3-4,). La roca es primitiva y poco diferenciada $\left(45 \% \mathrm{SiO}_{2}, 0,3 \% \mathrm{~K}_{2} \mathrm{O}\right)$, toleítica, en el diagrama $R_{1}-R_{2}$ se proyecta entre los campos de toleíta y picrita, en el diagrama $\mathrm{Nb} / \mathrm{Y}$ vs. $\mathrm{Zr} / \mathrm{TiO}_{2}$ hacia el campo de basalto subalcalino. Tiene valores altos de $\mathrm{Mg}, \mathrm{Ca}, \mathrm{Cr}$, Ni y valores bajos hasta extremadamente bajos de $\mathrm{K}, \mathrm{Na}, \mathrm{Rb}, \mathrm{Nb}$ y $\mathrm{Zr}$. Geoquímicamente es similar a las lavas del Grupo Aguacate pobres en potasio.

\section{Stock de gabrodiorita}

En este trabajo se descubrió un cuerpo de gabro hasta diorita localizado cerca de Piedades Sur. Éste es de composición alcalina e intermedia con un rango relativamente amplio de basicidad y elementos mayores: 46,2-54,2\% $\mathrm{SiO}_{2}, 14,6-19,7 \%$ $\mathrm{Al}_{2} \mathrm{O}_{3}, 0,70-0,84 \% \mathrm{TiO}_{2}, 3,6-7,4 \% \mathrm{MgO}, 0,7-3,0 \%$ $\mathrm{K}_{2} \mathrm{O}, 0,19-0,31 \% \quad \mathrm{P}_{2} \mathrm{O}_{5}$ y $0,044-0,290 \% \mathrm{BaO}$. Según el diagrama TAS se trata de gabro (Cuadro $\left.3-4, n^{\circ} 28, n^{\circ} 32\right)$ y monzodiorita $\left(n^{\circ} 27\right)$. En el diagrama AFM se ubica en la serie toleítica y la monzodiorita en la serie calco-alcalina, todos son meta-alumínicos. Lo mismo ocurre con las concentraciones de oligoelementos y tierras raras. Los gabros tienen valores bajos de Rb, Zr, Y, La, Ce y su imagen es similar a las rocas del Grupo Aguacate.
En todas las muestras analizadas la $\Sigma R E E$ varía entre 92-235 ppm, la anomalía de europio es positiva y no significativa $\left(\mathrm{Eu} / \mathrm{Eu}^{*}=1,09-1,41\right)$ y la proporción del $\mathrm{Nd}_{\mathrm{N}} / \mathrm{Sm}_{\mathrm{N}}$ es de 2,76-3,91.

La monzodiorita está más diferenciada, es relativamente más rica en $\mathrm{Rb}, \mathrm{Zr}$, La y microquímicamente (oligoelementos y REE) es semejante a las rocas de la Formación Monteverde o se sitúa en la interface entre Monteverde y Aguacate. Las rocas del intrusivo de Guacimal (granitos y diorita) están mas diferenciadas con una anomalía negativa de europio (Žáček et al., 2011).

\section{Intrusión riolítica de Miramar}

En la diagrama de TAS la muestra estudiada (Cuadro 3-4, n 9) se ubica dentro del campo de la riolita $\left(77 \% \mathrm{SiO}_{2}, 3,5 \% \mathrm{~K}_{2} \mathrm{O}\right)$, en el diagrama $\mathrm{SiO}_{2}$ vs $\mathrm{K}_{2} \mathrm{O}$ cae en la serie calco-alkalina con alto contenido de $\mathrm{K}$. Es rica en $\mathrm{Rb}(55,5 \mathrm{ppm})$ y pobre en $\mathrm{TiO}_{2}(0,19 \%), \mathrm{P}_{2} \mathrm{O}_{5}(0,06 \%), \mathrm{Zr}(76,7$ ppm) y en $\mathrm{Sr}(223 \mathrm{ppm})$. El valor de $\Sigma \mathrm{REE}=128$ $\mathrm{ppm} ; \mathrm{Eu} / \mathrm{Eu}^{*}=1,21$.

\section{Lavas de la Formación Monteverde}

Se analizaron 10 muestras (Cuadro 3-4, $\mathrm{n}^{\circ} 2$, $3,4,14,15,23,24,25,26,30)$ para la caracterización geoquímica de estas lavas. Según el diagrama TAS se sitúan en el campo de las andesitas hasta andesitas basálticas con el rango de óxidos mayores: $53,4-58,5 \% \mathrm{SiO}_{2}, 16,1-18,4 \% \mathrm{Al}_{2} \mathrm{O}_{3}$, $0,60-1,20 \% \mathrm{TiO}_{2}, 2,6-4,8 \% \mathrm{MgO}, 1,5-2,5 \% \mathrm{~K}_{2} \mathrm{O}$, $0,19-0,33 \% \mathrm{P}_{2} \mathrm{O}_{5}$ y $0,09-0,37 \% \mathrm{BaO}$.

Las rocas presentan altos valores de $\mathrm{Rb} 26,7-$ $62 \mathrm{ppm}, \mathrm{Sr} 712-1280 \mathrm{ppm}, \mathrm{Zr}$ 112,5-183,9 ppm y

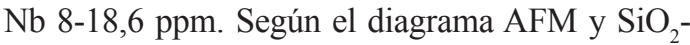
$\mathrm{K}_{2} \mathrm{O}$ pertenecen a la serie calco-alcalina con alto contenido de potasio (ver Fig.19b). A diferencia de las lavas del Aguacate son más diferenciadas y con valores más altos de $\mathrm{Na}, \mathrm{K}, \mathrm{P}, \mathrm{Rb}, \mathrm{Ba}, \mathrm{Sr}, \mathrm{Zr}, \mathrm{Y}$, Th (5,8-11 ppm), U (1,9 -3,5 ppm) y $\Sigma$ REE (183-190 ppm). Sin embargo la anomalía de Eu varia entre: $\mathrm{Eu} / \mathrm{Eu}^{*}=0,97-1,39$, muy parecida a las muestras de la Formación Aguacate. Por otro lado la proporción del $\mathrm{Nd}_{\mathrm{N}} / \mathrm{Sm}_{\mathrm{N}}$ es poco elevada de 3,68-4,30. 


\section{Domos riodacíticos}

Según el diagrama de TAS, las rocas de los domos del cerro La Cruz y cerro San Miguel, se sitúan en los campos correspondientes a dacitas, riolitas (Cuadro 3-4, $\mathrm{n}^{\circ} 7, \mathrm{n}^{\circ} 13, \mathrm{n}^{\circ}$ 1) y ocasionalmente a andesitas $\left(\mathrm{n}^{\circ} 5\right)$; todas son peralumínicas. Los valores de $\mathrm{SiO}_{2}$ varían entre 62$73 \%$, tienen valores altos de $\mathrm{K}_{2} \mathrm{O}(2,48-3,19 \%)$, $\mathrm{Ba}$ (1287-1859 ppm), Rb (28,5-70,0 ppm), Zr (129-177 ppm), Nb (9-72,6 ppm), Th (19,2-26,8 ppm), U (5,8-6,9 ppm) y $\Sigma$ REE (161-344) ppm. Son bajos los niveles de $\mathrm{TiO}_{2}(0,29-0,56 \%)$, $\mathrm{P}_{2} \mathrm{O}_{5}(0,07-0,10 \%)$ y $\mathrm{Sr}(181-555$ (1185) $\mathrm{ppm})$. Geoquímicamente existe cierta similitud con las lavas de Monteverde; pero presentan valores más altos de $\mathrm{Nb}$, Th, $\mathrm{U}$ y son más pobres en $\mathrm{K}$, $\mathrm{Rb}, \mathrm{Zr}$ y $\mathrm{Sr}$. La anomalía de Eu es débilmente positiva $\mathrm{Eu} / \mathrm{Eu}^{*}=1,19-1,36$, la proporción de $\mathrm{Nd}_{\mathrm{N}} / \mathrm{Sm}_{\mathrm{N}}$ varía entre 4,99-7,26. Según la distribución de REE son las rocas más diferenciadas de la hoja Miramar.

\section{Ignimbritas silíciceas}

Dentro del territorio mapeado se analizaron muestras de cuatro localidades de ignimbritas silíceas: en los alrededores de Piedades Sur y pueblo Río Jesús donde se tomaron muestras de ignimbritas, una muestra de San Jerónimo (al N de Esparza) y otra de la unidad Peñas Blancas (localidad con el mismo nombre).

Unidad Alto Palomo. Fueron analizadas tres muestras. Ignimbritas típicas de Río Jesús (Cuadro 3-4, $\mathrm{n}^{\circ}$ 20), ignimbrita de Las Musas (Cuadro 3-4, n 33) y una toba ácida del Bajo Barrantes (Cuadro 3-4, $\mathrm{n}^{\circ}$ 18). La composición química de las muestras corresponde a dacitas, según el diagrama TAS, y de acuerdo al diagrama $\mathrm{R} 1-\mathrm{R} 2$ a riodacitas $\left(62,2-69,1 \% \mathrm{SiO}_{2}\right.$ y $1,72-$ $3,72 \% \mathrm{~K}_{2} \mathrm{O}$ ). De las muestras, una encaja en la serie calco-alcalina y dos en el campo calco-alcalino con alto contenido de potasio. Las ignimbritas contienen altos niveles de Fe, Ti y Th (8-19,5 ppm), pero valores relativamente bajos de $\mathrm{Mg}$ e Y. En las muestras hay grandes diferencias sobre todo en los valores de $\mathrm{Ni}$ y $\mathrm{Cr}$, probablemente debido a diferentes grados de contaminación que ocasionan los líticos de las andesitas (se analizó la roca total). La ignimbrita de Las Musas (Cuadro 3-4, n 33) muestra una anomalía de Eu positiva significativa: $\mathrm{Eu} / \mathrm{Eu}^{*}=1,50$ y alto ratio o relación $\mathrm{Nd}_{\mathrm{N}} / \mathrm{Sm}_{\mathrm{N}}=9,31$.

Unidad Peñas Blancas (Cuadro 3-4, $\mathrm{N}^{\circ} 11$ ) según el diagrama TAS y R1- R2 tiene una composición riolítica, en el diagrama $\mathrm{Nb} / \mathrm{Y}$ vs $\mathrm{Zr}$ / $\mathrm{TiO}_{2}$ se ajusta en el campo de la traquiandesita. Pertenece a la serie calco-alcalina con alto contenido de potasio y de todas las ignimbritas analizadas es la que presenta el valor más alto de $\mathrm{K}_{2} \mathrm{O}(4,1 \%)$. Además, tiene valores altos de $\mathrm{Rb}(55,8 \mathrm{ppm}), \mathrm{Nb}(23,8 \mathrm{ppm}), \mathrm{U}$ (6,2 ppm) Th (19,5 ppm) y $\Sigma$ REE (140 ppm). Por otro lado tiene valores muy bajos de $\mathrm{Ti}, \mathrm{Ca}, \mathrm{Fe}, \mathrm{Mg}, \mathrm{P}$, $\mathrm{Cr}, \mathrm{Ni}, \mathrm{Y}$. Geoquímicamente, según el diagrama REE, presenta cierta similitud con las rocas cercanas al domo riodacítico del cerro La Cruz. También manifiesta una anomalía positiva de europio $\left(\mathrm{Eu} / \mathrm{Eu}^{*}=1,46\right)$ y alto ratio $\mathrm{Nd}_{\mathrm{N}} / \mathrm{Sm}_{\mathrm{N}}=$ 7,04 mostrándose casi idéntico a la muestra de la ignimbrita de las Musas.

Ignimbrita (o intrusivo) de San Jerónimo (Cuadro 3-4, $\mathrm{n}^{\circ}$ 12) de acuerdo al diagrama de TAS esta corresponde a la serie calco-alcalina y se sitúa en el campo de la dacita, en el diagrama $\mathrm{Nb}$ / Y vs $\mathrm{Zr} / \mathrm{TiO}_{2}$ se ubica más bien sobre el campo de la andesita. Es altamente peralunínica, lo que indica cambio de composición primario debido a una fuerte alteración hidrotermal.

\section{Otras rocas}

Toba de color café con hematita (Cuadro 3-4, $\left.n^{\circ} 19\right)$ aparece como un horizonte estratigráfico en el Grupo Aguacate cerca de la planta hidroeléctrica Nagatac (Mi307). El análisis químico y por difractometría reveló que se trata principalmente de una mezcla de silicatos de aluminio hidratados (caolinita o pirofilíta) y hematita $\left(36 \% \mathrm{SiO}_{2}\right.$, $29,5 \% \mathrm{Al}_{2} \mathrm{O}_{3}, 18,6 \% \mathrm{Fe}_{2} \mathrm{O}_{3}$, con valores de óxidos de $\mathrm{Mg}, \mathrm{Ca}, \mathrm{K}, \mathrm{Na}$ por debajo del $0,2 \%$ y más del $\left.13 \% \mathrm{H}_{2} \mathrm{O}\right)$.

Roca hidrotermalmente alterada del domo del cerro La Cruz (Cuadro 3-4, nº 6), según el estudio 
de difractometría está formada de tridimita (mineral que es dominante), caolinita y natroalunita, lo que confirma el alto contenido de $\mathrm{SO}_{3}(6,86 \%)$.

\section{DESCRIPCIONES ESTRUCTURALES}

La geología de la hoja Miramar, desde el punto de vista de evolución estructural y tectónica, esta influenciada de forma significativa por su ubicación. Esta se ubica en el eje del arco volcánico, sobre la zona de subducción y al mismo tiempo en el borde de la zona transcurrente regional denominada como la Zona Tectónica Nicoya Oriental (Fisher et al., 1994, 1998; Marshall et al., 2000).

El estudio tectónico-estructural del área se realizó mediante el análisis mesoscópicos (en el campo) de zonas frágiles de la corteza, donde se detectaron sistemas de estructuras tectónicas tales como pliegues y fracturas (diaclasas, grietas, fisuras y fallas). También se realizaron estudios morfotectónicos con el uso de teledetección (datos satelitales) y fotografías aéreas. En el mapa se plasmaron una serie de alineamientos y fallas, las cuales en su mayoría se tratan de fallas inferidas que se reconocieron a partir de su geomorfología (Fig. 21). Con respecto a las estructuras más importantes de la hoja Miramar, estas se describen a continuación.

\section{Deformaciones dúctiles}

Las deformaciones dúctiles son las más antiguas y se relacionan con una fase de compresión. Están representadas por estructuras de pliegues combinadas con fallas inversas, que se documentaron principalmente en las hojas vecinas Barranca y Chapernal, propiamente en las formaciones sedimentarias del Cretáceo Superior hasta el Mioceno (Denyer et al., 2003; Žáček et al., 2010b, c). En la hoja Miramar se preservaron solamente en el cuadrante SO, en los sedimentos de la Formación Punta Carballo del Mioceno Medio, como pliegues convergentes hacia S-SSO y con buzamientos dominantes de los estratos hacia el NNO.

\section{Fallas del rumbo NE-SO hasta ENE-OSO}

Según el análisis estructural mesoscópico, se comprobó un sistema de grietas y fallas con rumbo NE-SO hasta ENE-OSO las cuales predominan en la hoja mapeada y también son más antiguas que las fallas con rumbo NO-SE. Los movimientos son dextrales y sinistrales con cierta componente vertical; sin embargo en algunos casos se puede tratar de fallas o sistemas de grietas sin movimientos evidentes. Algunas están acompañadas por alteraciones hidrotermales y también se relacionan con nacientes de aguas termales en el valle del río Barranca, cerca de la planta hidroeléctrica Nagatac. Las fallas con este rumbo representan la fase relacionada con la compresión del arco volcánico sobre la zona de subducción.

Falla Barranca: Continúa desde la hoja colindante Barranca, tiene rumbo $\mathrm{N} 30-45^{\circ} \mathrm{E}$ y está dibujada en el mapa de Denyer et al. (2003). Probablemente predomina un movimiento sinestral y se estima de edad cuaternaria, que concuerda con lo expuesto en Denyer et al. (2003). Fischer et al. (1998) le da un movimiento dominante vertical en donde el bloque NO baja con respeto al SE.

Falla Jesús María: Es una falla con rumbo $\mathrm{N} 60^{\circ} \mathrm{E}$ en donde se terminan varias unidades de la hoja colindante Barranca. En la hoja cartográfica Miramar atraviesa solamente las rocas del Grupo Aguacate pero por su morfología es también muy evidente. Marshall et al. (2003) y Denyer et al. (2003) indican que su movimiento es dextral y también vertical, donde el bloque SE baja con respeto al NE.

Falla La Unión: Es una falla con rumbo $\mathrm{N} 60^{\circ} \mathrm{E}$, paralela al rumbo del valle del río Seco en el área de las minas La Unión. Es más antigua que las fallas de rumbo $\mathrm{N}-\mathrm{S}$ o $\mathrm{N} 10^{\circ} \mathrm{O}$, mientras la relación con las fallas de rumbo $\mathrm{N} 30-40^{\circ} \mathrm{O}$ no esta bien definida.

\section{Fallas de rumbo NO-SE y N-S}

Son aquellas fallas con rumbo $\mathrm{N} 30-45^{\circ} \mathrm{W}$, son las más comúnes y según el análisis estructural de 


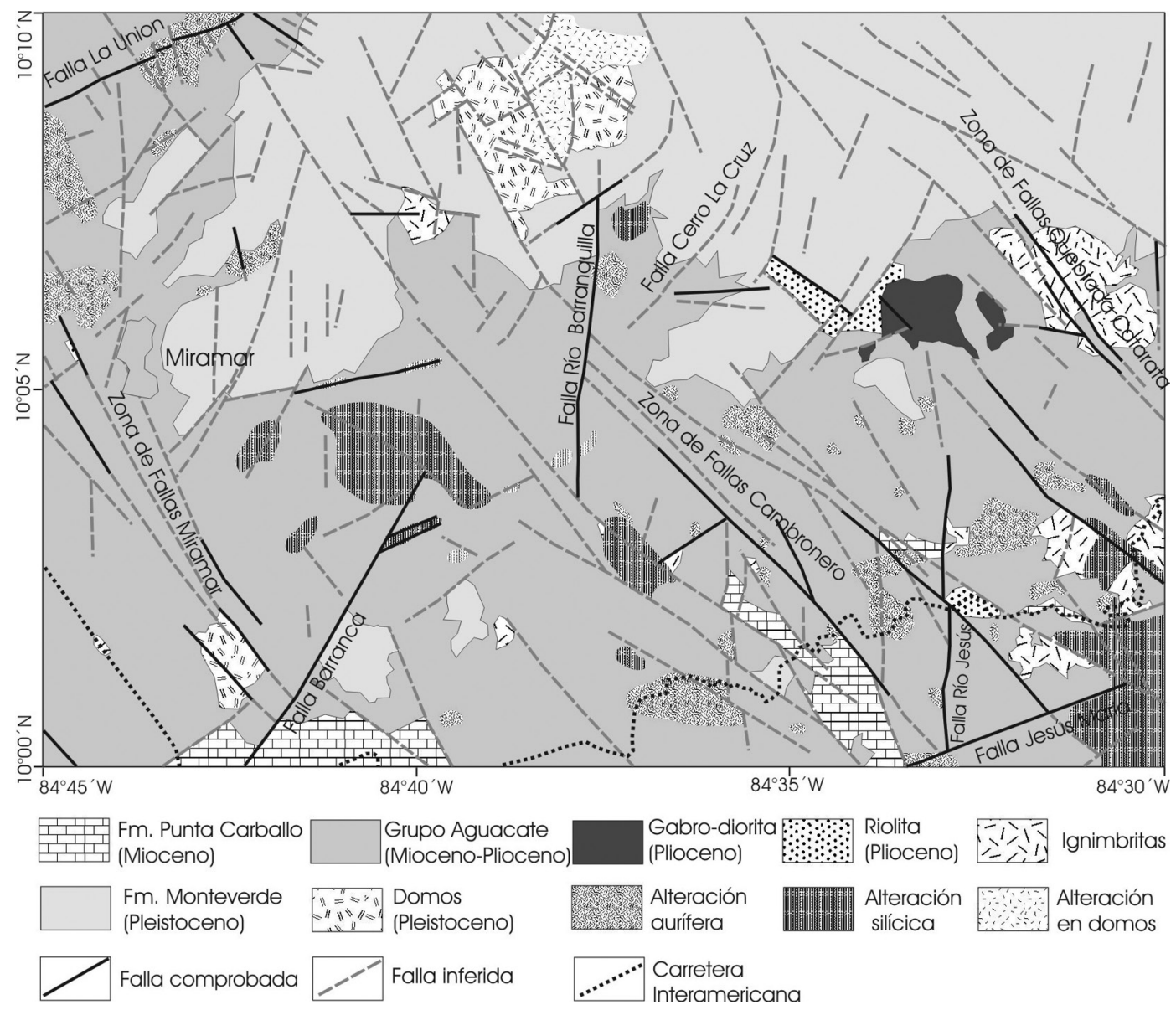

Fig. 21: Mapa geológico esquemático de la hoja Miramar con las estructuras tectónicas.

éstas y sus relaciones estratigráficas, se tratan de fallas normales o tranversales con una dominante componente dextral. Esta fase de tectonismo se relaciona sobre todo con un levantamiento relativamente rápido del antiguo arco volcánico sobre la zona de subducción, principalmente en el Cuarternario (Fischer et al., 1994; Marshall et al., 2003). Las fallas con estos rumbos son los que predisponen muchos deslizamientos antiguos y recientes en la zona. En el área de estudio aparecen tres zonas significativas de estas fallas, las cuales se nombran a continuación de oeste a este: Zonas de Miramar, la Zona de Cambronero y la Zona de Quabrada Catarata. Estas son genéticamente relacionadas con las fallas de rumbo N-S hasta NNO-SSE las cuales son menos abundan- tes, formándose de esta manera un sistema con dos componentes. Además se relaciona con una paleoextensión de rumbo ENE-OSO hasta O-E.

Falla Río Jesús: forma parte del sistem más importante con rumbo N-S con una probable componente dextral. Existe una naciente de agua con contenido de $\mathrm{H}_{2} \mathrm{~S}$ que se relaciona con la misma. Igual rumbo presenta la falla del río Baranquilla que se úbica en el centro del mapa.

Fallas del domo cerro La Cruz: son fallas lístricas que rodean el domo dacítico al oriente del cuerpo. Tienen un movimiento dominante vertical y se relacionan con la intrusión y colapso del domo dacítico en el Pleistoceno. También se presentan esquemáticamente en el mapa de Schulz et al. (1987). 


\section{AGRADECIMIENTOS}

Este proyecto geológico fue realizado en el marco de la Cooperación Técnica Internacional entre el Ministerio del Medio Ambiente de la República Checa y el Ministerio de Ambiente, Energía y Telecomunicaciones (MINAET) de Costa Rica. El financiamiento por parte del Gobierno Checo se realizó en el marco del proyecto $\mathrm{N}^{\circ} \mathrm{RP} / 6 / 2007$, siendo el garante el Ministerio del Medio Ambiente Checo y el ejecutor el Servicio Geológico Checo (sede Praga).

El trabajo de campo durante el periodo de ejecución (2007-2009, trabajos preliminares en el 2006) fue realizado de forma conjunta con la Dirección de Geología y Minas.

La publicación de este trabajo fue finalizado en el marco del proyecto número 321010 del Servicio Geológico Checo.

Se agradece a los señores Dr. Siegfried Kussmaul y MSc. Alejandro Arauz Cavallini, por la revisión final del manuscrito, por sus comentarios y aportes a este artículo. Otro agradecimiento al Dr. Percy Denyer, Director de la Revista Geológica de América Central, por la amable cooperación.

\section{REFERENCIAS}

ALÁN, M.M.A., 1983: Geología y estudio de lateritas en el extremo noroeste del Valle de El General: San José.- 123 págs. Univ. Costa Rica, San José [Tesis Lic.].

ALVARADO, G.E., 1986: Hallazgos de megamamíferos fósiles en Costa Rica.- Rev. Geol. Amér. Central, 4: 1-46.

ALVARADO, G.E., KUSSMAUL, S., CHIESA, S., GILLOT, P.Y., APPEL, H., WORNER, G. \& RUNDLE, C., 1992: Resumen cronoestratigráfico de las rocas ígneas de Costa Rica basado en dataciónes radiométricas.- J. Southr. Amer. Sci. 6: 151-168.

ALVARADO, G.E. \& CARR, M.J., 1993: The Platanar - Aguas zarcas volcanic centers,
Costa Rica: Spatial temporal association of Quaternary calc-alkaline and alkaline volcanism.- Bull. Volcanol. 55: 443-453.

AMOS, B.J. \& ROGERS, P.J., 1983: The geology and exploration geochemistry of the Cordillera Tilarán - Montes del Aguacate gold field, Costa Rica.- Inst. Geol. Sci., Overseas Division, Open-File Report: 1-33.

BALOGH, K., 1985: K/Ar dating of neogene volcanic activity in Hungary: Experimental technique, experiences and methods of chronologic studies.- ATOMKI Rep. D/1: 277-288. Debrecen.

BELLON, H. \& TOURNON, J., 1978: Contribution de la géo chronometrie K-Ar a l'étude du magmatisme de Costa Rica, Amérique Central.- Bull. Soc. Geol. France, 20, 6: 955-959.

BOYNTON, W.V., 1984: Cosmochemistry of the rare earth elements: meteoritic studies.- In: HENDERSON, P. (ed.): Rare Earth Elements Geochemistry.- Elsevier. Amsterdam.

CHAVES, R. \& SÁENZ, R., 1974: Geología de Cordillera de Tilarán (proyecto de Aguacate, $2^{\mathrm{a}}$ Fase): Costa Rica.- Dirección de Geología, Minas y Petróleo, Informes Técnicos y Notas Geológicas. 12(53): 1-49.

CIGOLINI, C. \& CHAVES, R., 1986: Geological, petrochemical and metallogenetic characteristics of the Costa Rican gold belt: contribution to new exploration.- Geol. Rundsch. 75, 3: 737-754.

DALRYMPLE, B.G. \& LANPHERE, M.A., 1969: Potassium-Argon Dating Principles, Techniques and Application to Geochronology.- W.H. Freenan and Co., San Francisco: 1-288.

DENYER, P. \& ARIAS, O., 1991: Estratigrafía de la región central de Costa Rica.- Rev. Geol. Amér. Central, 12: 1-59. 
DENYER, P., AGUILAR, T. \& ALVARADO G.E., 2003: Geología y estratigrafía de la hoja Barranca, Costa Rica.- Rev. Geol. Amér. Central, 29: 105-125.

DENYER, P. \& KUSSMAUL, S., EDS., 2006: Geología de Costa Rica.- 515 págs. Inst. Tec. de Costa Rica, Cartago.

DENYER, P. \& ALVARADO, G.E., 2007: Mapa Geológico de Costa Rica 2007.Escala 1: 450 000, Libreria Francesa, San José.

FISHER, D.M., GARDNER, T.W., MARSHALL, J.S. \& MONTERO, W.P., 1994: Kinematics associated with late Cenozoic deformation in central Costa Rica: Western boundary of the Panama microplate.- Geology, 22: 263-266.

FISHER, D.M., GARDNER, T.W., MARSHALL, J.S., SAK, P.B. \& PROTI, M., 1998: Effect of subducting sea-floor roughness on forearc kinematics, Pacific coast, Costa Rica.Geology, 26: 467-470.

FLORES, R.C., QUIRÓS, M.C., CORTÉS, J.C. \& BADILLA, A.R., 2001: Estudio geomorfológico y de amanazas naturales para propiciar el plan de ordenamiento territorial de la subcuenca del río Jabonal, Esparza, Puntaarenas.- 96 págs. Univ. Costa Rica, San José [Tesis Lic.].

GANS, P.P., MACMILLAN, I., ALVARADO, G., PEREZ, W. \& SIGARAN, C., 2002: Neogene evolution of the Costa Rican Arc.- Denver Annual Meetening, October 27-30. Denver: 224.

GANS, P.P., ALVARADO, G., PEREZ, W., MACMILLAN, I. \& CALVERT, A., 2003: Neogene evolution of the Costa Rican Arc and development of the Cordillera Central.- The Carribean and Central American Realms of the Southernmost Cordillera, April 1-3.Yelapa:33.
GILLOT, P.-Y., CHIESA, S. \& ALVARADO, G.E., 1994: Cronostratigraphy of upper Miocene - Quaternary volcanism in northern Costa Rica.- Rev. Geol. Amér. Central, 17: 45-53.

HOLLAND, T.J.B. \& BLUNDY, J.D., 1994: Non-ideal interactions in calcic amphiboles and their bearing on amphibole - plagioclase thermometry.- Contrib. Mineral. Petrol. 116: 433-447.

IRVINE, T.N. \& BARAGAR, W.R.A., 1971: A guide to the chemical classification of the common volcanic rocks.- Can. J. Earth. Sci. 8: 523-548.

JANOUŠEK, V., FARROW, C. \& ERBAN, V., 2006: Interpretation of whole-rock geochemical data in igneous geochemistry: introducing Geochemical data Toolkit (GCDkit).- J. Petrol, 47, 6: 1255-1259.

KUSSMAUL, S., 1987: Petrología de las rocas intrusivas neogenas de Costa Rica.- Rev. Geol. Amér. Central, 7: 83-111.

KUSSMAUL, S., TOURNON, J. \& ALVARADO, G.E, 1994: Evolution of the Neogene to Quaternary igneous rocks of Costa Rica.Profil 7: 97-123. Stuttgart.

KYCL, P., ŽÁČEK, V., ČECH, S., GRYGAR, R., HRAZDÍRA, P., HUAPAYA, S., KARENOVÁ, J., KONDROVÁ, L., MENDOZA. E.Q., METELKA. V., MIXA, P., ŠEVČÍK, J., VOREL, T, HRADECKÁ, L., REJCHRT, M. \& ŠVÁBENICKÁ, L., 2010: Estudio geológico, informe final (2006-2009): hojas 3246 II - Miramar, 3246 III - Chapernal, 3246 IV - Juntas, Costa Rica.- 263 págs. Servicio Geológico Checo, Praga y DGM, San José, [Inf. interno].

KRETZ, R., 1983: Symbols for rock-forming minerals.- Amer. Miner. 6: 277-279. 
LAGUNA, M.J., 1983: Hydrothermale Veänderung und Verwitterungseffekte in Vulkaniten der Aguacate Formacion (Miozän, Pliozän), Costa Rica, Zentralamerika.- Zbl. f. Geologie und Paläontologie, 1: 223-233.

LAGUNA, M.J., 1984: Efectos de Alteración Hidrotermal y Meteorización en Volcanitas del Grupo Aguacate, Costa Rica.- Rev. Geol. Amér. Central, 1: 1-18.

LEAKE, B.E., WOOLEY, A.R., ARPS, C.E.S., BIRCH, W.D., GILBERT, M.C., GRICE, J.D., HAWTHORNE, F.C., KATO, A., KISCH, H.J., KRIVOVICHEV, V.G., LINTHOUT, K., LAIRD, J., MANDARINO, J., MARESCH, W.V., NICKEL, E.H., ROCK, N.M.S., SCHUMACHER, J.C., SMITH, J.C., STEPHENSON, N.C.N., WHITTAKER, E.J.W. \& YOUZHI, G., 1997: Nomenclature of amphiboles: Report of the Subcommittee on Amphiboles of the International Mineralogical Association Commission on New Minerals and Mineral Names.- Mineral. Mag., 61: 295-321.

LE BAS, M.J., LE MAITRE, R.W., STRECKEISEN, A. \& ZANETTIN, B., 1986: A chemical classification of volcanic rocks based on the total alkali-silica diagram.- J. Petrol. 27: 745-750.

LUCAS, S.G., ALVARADO, G.E. \& VEGA, E., 1997: The pleistocene mammals of Costa Rica.- J. Vert. Paleont. 17, 2: 413-427.

MADRIGAL, O., 1980: Geología y Potencial de una Parte del Distrito Minero de Abangares, Guanacaste.- Univ. Costa Rica, San José [Tesis Lic.].
MADRIGAL, R., 1967: Estudio geotécnico y evaluación de algunos yacimientos de piedra pómez en Costa Rica.- Notas Téc. y geol. MEIC: 1-26.

MARSHALL, J.S., FISHER, D.M. \& GARDNER, T.G., 2000: Central Costa Rica deformed belt: Kinematics of diffuse faulting across the western Panama block.- Tectonics, 19: 468-492.

MARSHALL, J.S., IDLEMAN, B.D, GARDNER, T.W \& FISCHER, D.M., 2003: Landscape evolution within a retreating volcanic arc, Costa Rica, Central America.- Geology, 31(5): 419-422.

MIXA, P., DOBEŠ, P., ŽÁČEK, V., LUKEŠ, P. \& QUINTANILLA E.M., 2001: The Epithermal Gold Mineralization in Montes del Aguacate and Cordillera de Tilarán, Costa Rica - Exploration Geochemistry and Genesis of Gold Deposits.- J.Geosci. 56: 81-104.

OLSSON, A.A., 1922: The Miocene of Northern Costa Rica.- Bull. Amer. Paleont. 9 (39): 1-309.

PECCERILLO, R. \& TAYLOR, S.R., 1976: Geochemistry of Eocene calc-alkaline volcanic rocks from the Kastamonu area, Northern Turkey.- Contrib. Mineral. Petrol. 58: 63-81.

POUCHOU, J.L. \& PICHOIR, F., 1985: 'PAP' $(\varphi-\rho-Z)$ correction procedure for improved quantitative microanalysis. In: ARMSTRONG, J.T. (ed.): Microbeam Analysis.- San Francisco Press: 104-106.

SEGURA, A., 1942: Sección de geología: informe rendido a la Secretaría de Educatión 
Pública sobre la labor realizada en 1940.Mus. Nac. de Costa Rica, Serie de Hist. del Mus. Nac. 1: 15-50.

SCHULZ, K., KOEPPEN, R., LUDINGTON, S., KUSSMAUL, S. \& GRAY, K., 1987: Volcanological framework for the gold deposits in the Cordillera de Tilarán and Montes del Aguacate, Costa Rica.- En: USGS, DIRECCIÓN GENERAL DE GEOLOGÍA, MINAS E HIDROCARBUROS, Y UNIVERSIDAD DE COSTA RICA. Mineral resource assessment of the Republic of Costa Rica:34-75.

SHAND, S.J., 1943: Eruptive Rocks; Their Genesis, Composition, Classification, and their Relation to Ore Deposits, with a chapter on Meteorites (revised second edition).444 págs. Hafner Publishing Co., New York.

STEIGER, R. H. \& JÄGER, E., 1977: Subcommission on geochronology: Convention on the use of decay constants in geo- and cosmochronology.- Earth Planet. Sci. Lett. 36: 359-362.

VALERIO, J., 1939: Sección de geología: informe rendido a la Secretaría de Educatión Pública sobre la labor realizada en 1938.Mus. Nac. de Costa Rica, Serie de Hist. del Mus. Nac. 1: 17-18.

VILLEGAS, F.A., 1997: Geodinamica de la Cordillera de Tilarán, relación entre la volcanología y la tectónica.- 147 págs. Univ. Costa Rica, San José [Tesis Lic.].

VILLEGAS, F.A., 2004: La formación Alto Palomo: flujos pumíticos de la Cordillera Volcánica Central, Costa Rica.- Rev. Geol. Amér. Central, 30: 73-81.
VOGEL, T.A., PATINO, L.C., ALVARADO, G.E. \& GANS, P.B. (2004): Silicic ignimbrites within the Costa Rican volcanic front: Evidence for the formation of continental crust.- Earth. Planet. Sci. Lett. 226: 149-159.

VOGEL, T.A., PATINO, L.C., EATON, J.K., VALLEY, J.W., ROSE, W.I., ALVARADO, G.E. \& VIRAY E.L., 2006: Origin of silicic magmas along the Central American volcanic front: genetic relationship to mafic melts.- J. Volcanol. Geotherm. Res. 156: 217-228.

VOGEL, T.A., PATINO, L.C., ALVARADO, G.E. \& ROSE, W.I., 2007: Petrogenesis of ignimbrites. In: Bundschuh J, Alvarado GE (eds) Central America: Geology, Resources, and Hazards. Taylor \& Francis, London: 591-618.

WOODRING, W.P., 1982: Geology and Paleontology of Canal Zone and Adjoining Parts of Panama. - Geol. Surv. Prof. Paper, 306-F: 541-759. Washington.

ŽÁČEK, V., KYCL, P., HUAPAYA, S., PÉCSKAY, Z., VOREL, T., MIXA, P., GRYGAR, R., METELKA, V., HRADECKÝ, P. \& ŠEVCÍK, J., 2008: Resultados preliminares del levantamiento geológico de la hoja Miramar, escala 1:50 000. Cooperación geológica Costa Rica - República Checa.Programa y resúmenes IX Congreso Geológico de América Central y VI Congreso geológico Nacional, San José: 118.

ŽÁC̆EK ,V., VOREL, T., KYCL, P. \& HUAPAYA, S., 2010a: Mapa geológico de la hoja Miramar.- Escala 1:50 000, Serv. Geol. Checo, Praga. 
ŽÁČEK, V.,ČECH, S., HAVLÍČEK,P., VOREL, T., DUDÍK SCHULMANNOVÁ, B., KYCL，P. \& HUAPAYA, S., 2010b: Mapa geológico de la hoja Chapernal.Escala 1:50 000, Serv. Geol. Checo, Praga.

ŽÁČEK, V., ČECH, S., DUDÍK SCHULMANNOVÁ, B., VOREL, T., KYCL, P., HUAPAYA, S., 2010c: Mapa geológico de la hoja Las Juntas.- Escala 1:50 000, Serv. Geol. Checo, Praga.

ŽÁČEK, V, JANOUŠEK, V, ULLOA, A., KOŠLER, J., HUAPAYA, S., MIXA, P., VONDROVICOVÁ, L. \& ALVARADO, G.E., 2011: The Late Miocene Guacimal Pluton in the Cordillera de Tilarán, Costa Rica: its nature, age and petrogenesis.- J. Geosci. 56: 51-79. 


\title{
PEPERITAS EN COSTA RICA
}

\author{
COSTA RICAN PEPERITES
}

\section{Daniel Soto ${ }^{1 *} \&$ Guillermo E. Alvarado 2,3}

\section{${ }^{1}$ Ministerio de Obras Públicas y Transportes, División Obras Públicas, Dirección Ingeniería, Departamento de Geología, Apdo. 10176-1000, San José, Costa Rica ${ }^{2}$ Instituto Costarricense de Electricidad, Apdo. 10032-1000, San José, Costa Rica ${ }^{3}$ Centro de Investigaciones Geológicas Universidad de Costa Rica, San José, Costa Rica \\ *Autor para contacto: danielsotoa@gmail.com}

(Recibido: 22/03/2012 ; aceptado: 17/12/2012)

\begin{abstract}
This paper describes petrographically and genetically, a number of peperites, as examples of spatial and temporal coexistence of magmatism and sedimentation in Costa Rica. The cases are presented in basic igneous complexes (ophiolites), mixtures varying from incomplete (megablocks of radiolarite with diabase in the Nicoya Complex) to complete mixes in various stages of Maastrichtian-Paleocene (Golfito Formation) or Paleocene pelagic limestones with basalts (Quepos Subcomplex or Tulín Formation) to form brechoid and pillowed peperites. Within the Oligo-Miocene arc, there are examples extended along the Talamanca range and its foothills, as well as Sarapiquí's plains represented for brechoid and bulbous (fluidal) peperites in latiandesitic lavas (Pacacua Formation) or brechoid peperitic pipes in ignimbrites (Mata de Limón Member) or possible brechoid peperites in lavas in the Crucitas mining prospect (Cureña Formation), or simple brechoid peperites in andesitic flow (Pacacua Formation, in Talamanca) or as hydroclastic breccias with fragments of dacitic composition in lava flow deposits of Carbonal Guanacaste, just between the beaches Cabuyal and Naranjo. All these rocks represented proximal equivalents of the explosive, effusive and subvolcanic volcanism (endogenous domes and criptodomes) and his concomitance with the fluvial sedimentation. In Quaternary period, we have a sample in the base of Tiribí Formation in contact with Palmares Lacustrine. Also this paper included possible and potential cases. It hopes that the description and interpretation of this type of rocks helps to its identification in other regions of Costa Rica and Central America in general, as well as a potential source for the exploration of valuable metals.
\end{abstract}

Keywords: Peperites, hydroclastic breccias, criptodomes, volcanism and sedimentation, Costa Rica

RESUMEN: El presente trabajo describe petrográfica y genéticamente, una serie de hallazgos de peperitas como ejemplos de coexistencia espacial y temporal del magmatismo con la sedimentación en Costa Rica. Los casos se presentan en complejos ígneos básicos (ofiolitas) variando desde mezclas incompletas (megabloques de radiolaritas con diabasas en el Complejo de Nicoya) hasta mezclas completas en varios grados de calizas pelágicas del Maastrictiano-Paleoceno 
(Formación Golfito) o del Paleoceno con basaltos (Subcomplejo Quepos o Formación Tulín) para dar peperitas brechoides y bulbosas. Dentro del arco Oligo-Mioceno, se tienen ejemplos a lo largo de la cordillera de Talamanca y sus estribaciones, así como en las llanuras de Sarapiquí, representados por peperitas brechoides, fluidales y bulbosas en cuerpos de lava latiandesíticos (Formación Pacacua) o chimeneas peperíticas brechoides en ignimbritas (Miembro Mata de Limón), o posibles peperitas brechoides en los depósitos de flujos de lava del prospecto minero de Crucitas (Formación Cureña), o simples posibles peperitas brechoides en flujos de lava andesíticas (Formación Pacacua en Talamanca), o como brechas hidroclásticas con fragmentos de composición dacítica de Carbonal en Guanacaste, justamente entre las playas Cabuyal y Naranjo. Todas ellas serían los equivalentes proximales del vulcanismo explosivo, efusivo y subvolcánico (domos endógenos y criptodomos) y su concomitancia con la sedimentación fluvial. En el Cuaternario, un ejemplo se da en la base de la Formación Tiribí al contacto con el lacustre de Palmares. Se incluyen en el presente trabajo, además, casos posibles o potenciales. Se espera que la descripción e interpretación de este tipo de rocas ayude a su identificación en otras regiones de Costa Rica y Centroamérica en general, así como una fuente potencial para la prospección de metales valiosos.

Palabras clave: Peperitas, brechas hidroclásticas, criptodomos, vulcanismo y sedimentación, Costa Rica.

\section{INTRODUCCIÓN}

La interrelación espacio-temporal del magmatismo (intrusiones y vulcanismo) con la sedimentación son casos muy tratados desde los primeros trabajos de geología, tanto a nivel mundial como a nivel local en Costa Rica. Así, en los esquemas paleogeográficos suelen presentarse como un hecho común la presencia de volcanes activos que evolucionaron con la intrusión de un magma que asciende sobre cuencas marinas hasta emerger y verter sus productos en la superficie $y$, de esta manera, coexistir con la sedimentación y ayudar a su colmatación. Sin embargo, las evidencias en el campo, de intrusiones o vulcanismo contemporáneo y asociado con la sedimentación de modo directo, prácticamente nunca se han mostrado, no por el hecho de no existir, sino porque suelen no reconocerse por desconocimiento o por interpretarse de otro modo.

Las peperitas, en términos generales, son una brecha volcano-sedimentaria producto de la intrusión subvolcánica en sedimentos inconsolidados o la mezcla de coladas de lava o depósitos de flujos piroclásticos con sedimentos normalmente saturados en agua, siendo una prueba de la coexistencia espacio-temporal del magmatismo (sea de textura plutónica hipoabisal o bien volcánica, o como una intrusión piroclástica) con la sedimentación (White et al., 2000, y referencias allí citadas). No solo nos dice que la intrusión posee una edad similar o cercana a la de los sedimentos y, por lo tanto, su relativo sincronismo y el estado plástico de los mismos, sino que pueden ser sectores interesantes para las mineralizaciones de metales preciosos dada su permeabilidad primaria relativamente elevada y por ser conductos ígneos en contacto con sedimentos húmedos.

Umaña \& Afonso (1969) quizás fueron de los primeros en identificar cómo materiales lacustrinos subían plásticamente por las fracturas de la colada de Cervantes. Schmidt-Effing (1979, 1980), por su parte, fue quizás el primero que interpreta que algunos sedimentos radiolaríticos o calcáreos presentes en complejos ígneos básicos u ofiolíticos de Costa Rica (Complejo de Nicoya, Subcomplejo Quepos, Formación Golfito) podrían ser mezclas o megabrechas volcano-sedimentarias. Sin embargo, sus observaciones no fueron en ese momento aceptadas por los investigadores y fueron puestas al nivel de tan solo como una mera cita, prácticamente anecdótica. Dos décadas después, observaciones geológicas similares volverían a ser tomadas en cuenta como una base para re-interpretar las asociaciones magmático-sedimentarias de los complejos ofiolíticos a la luz de modernas técnicas isotópicas y trabajo de campo adicionales.

Alvarado (1984) menciona la posibilidad de que parte de las lavas mapeadas por Rivier (1979) sean contemporáneas con la sedimentación de Pacacua, hecho que tampoco fue tomado 
en consideración en investigaciones posteriores. Pasaría una década, cuando De la Cruz (1994) describe y al parecer menciona por primera vez el término peperita para Costa Rica, a raíz de una serie de núcleos realizados para la evolución vulcanológica del prospecto minero de Crucitas, pero adolece del hecho de que siempre se cuenta con la limitante de que las perforaciones no dan una buena perspectiva de la tercera dimensión o de las inter-relaciones.

Ya en el presente siglo, Alvarado \& Gamboa (2008), Quintanilla et al. (2008) y Alvarado et al. (2009b) mencionan la existencia de peperitas, pero sus descripciones son escuetas, dado que los objetivos de dichos trabajos eran otros.

La presente investigación expone y describe con más detalle una serie de casos de peperitas que varían desde aquellos bien identificados en Costa Rica (Fig. 1) hasta otros que por la escala o tipo de afloramiento, o por ser descripciones a partir de perforaciones, no lo son, pero presentan características suficientes para hacerles potencialmente acreedores de dicho calificativo. Como fin último, pero quizás el más importante, es que se espera que el presente trabajo sea una base para que otros geólogos puedan reconocer en su trabajo de campo, casos similares no solo en nuestro país, sino en el resto de los países vecinos centroamericanos.

\section{TERMINOLOGÍA}

El término peperita (pépérite) nace a inicios del siglo XIX. La mayoría de autores están de acuerdo en que las primeras descripciones detalladas de rocas que dieron origen al término son del inglés G.P. Scrope en los años de 1827, 1858 y 1862, aunque fue P.L. Cordier en 1816 quien la describe para Francia en Limagne d'Auvergne de la región central, como una toba clara, de aspecto brechoso, siendo está la localidad tipo de esta clase de roca. Scrope le da el nombre de calcareous peperino a un conglomerado volcánico compuesto de fragmentos de basalto y escoria (sin pómez o sin material traquítico), unidos ya sea por adhesión o simplemente por cemento calcáreo o arcilloso, originalmente blando de origen lacustrino que fue perturbado por la intrusión. Su nombre peperino, después cambiado a peperita, proviene del hecho que esta mezcla se parece a los granos de pimienta y sal (Goër de Herve, 2000).

White et al. (2000) redefine el término peperita como la roca formada generalmente in situ por la desintegración de una intrusión magmática y mezcla con sedimento inconsolidado o poco consolidado y generalmente húmedo. Así, el término peperita se refiere también a mezclas generadas por el mismo proceso que opera en los contactos de lavas y depósitos volcaniclásticos calientes con sedimentos. Claramente, existen otras acepciones o modo de ver las peperitas (ver Goër de Herve, 2000), pero para nuestros fines, utilizaremos el trabajo de White et al. (2000).

En la formación de peperitas se genera una desintegración o fragmentación del magma para formar clastos juveniles y una mezcla de estos clastos en un sedimento huésped, con una gran variedad de tamaño de grano, composición, cohesión, porosidad y permeabilidad, ha sido descrito como huésped de la peperita (Skilling et al., 2002).

\section{Tipos de peperitas}

Busby-Spera \& White (1987) distinguen dos tipos texturales de peperitas con respecto a la forma de los clastos juveniles que predominan (Fig. 1). Una de ellas son las peperitas blocosas en donde los clastos juveniles van a presentar formas angulares, poliédricas, blocosas a irregulares. Squire \& McPhie (2002) las describen como grupos de clastos blocosos que pueden presentar texturas en rompecabezas (jigsaw) y clastos rotados. El otro tipo son las denominadas peperitas globulares también llamadas como fluidales en donde los clastos presentan formas similares a los flujos de lava en almohadillas envueltos por el sedimento huésped y viceversa (Busby-Spera \& White, 1987). En la literatura también han sido descritas peperitas resultantes de la mezcla de estos dos tipos o transicionales.

Las evidencias de campo para el reconocimiento de peperitas son: a) contactos discordantes y anómalos o extraños (geometría irregular) entre la intrusión magmática con los sedimentos huésped, 


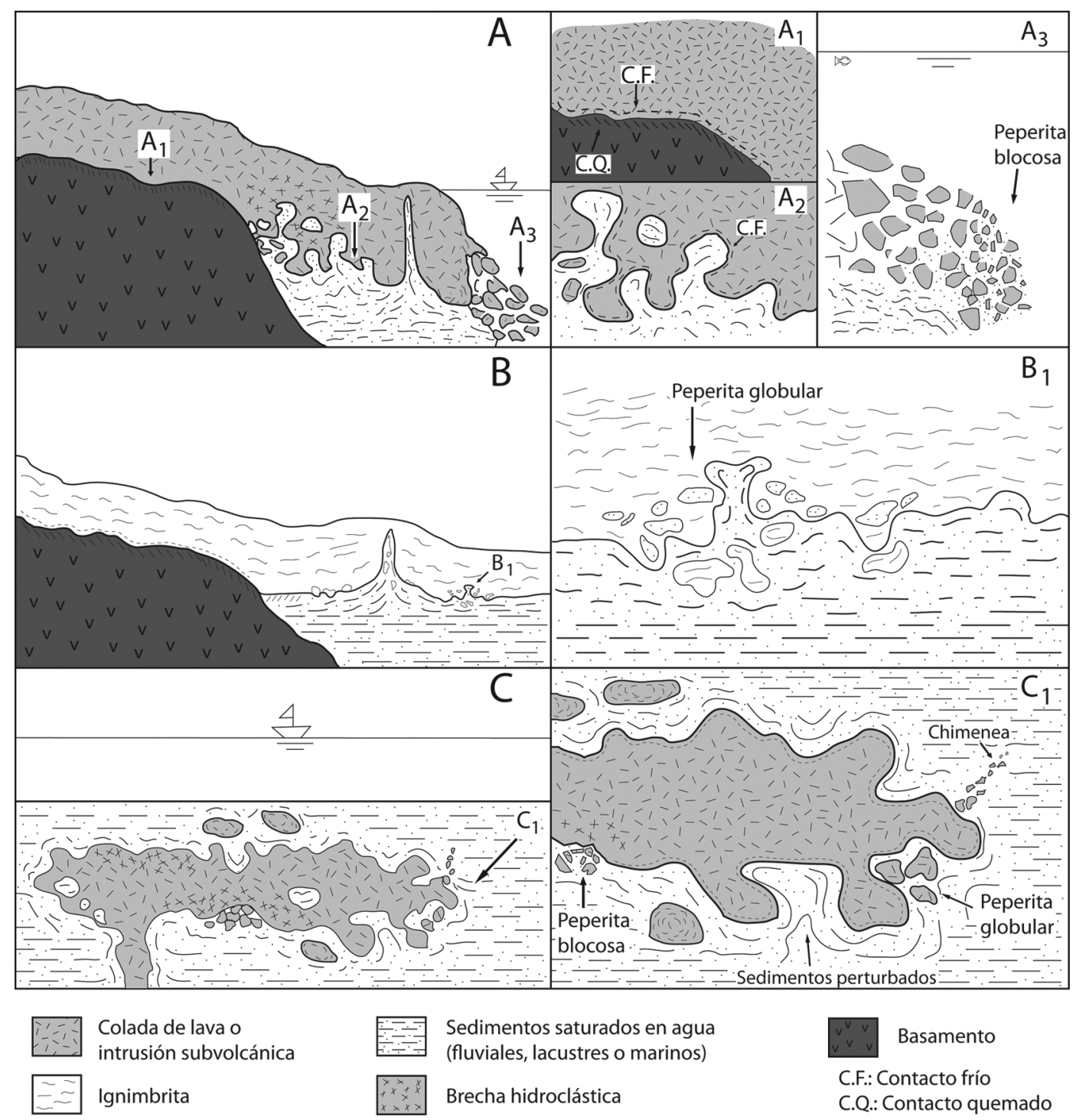

Fig. 1: Tipos de peperitas según textura de los clastos juveniles (ver explicación en el texto así como referencias complementarias).

b) destrucción de estructuras sedimentarias de los componentes sedimentarios adyacentes debido a la intrusión ígnea, perdiendo normalmente -pero no siempre- parte de su estratificación y gradación, c) sedimentos vesiculados debido a la descompresión de la intrusión, así como presencia de sedimentos rellenando vesículas o fracturas en la intrusión (Skilling et al., 2002), d) el componente ígneo, presenta enfriamiento parcial o total (contacto frio) en contacto con el sedimento (White et al. 2000). 


\section{CASOS POSIBLES Y COMPROBADOS DE PEPERITAS EN COSTA RICA}

A continuación enumeraremos una serie de casos de estudio, descritos desde las litologías más antiguas a las más jóvenes. Se subdividen en casos comprobados y casos probables o posibles, ya sea o que requieran de mas investigación, o que el afloramiento desapareció por cobertura vegetal o la construcción de obras de infraestructura, o por que se trate de perforaciones no disponibles y cuya interpretación espacial resulta más complicada (Fig. 2).

\section{Casos comprobados de peperitas}

\section{Península de Nicoya (Jurásico-Cretácico)}

La existencia e interpretación de rocas sedimentarias pelágicas, principalmente radiolaritas con rocas ígneas (intrusivas y extrusivas) ha sido motivo de estudio por décadas en la península de Nicoya en correspondencia con la unidad llamada Complejo de Nicoya. Schmidt-Effing $(1979,1980)$ fue quizás uno de los primeros en proponer que algunos sedimentos radiolaríticos presentes en el Complejo de Nicoya corresponderían con inclusiones sedimentarias (xenolitos o "mélange" volcánico).

La anterior interpretación no fue tomada en consideración o como relevante por los subsiguientes investigadores, quienes optaron por una gran diversidad de modelos, prevaleciendo estos sobre las evidencias de campo, en gran parte bajo la conceptualización válida, pero no única, de que las radiolaritas se deben de depositar sobre un basamento ígneo básico. Aunque lo anterior es cierto, impidió que se visualizaran las evidencias de campo que indicaban que las radiolaritas, en su mayor parte, estaban claramente intruidas por cuerpos diabásicos y nunca en contacto sedimentario con los depósitos de coladas de lava (ver discusión histórica en Alvarado et al., 2009a). No fue sino hasta que las dataciones radiométricas argónargón aportaron las evidencias de que los eventos magmáticos eran en gran parte más jóvenes que las radiolaritas (Sinton et al., 1997; Hauff et al., 2000), por lo que Hauff et al. (2000) propone a modo más regional que los contactos, tanto tectónicos como magmáticos, prevalecían con respecto a los contactos sedimentarios, aspectos previamente observado por otros autores (Gursky \& Gursky, 1989), pero no conceptualizado de modo regional, ni interpretado como peperitas o como intrusiones contemporáneas (i.e., Schwarzer \& Gursky, 2007). Todo lo anterior, más nuevos trabajos de campo, permitieron readecuar los modelos (ver Denyer \& Baumgartner, 2006; Denyer et al., 2006; Alvarado et al., 2009a).

Efectivamente, las radiolaritas se presentan intruidas y en parte afectadas en su estratificación (deformación plástica) por cuerpos hipoabisales diabásicos, presentando decoloración en sus contactos y contactos fríos en los cuerpos ígneos (Gursky \& Gursky, 1989; Denyer \& Baumgartner, 2006), pero hasta el momento no se ha llegado a observar típicas estructuras brechoides, bulbosas o fluidización a nivel de micro-escala entre los componentes ígneos y los sedimentarios. Sin embargo, si se observan megabloques de radiolaritas con intensa deformación plástica, brechiación y pérdida de la estratificación, así como una profusa decoloración y sobre todo, la presencia de una textura de pimienta en las radiolaritas, debido a la intrusión (Fig. 3-A). Excelentes ejemplos se observan al oeste de playa Conchal, por playa Negra (por Paraíso), y las playa Pedregosa y Honda.

Quizás la elevada profundidad a donde ocurrió la intrusión (al menos unos 3 km o más de carga hidrostática), dado que las radiolaritas son distales y los basaltos no vesiculados, aunado a la carga litostática de los sedimentos radiolaríticos (de al menos unos $50 \mathrm{~m}$ ), inhibió la vaporización y explosividad, y por consiguiente la brechiación. Por otro lado, la intrusión al parecer fue lenta dado que los contactos fríos no están muy bien 


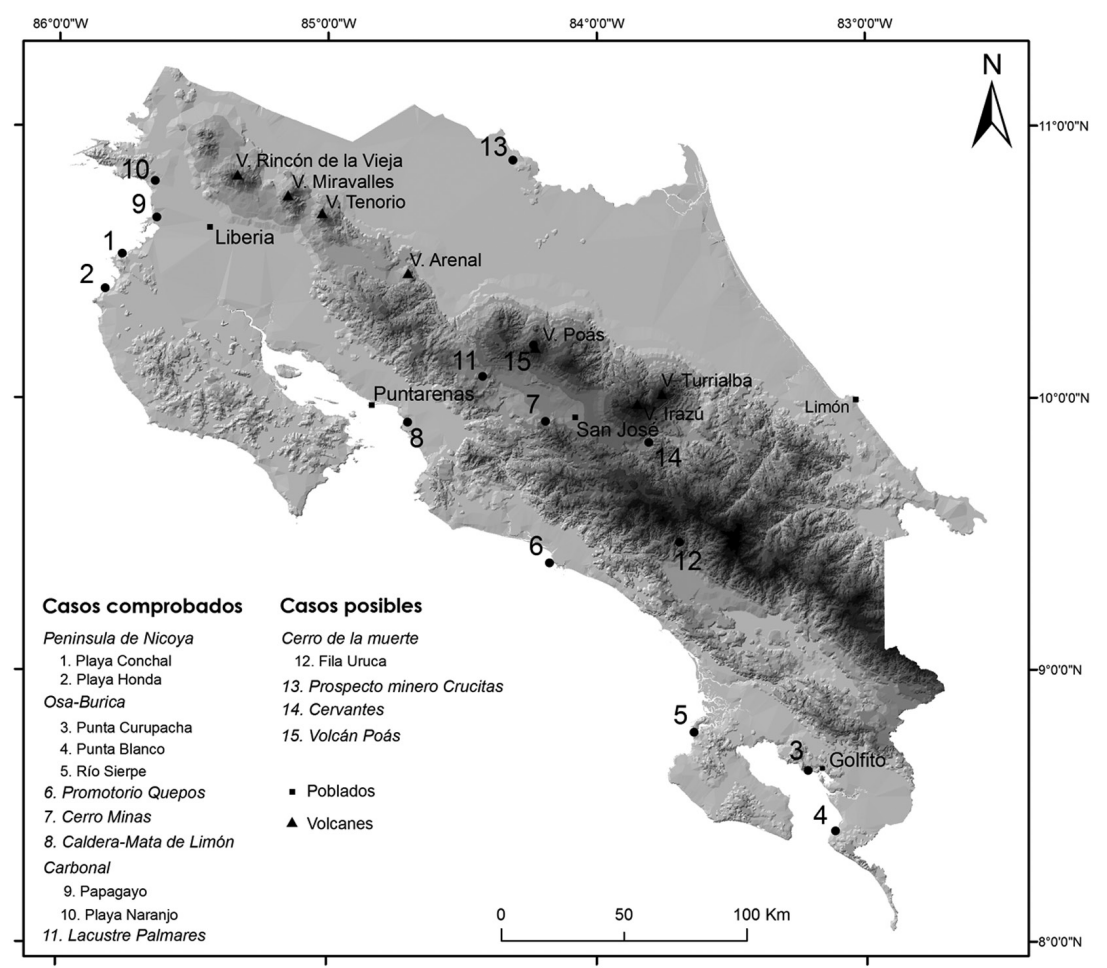

Fig. 2: Mapa de ubicación de los casos de estudio.

definidos, y la bipolaridad geoquímica entre los sedimentos radiolaríticos, (extremadamente ricos en sílice: más de un $95 \% \mathrm{SiO}_{2}$ ) y las lavas basálticas (45-50\% $\mathrm{SiO}_{2}$ ), posiblemente favoreció la inmiscibilidad de ambos tipos de rocas.

Otros ejemplos de posibles peperitas se observan en diversos sectores costeros de la península de Nicoya, en donde los afloramientos debido a la erosión marina, son bastante buenos.

\section{Osa-Burica (Cretácico-Paleoceno)}

En punta Curupacha (aprox. 831' $0.53^{\prime \prime} \mathrm{W} /$ $8^{\circ} 37^{\prime} 56.3^{\prime}$ 'N), en el Golfo Dulce, cerca de Golfito, se observan en los acantilados intrusiones de composición basáltica dentro de las calizas pelágicas del Maastrichtiano-Paleoceno, descritas por Obando (1986) y Di Marco (1994). Aunque ambos autores las habían señalado como indicadores de la coexistencia de un vulcanismo contemporáneo con la sedimentación, no se habían inter- pretado como brechas peperíticas. Efectivamente, poseen un contacto brechoso, de clastos volcánicos angulosos, algunos de formas caprichosas con bordes sinuosos, indicadores de un estado plástico de la lava al momento de la intrusión, en algunos casos contactos fríos y pirometamórficos, pero en otros, la mezcla de los dos componentes es clara y disminuye conforme se aleja de la intrusión (Fig. 5-C). La mezcla ocurre desde escala decimétrica hasta métrica y los clastos desde milimétricos hasta decimétricos, algunos con estructura en rompecabezas.

Otra localidad se ubica por punta Banco, cer-

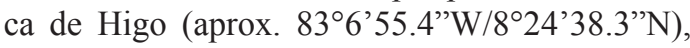
camino a Pavones. Allí se observan cómo las rocas volcánicas intruyen a las calizas silíceas, desarrollando brechas hidroclásticas con estructura en rompecabezas. Las calizas son del Paleoceno Tardío-Eoceno Temprano (Obando, 1986).

En la desembocadura del río Sierpe $\left(83^{\circ} 38^{\prime} 17.5^{\prime \prime} \mathrm{W} / 8^{\circ} 46^{\prime} 24.5^{\prime \prime} \mathrm{N}\right)$ existen rocas de composición basáltica al parecer del Cretácico 

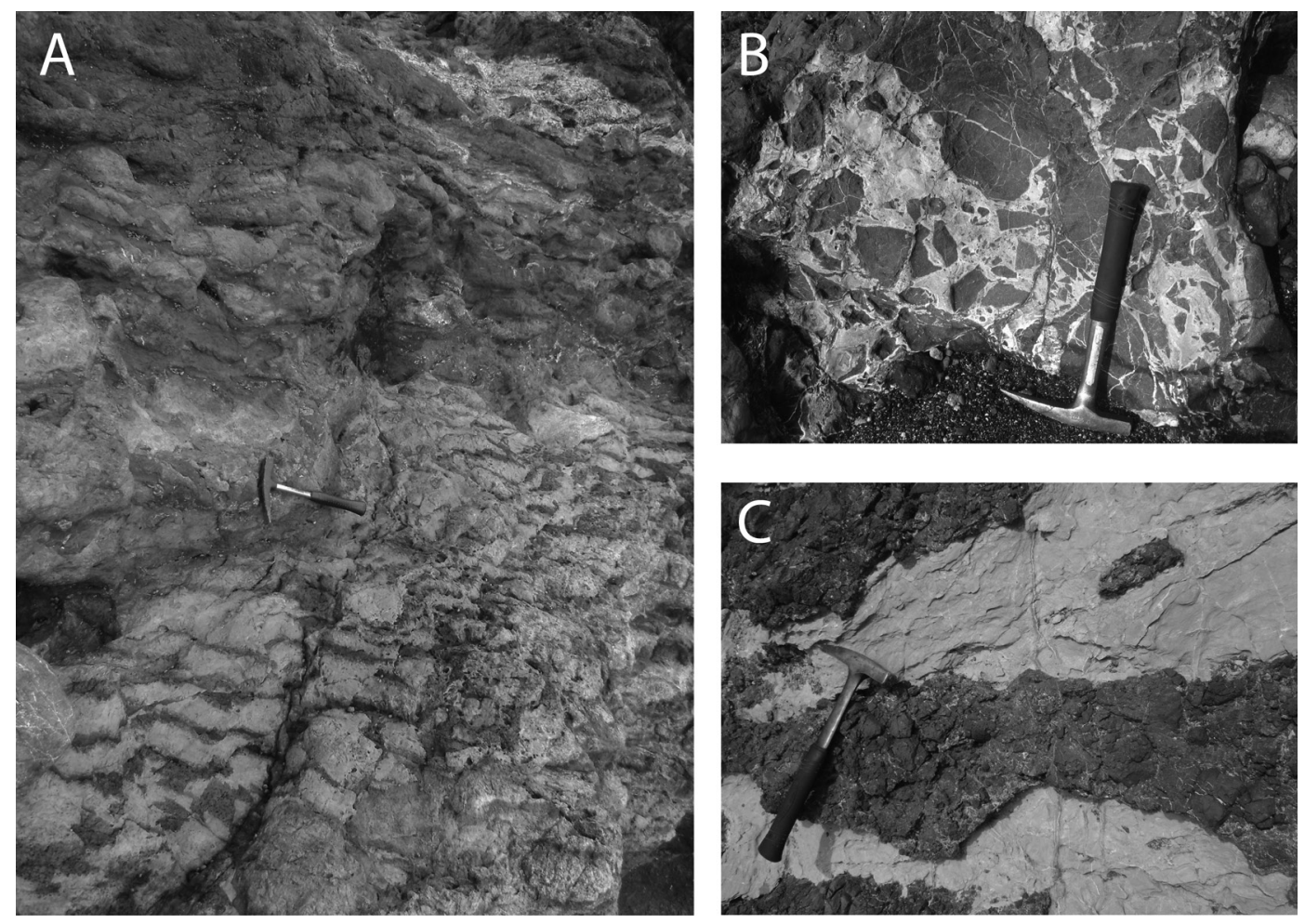

Fig. 3: A) Textura en "sal y pimienta" (megapeperita?) producto de la disrupción de las radiolaritas por efecto de la intrusión básica (extremo sur de playa Conchal, cerro el Encanto). B) Formación de peperitas blocosas por la intrusión de magma basáltico en sedimentos inconsolidados, con textura en rompecabezas indicativa de una fragmentación in situ por hidrofracturación (extremo oeste de playa Espadilla, punta Quepos). C) Delgadas intrusiones de composición basáltica en sedimentos (calizas pelágicas) del Paleoceno, con lentes de arenas hialoclastícas y contactos fríos pero no quemados (punta Quepos).

Superior al Paleoceno (Tournon, 1984; Berrangé et al., 1989). Se trata de flujos de lava en almohadilla basculados, algunos masivos, otros ricos en olivino, intruyendo a radiolaritas, deformándolas y desmembrándolas, con una clara decoloración en los clastos deformados en su borde externo, al contacto con las rocas volcánicas.

\section{Promontorio de Quepos (Paleoceno)}

Schmidt-Effing (1979) interpretó las mezclas de rocas que se observan al oeste de playa Espadilla como resultado de eventos volcánicos. En efecto, observaciones de campo detalladas, evidencian que dichos sedimentos ya existían al momento de que el vulcanismo se desarrollaba, lo que conllevó a interpretarlos como peperitas.
Excelentes ejemplos se observan en punta Quepos y en puerto Escondido. Las principales evidencias son la presencia de bordes fríos en algunos de los clastos basálticos (y menos frecuentemente picríticos) curviplanares a angulares, con la formación de arenas hialoclásticas verdosas (Fig. 4-B), la perturbación de la estratificación de los sedimentos pelágicos (calizas rosadas y blancas del Paleoceno, Fig.3-C), la existencia de estructuras de fluidización y de esquirlas con estructura en mosaico o rompecabezas. Todo esto como evidencias de peperitas blocosas (Fig.3-B), con evidencias claras de hidrofracturación. Sin embargo, también, las lavas en almohadilla suelen tener sedimentos interalmohadilla con hialoclastita entre-mezcladas y con la laminación pelágica claramente disturbada, indicativo que las calizas no obedecen a una lluvia pelágica tranquila pos-vulcanismo e intra-alhomadilla, 

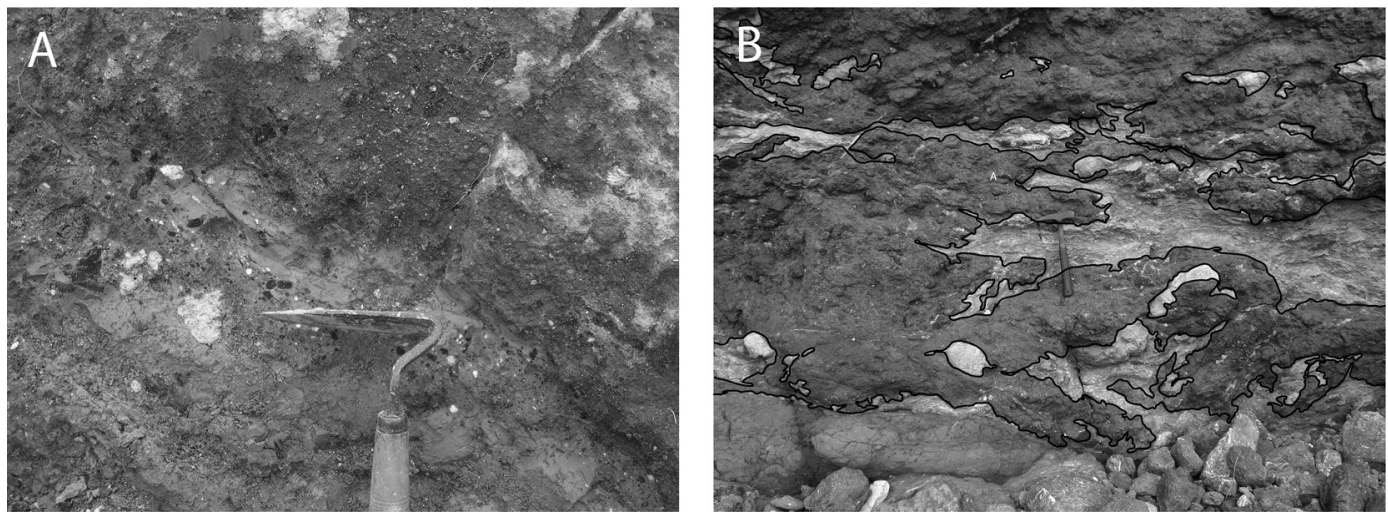

Fig. 4: A) Brecha volcano-sedimentaria entremezclada con una ignimbrita (lapilli pumíticos, escorias, en una matriz de ceniza (cerca de río Grande Palmares). B) Mezcla de dos cuerpos basálticos en sedimentos pelágicos, se aprecia como las calizas rosadas del Paleoceno son envueltas por el material ígneo (punta Quepos).

sino a una intrusión lobular intrasedimentaria, que permitió la disrupción de la laminación pelágica y su mezcla con hialoclastita. La interacción de la lava con los sedimentos húmedos, todavía plásticos, generó lavas en almohadillas, que suelen tener una apariencia brechoide, al grado que se les puede confundir con meras brechas basálticas producto de la erosión de estas lavas. Estos serían ejemplos de peperitas globulares.

\section{Cerro Minas (¿Oligoceno Superior-Mioceno Inf.?)}

Alvarado \& Gamboa (2008) describen los afloramientos de lavas del cerro Minas $\left(84^{\circ} 11^{\prime} 17.6^{\prime \prime} \mathrm{W} / 9^{\circ} 55^{\prime} 8.1^{\prime \prime} \mathrm{N}\right)$ o antiguo Tajo Bretaña, los cuales han sido descritos de una forma somera pese a corresponder con exposiciones excelentes desde hace al menos cuatro décadas. Las descripciones corresponden con dos cuerpos lávicos en el cerro Minas al SW de Santa Ana. Uno de ellos está representada por un roca de composición andesítica porfirítica algo silicificada en la base del tajo como apófisis entre epiclastitas (vulcanoruditas y vulcarenitas y tobas ácidas), estos sedimentos de coloración rojiza a morada se correlacionan con la Formación Pacacua. El otro cuerpo lávico corresponde con una roca de composición andesítica y textura fluidal-bandeada, localmente perlítica devitrificada?, con rampas de progresión "intruidas" por chimeneas de brechas de almohadillas y brechas hialoclásticas. Esta lava presenta en su contacto inferior con la Formación Pacacua, brechas hidroclásticas y peperitas, lo cual sugiere un emplazamiento subvolcánico dentro de los sedimentos. El contacto superior es igualmente con los sedimentos, pero no fue estudiado en detalle (Alvarado \& Gamboa, 2008). Las peperitas suelen ser brechosas al contacto con los sedimentos o globulares, emulando depósitos de flujos de lava en almohadillas (Fig. 5-B).

Estas lavas han tenido diferentes asociaciones litoestratigraficas y edades dependiendo del autor. Sin embargo, las evidencias descritas anteriormente hacen pensar en cuerpos subvolcánicos (criptodomo) que intruyeron a sedimentos inconsolidados y todavía húmedos de la Formación Pacacua (Mioceno Inferior), por lo tanto coetáneos (Alvarado \& Gans, 2012).

\section{Caldera-Mata de Limón (Oligoceno Superior- Mioceno Inferior)}

En un corte reciente de la ampliación de la carretera a Caldera $\left(84^{\circ} 41^{\prime} 29.1^{\prime \prime} \mathrm{W} / 9^{\circ} 55^{\prime} 15.5^{\prime \prime} \mathrm{N}\right)$ en la región del Pacífico Central, se observó un depósito de $5 \mathrm{~m}$ de espesor, compuesta por abundantes fragmentos pumíticos (tamaño de grano medio a grueso) y algunos clastos de lavas, flotando en una matriz vítreo-cristalina, que se interpreta 

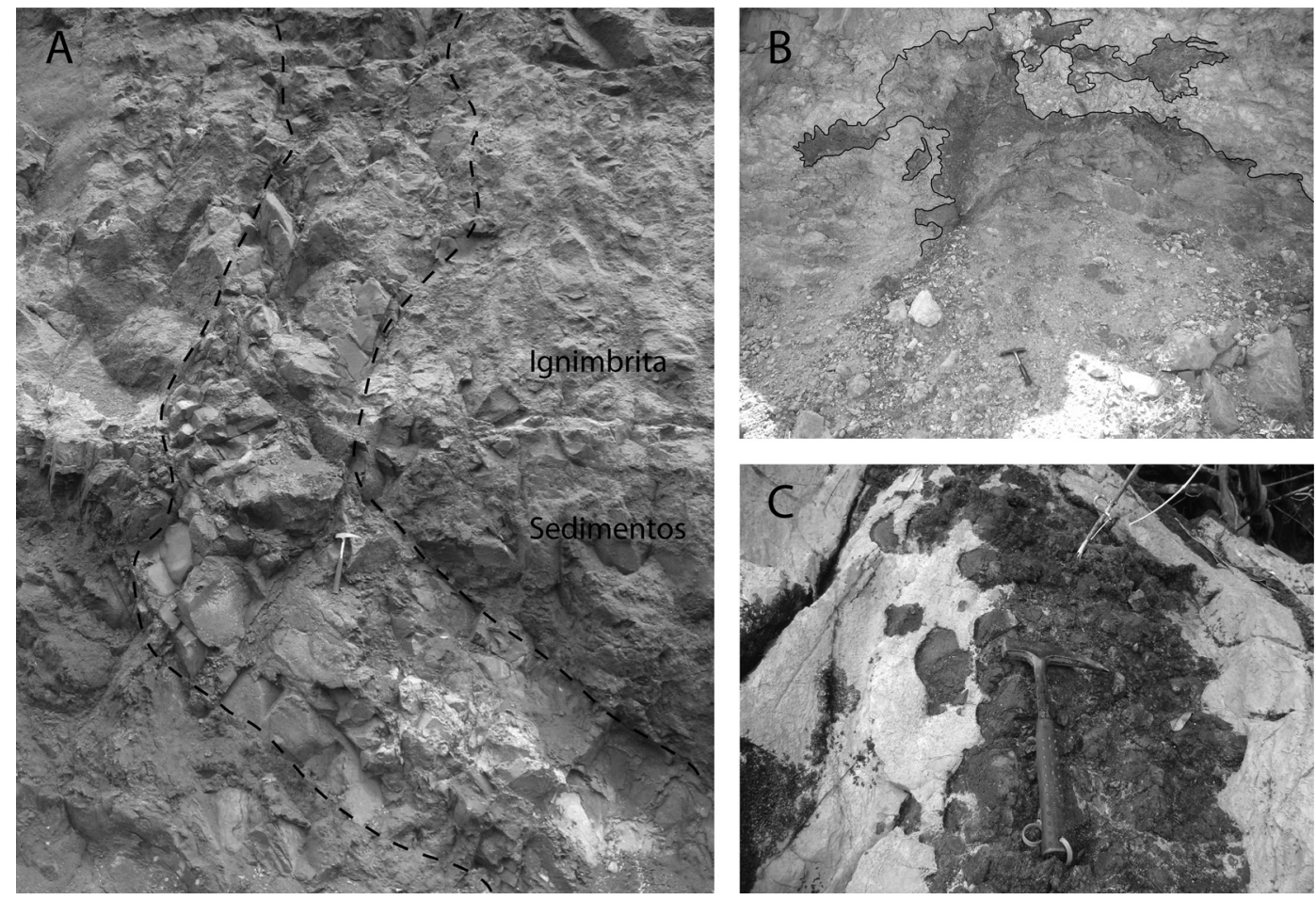

Fig. 5: A) Pipe peperítico, formado por la depositación de una ignimbrita sobre sedimentos fluiviales húmedos del Miembro Mata de Limón. Se observan clastos de los sedimentos rojizos dentro de la ignimbrita verdosa y viceversa (al este de Caldera). B) Sedimentos deformados, brechiados y mezclados con flujos de lava andesíticos (cerro Minas). C) Formación de peperitas con textura mixta por la intrusión de magma basáltico en sedimentos inconsolidados (punta Curupacha, cerca de Golfito).

como un deposito de ignimbrita. La existencia de troncos carbonizados dentro de la ignimbrita soporta la presencia de elevadas temperaturas. Este depósito sobreyace a lutitas y limolitas rojizas, que han sido interpretadas como de origen fluvial, asociado y cartografiado como el Miembro Mata de Limón (Denyer et al., 2003).

$\mathrm{Al}$ contacto entre ambas unidades, se observa como una estructura con forma de dique o chimenea, asciende y se visualiza como una brecha angular mal seleccionada de los fragmentos verdosos ignimbríticos con los sedimentos rojizos, así como un cambio en la decoloración de los sedimentos inferiores de rojizo a crema (Fig. 5-A). Esta estructura se interpreta como una brecha peperítica originada al depositarse la ignimbrita a elevadas temperaturas sobre un lecho de sedimentos todavía saturados en agua, originando una explosión hidroclástica con la consiguiente brechiación, intrusión y mezcla de los sedimentos húmedos dentro del depósitos piroclásticos, y la decoloración y perturbación del paquete de sedimentos rojizos hacia abajo.

Peperitas similares en rocas piroclásticas han sido descritas a nivel mundial, entre ellas en Australia en Mount Read Volcanics al oeste de Tasmania y al noreste de Honshu, en el distrito de Hokuroku, Japón (Gifkins et al., 2002).

\section{Carbonal (Mioceno Superior)}

En los alrededores del complejo turístico Papagayo $\left(85^{\circ} 38^{\prime} 6.5^{\prime \prime} \mathrm{W} / 10^{\circ} 39^{\prime} 53.5^{\prime \prime} \mathrm{N}\right)$ así como cerca de playa Naranjo $\left(85^{\circ} 38,28.2\right.$ " W/ $10 \circ 47,59.8 \% \mathrm{~N}$; $\left.85^{\circ} 37^{\prime} 50.3^{\prime \prime} \mathrm{W} / 10^{\circ} 39^{\prime} 15.5^{\prime \prime} \mathrm{N}\right)$ en el Parque Nacional Santa Rosa, al tope del depósito de flujo de lava dacítico de Carbonal (8 Ma, Alvarado \& Gans, 2012), que constituye en términos regio- 
nales la base de la Formación Bagaces, se observaron mesobrechas angulosas. Poseen contacto puntual a flotante, de espesor variable, algunas con contactos verticales con el depósito, que se presentan mezcladas con sedimentos de origen volcánico amarillentos, sobreyacentes. La mezcla ocurre a escala decimétrica hasta métrica y los clastos varían de tamaños desde milimétricos hasta decimétricos de formas angulares hasta subcurvilíneas e incluso diques clásticos. Se interpretan como brechas hidroclásticas, producto de un contacto hidro-explosivo entre la lava y los sedimentos fluviales sobreyacentes, fluidizando los sedimentos y destruyendo su estructura original. Todo parece indicar que corresponde con una intrusión subvolcánica somera, tipo criptodomo, posiblemente a lo largo de una fisura, bajo sedimentos fluviales volcánicos, aún húmedos.

\section{Lacustre Palmares (Pleistoceno Medio)}

En Palmares, cerca del río Grande, en un corte artificial para construcción a la par de la carretera Interamericana $\left(84^{\circ} 25^{\prime} 18.9^{\prime} \mathrm{W} / 10^{\circ} 4^{\prime} 57.6^{\prime} \mathrm{N}\right)$, se observa como un depósito de ignimbrita con escorias negras, presumiblemente asociada con la Formación Tiribí, que sobreyace al lacustre de Palmares. El contacto es difuso, a través de una brecha sedimentaria tobácea infrayacente, entremezclada con los lapilli pumíticos de la ignimbrita y su matriz de ceniza (Fig. 4-A). No solo se observan clastos sedimentarios angulosos incluidos, sino además, pequeñas intrusiones sedimentarias dentro del depósito de ignimbrita y algunas chimeneas de desgasificación, así como una tosca gradación inversa de los fragmentos de escorias, e incluso de pómez negras mezcladas con los sedimentos. No presenta un contacto quemado bien definido. Todos estos elementos son indicadores de que el depósito de ignimbrita se emplazó al tiempo que el lago aún existía.

\section{Casos posible o potenciales de peperitas}

\section{Cerro de La Muerte (Mioceno Inferior-Medio)}

En el cerro de la Muerte, Quintanilla et al. (2008) reportaron la presencia de posibles peperitas formadas por rocas andesíticas entremezcladas con sedimentos rojizos. Su existencia no sería de extrañar al visualizarse que las edades radiométricas de las rocas ígneas (tanto intrusivas como volcánicas) son contemporáneas con las edades de las rocas sedimentarias (MacMillan et al., 2004). Es por ello, que para la presente investigación, se realizó un reconocimiento geológico más de detalle para situar localidades con peperitas en la región del Cerro de La Muerte. Aunque la localidad específica no se encontró dentro de los taludes cambiantes por inestabilidad y cobertura vegetal, sí se localizó la zona en donde se hallaban los depósitos de flujos de lavas porfiríticos y los sedimentos rojos correlacionados con la Formación Pacacua, en los alrededores de la fila Uruca (aprox. $84^{\circ} 21^{\prime} 31.9^{\prime \prime} \mathrm{W} / 11^{\circ} 26^{\prime} 51.7^{\prime} \mathrm{N}$ ), en donde la carretera Interamericana corta dicha unidad (Alvarado et al., 2009b). También se cuenta con la muestra de mano que evidencia los contactos volcano-sedimentarios.

\section{Crucitas (Mioceno Inferior Tardío-Medio Tardio)}

En el prospecto aurífero de Crucitas, en la zona norte del país cerca de la frontera con Nicaragua, De la Cruz (1994) describe la existencia de peperitas relacionadas con intrusiones magmáticas de composición ácida e intermedia en sedimentos saturados en agua, sugiriendo la existencia de un posible ambiente lagunar intracaldérico. En dichos núcleos, aunque si bien es cierto se observaban sedimentos carbonáceos al contacto con las lavas, estructuras brechoides y 
contactos anómalos, no son claras las relaciones tridimensionales entre las unidades para asignarlas con facilidad el término de peperitas. Estos cuerpos volcánicos y subvolcánicos se asocian al Mioceno Inferior Tardío hasta el Mioceno Medio Tardío (Obando, 1995; Gazel et al., 2005).

\section{Volcán Irazú (Pleistoceno Superior)}

En las investigaciones realizadas por el ICE en el sitio de presa de Cachí (aprox. 8348'16.1'”/ $/ 9^{\circ} 50^{\prime} 26.8^{\prime}$ 'N), Umaña \& Afonso (1969) mencionan que el contacto inferior de la colada de Cervantes (procedente del cono Pasquí, volcán Irazú) con el lacustre infrayacente "está completamente impregnado con materiales plásticos que subieron a las fisuraciones e intersticios de la lava, presionadas por el peso litostático de la colada suprayacente." Ellos no hablan de un contacto quemado en dicho sector y por su descripción, resulta muy sugestivo el pensar de que los sedimentos aún estaban húmedos y que fueron deformados e intruyeron la lava a modo de peperitas.

\section{Volcán Poás (Holoceno)?}

El cráter activo del volcán Poás posee en su interior una laguna intracratérica termomineral hiperácida, de la cual existen espesos (varias decenas de metros) sedimentos tanto lacustrinos antiguos como recientes preservados en sus paredes y bordes de playa. En 1953 se formó un domo colada en el interior de la laguna, llegándose a secar temporalmente la laguna. Hoy día se logran reconocer parte del domo aún no destruido y el flujo de lava en las paredes de la nueva laguna caliente (Soto \& Alvarado, 1989). La existencia de un vulcanismo efusivo y estromboliano en 1953 dentro de un lago volcánico rico en sedimentos finos, hace de este sector un lugar ideal para la formación de peperitas. Desgraciadamente, el nivel actual de la laguna, su peligrosidad (continuas erupciones freáticas) y la alteración hidrotermal, dificultan la detallada observación de la base del flujo.

\section{CONCLUSIONES}

Se presentaron casos en Costa Rica de la inter-relación espacio-temporal entre el magmatismo básico (diabasas, basaltos) con sedimentos plásticos desde pelágicos (radiolaritas y calizas) del Jurásico-Paleoceno, hasta la coexistencia y brechiamiento de basaltos hasta dacitas con sedimentos continentales (sedimentos fluviales hasta lacustres) del Oligoceno Superior y del Mioceno. Las peperitas variaron desde sus tipos brechoides hasta globulares. Un probable caso potencial, histórico, podría corresponder con la erupción del Poás en 1953, en donde la efusión de un domo-colada dentro de la laguna termomineral hiperácida, podría haber desarrollado peperitas en su base.

Relacionados con algunas peperitas se presentan mineralizaciones de oro (p.ej. Crucitas) o posiblemente de cobre tipo malaquita (fila Uruca), o de amatista (cerro Minas), o inclusive alteración hidrotermal hiperácida reciente, como en el caso del domo-colada del Poás. Sin embargo, más estudios son requeridos al respecto.

Se espera que su descripción de campo, criterios de reconocimiento e interpretación, ayuden a reconocer más casos en América Central y su importancia para datar eventos magmáticos y sedimentarios, así como para la prospección de metales preciosos, dada la porosidad congénita de estas brechas y su cercanía con cuerpos dómicos ácidos y sectores con ascensos de fluidos hidrotermales sin y poseruptivos. Muchos más ejemplos de peperitas serán identificadas conforme las investigaciones avancen. 


\section{AGRADECIMIENTOS}

Se aprovecharon algunas giras del ICE y de la Escuela Centroamericana de Geología, para visitar casos conocidos y potenciales junto con el curso de Vulcanología (2009-2010) del I Semestre del IV año de la carrera. Discusiones con James White, fueron muy fructíferas. A Hugo Murcia, Carlos Borrego, Marcelo Arnosio y Teodosio Donaire por sus atinadas observaciones y discusiones al manuscrito y su terminología.

\section{REFERENCIAS}

ALVARADO, G.E., 1984: Aspectos petrológicosgeológicos de los volcanes y unidades lávicas del Cenozoico Superior de Costa Rica.- 183 págs. Univ. Costa Rica, San José [Tesis Lic].

ALVARADO, G.E. \& GAMBOA, D.G., 2008: Las lavas del Cerro Minas (Mioceno Inferior): Un ejemplo de cuerpos subvolcánicos coetáneos con la sedimentación de la Formación Pacacua.- IX Congr. Geol. Amér. Central, San José, Costa Rica: 58.

ALVARADO, G.E. \& GANS, P.B., 2012: Evolución tectono-magmática, metamórfica y metalogenética de Costa Rica, América Central.- Rev. Geol. Amér. Central, 46:7-22.

ALVARADO, G.E., DENYER, P. \& GAZEL, E., 2009a. Endeavor research into evolving paradigms around ophiolites: the case of the oceanic igneous complexes of Costa Rica.- Rev. Geól. Amér. Central, 40: 49-73.

ALVARADO, G.E., BARQUERO, R., TAYLOR, W., MORA, M., PERALDO, G., SALAZAR, G. \& AGUILAR, T., 2009b: Geología de la Hoja San Isidro, Costa Rica.Rev. Geol. Amér. Central, 40: 111-122.
BERRANGÉ, J.P., BRADLEY, D.R. \& SNELLING, N.J., 1989: K/Ar age dating of the ophiolitic Nicoya Complex of the Osa Peninsula, southern Costa Rica.- J. South Amer. Earth Sci., 2(1): 49-59.

BUSBY-SPERA, C.J. \& WHITE, J., 1987: Variation in peperite textures associated with differing host-sediment properties.Bull. Volcanol, 49:765-775.

DE LA CRUZ, R., 1994: Estudio de secciones estratigráficas. Sondajes CP-1 a CP-24, Proyecto Crucitas.- 68 págs. Placer Dome, San José [Inf. Interno].

DENYER, P., AGUILAR, T. \& ALVARADO, G.E., 2003: Geología y estratigrafía de la hoja Barranca, Costa Rica.- Rev. Geol. Amér. Central, 29: 105-125.

DENYER, P. \& BAUMGARTNER, P.O., 2006: Emplacement of Jurassic-Lower Cretaceous radiolarites of the Nicoya Complex (Costa Rica).- Geologica Acta, 4(1-2): 203-218.

DENYER, P., BAUMGARTNER, P.O. \& GAZEL, E., 2006: Characterization and tectonic implications of MesozoicCenozoic oceanic assemblages of Costa Rica and Western Panama.- Geologica Acta, 4 (1-2): 219-235.

DI MARCO, G., 1994: Les terrains accrétés; du sud du Costa Rica: Evolution tectonostratigraphique de la marge occidentale de la plaque Caribe de Costa Rica. -184 págs. Université de Laussane, Mém. Géologie, 20 [Tesis Ph.D.].

GAZEL, E., ALVARADO, G.E., OBANDO, J. \& ALFARO, A., 2005: Geología y evolución magmática del arco de Sarapiquí, Costa Rica.- Rev. Geol. Amér. Central, 32: 13-31. 
GIFKINS, C., McPHIE, J. \& ALLEN, R., 2002: Pumiceous rhyolitic peperite in ancient submarine volcanic successions.- J. Volcanol. Geotherm. Res. 114: 181-203.

GOËR DE HERVE, A., 2000: Peperites from the Limagne trench (Auvergne, French Massif Central: A distinctive facies of phreatomagmatic pyroclastics. History of a semantic drift.- En: LEYRIT, H \& MONTENAT, C. (eds): Volcaniclastic rocks from magmas to sediments.- Gordon \& Breach Sc. Pu, 91-110.

GURSKY, H.G. \& GURSKY, M.M., 1989: Thermal Alteration of Chert in the Ophiolite Basement of Southern Central America.En: HEIN, J.R. \& OBRADOVIĆ, J.A (eds.): Siliceous Deposits of the Tethys and Pacific Regions. Springer, Berlin: 217-233.

HAUFF, F., HOERNLE, K., VAN DEN BOGAARD, P., ALVARADO, G. \& GARBE-SHÖNBERG, D., 2000: Age and geochemistry of basaltic complexes in western Costa Rica: Contributions to the geotectonic evolution of Central America.- Geochemistry, Geophysics, Geosystems, 1(5): 1999GC000020, doi: 10.1029/1999GC000020.

MACMILLAN, I., GANS, P.B. \& ALVARADO, G., 2004: Middle Miocene to present plate tectonic history of the southern Central American Volcanic Arc.- Tectonophysiscs, 392: 325-348.

OBANDO, J., 1986: Sedimentología y tectónica del Cretácico y Paleógeno de la región de Golfito Península de Burica y Península de Osa, provincia de Puntarenas, Costa Rica.- 210 págs. Univ. Costa Rica, San José [Tesis Lic].
OBANDO, J., 1995: Estudio geológico del arco de Sarapiquí: Contribución a las nuevas exploraciones mineras en la región.135 págs. Placer Dome, San José [Inf. Interno].

QUINTANILLA, E.,ALVARADO, G.E., MARÍN, C. \& DURÁN, M., 2008: Estratigrafía de pozos como un aporte al conocimiento de la geología del Cuaternario del valle de El Guarco (Cartago), Costa Rica.- Rev. Geol. Amér. Central, 38: 53-64.

RIVIER, F., 1979: Geología del área norte de los Cerros de Escazú, Cordillera de Talamanca, Costa Rica.- Inf. Sem. IGN, 1972(1): 99132.

SCHMIDT-EFFING, R., 1979: Alter und genese des Nicoya-Komplexes, einer ozeanischen Palaokruste (Objura bis Eozan) im sudlichen Zentral-Amerika.- Geologische Rundschau, 68 (2): 457-494.

SCHMIDT-EFFING, R., 1980: Rasgos fundamentales en la historia del Complejo de Nicoya (América Central Meridional).Brenesia, 18: 231-252.

SCHWARZER, A. \& GURSKY, H.-G., 2007: Ophiolite breccias of the Nicoya Complex, NW Costa Rica - an overview.- Abstracts $20^{\text {th }}$ Colloquium on Latin American Earth Sciences, Kiel, Germany: 11-13.

SKILLING, I.P., WHITE, J.D.L. \& McPHIE, J., 2002: Peperite: a review of magma-sediment mingling.- J. Volcanol. Geotherm. Res., 114 (2002) 1-17.

SINTON, C. W., DUNCAN, R.A. \& DENYER, P., 1997: Nicoya Peninsula, Costa Rica: A single suite of Caribbean oceanic plateau magmas.- J. Geophys. Res., 102: 15507-15520. 
SQUIRE, R., McPHIE, J., 2002: Characteristics and origin of peperite involving coarse-grained host sediment.- J. Volcanol. Geotherm. Res. 114: 45-61.

SOTO, G. \& ALVARADO, G.E., 1989: Procesos volcánicos asociados con el agua subterránea. El caso de los volcanes Arenal y Poás, Costa Rica.- III Congreso Nacional de Recursos Hídricos, San José: 249-261.

TOURNON, J., 1984: Magmatismes du Mesozoique a l' Actuel en Amerique Centrale: L'example de Costa Rica, des
Ophiolites aux Andesites.- 335 págs. Univ. Curie, París [Tesis Ph.D.].

UMAÑA， J.E. \& AFONSO, P.S., 1969: Confección cortina de impermeabilización en lavas cuaternarias de la margen izquierda de la ampliación del proyecto de Cachí.- v +93 págs. Oficina de Geología, Inst. Costarricense de Electricidad, San José [Inf. Interno].

WHITE, J.D.L., McPHIE, J. \& SKILLING, I.P., 2000: Peperite: a useful genetic term.Bull. Volcanol. 62: 65-66. 


\title{
VOLCANO-ESTRATIGRAFÍAY TECTÓNICA DEL VALLE CENTRAL OCCIDENTAL Y LAS ESTRIBACIONES DE LOS MONTES DEL AGUACATE A LO LARGO DE LA RUTA 27, COSTA RICA
}

\author{
VOLCANO-STRATIGRAPHY AND TECTONICS OF THE WESTERN CENTRAL \\ VALLEY AND MONTES DEL AGUACATE ALONG ROAD 27, COSTA RICA
}

\author{
Hernán Porras $^{1 *}$, Monserrat Cascante ${ }^{1}$, Raquel Granados ${ }^{2} \&$ \\ Guillermo E. Alvarado ${ }^{3,4}$
}

${ }^{1}$ Departamento de Geología, FCFM, Universidad de Chile, Plaza Ercilla 803, Casilla 13518, Correo 21, Santiago, Chile

${ }^{2}$ Fundación de la Universidad de Costa Rica para la Investigación, San José, Costa Rica ${ }^{3}$ Instituto Costarricense de Electricidad, Apdo. 10032, 1000 San José, Costa Rica ${ }^{4}$ Centro de Investigaciones en Ciencias Geológicas, Apdo. 214-2060 San Pedro, Montes de Oca, Costa Rica *Autor para contacto: porrashernan@gmail.com

(Recibido: 10/07/2012 ; aceptado: 17/12/2012)

\begin{abstract}
Route 27, known as Ciudad Colón-Caldera Highway, offers excellent geological sections showing much of the volcanic and sub-volcanic stratigraphy of the western part of the Central Valley and the Aguacate Mountains foothills. Here a volcaniclastic succession correlated with the Grifo Alto Formation (Pliocene) is exposed. It consists of lavas, breccias and epivolcanic deposits (hyperconcetrated fluvial and debris avalanches deposits) that locally show strong propilitic alteration. In some places the succession is slightly to moderately tilted, faulted and cut by dykes. A series of old debris avalanche deposits is also present, related to the volcanic activity in the Aguacate Mountains. Locally, a series of monomictic mesobreccias units is exposed consisting of glassy andesitic blocks in a vitro-crystalline matrix ash interpreted as block and ash-flow deposits, which is probably coeval with the volcanic Monteverde Formation (Lower Pleistocene). At least, 4 units of debris flow/debris avalanche deposits are associated with Nuestro Amo Formation. At the upper part of the succession, several porphyrytic andesitic lava-flows, correlated to the Lower Colima Formation are followed by ignimbrites of the Puente de Mulas and Tiribí Formations, of middle Pleistocene age, containing hyperconcentrated fluvial-ignimbrite deposits with decreasing thicknesses. A propagation fold deforms these ignimbrites, indicating the existence of a thin-skinned type overthrust with a SW vergency, which was active since, at
\end{abstract}


least, the middle Pleistocene. The tilting of the rocks exposed along Route 27, the type of fracturing/faulting and folding, and the existence of some structural highs, is well explained with the thrust faulting model proposed in this article. Keywords: Route 27, Volcano-stratigraphy, tectonics, Occidental Central Valley, Río Grande Quadrangle, Costa Rica.

RESUMEN: La Ruta 27, también conocida como carretera Ciudad Colón-Caldera, ofrece cortes geológicos de entre 5 y $40 \mathrm{~m}$ de altura que muestran una buena parte de la estratigrafía, en su mayoría volcánica y subvolcánica, del extremo occidental del Valle Central y las estribaciones de los Montes del Aguacate. Se observa una secuencia volcánica correlacionable con la Formación Grifo Alto (Plioceno), profundamente hidrotermalizada (alteración propilítica) en varios sectores, compuesta por lavas, brechas y depósitos epivolcánicos, (depósitos fluviales de corrientes hiperconcentradas, depósitos de debris avalanches) algunos ligera a moderadamente basculados, cortados por diques. Una serie de depósitos de debris avalanches antiguos también está presente, relacionados con el vulcanismo de los Montes del Aguacate. Localmente, una secuencia de varias unidades de mesobrechas de bloques andesíticos vidriosos, monomícticos en una matriz de cenizas vitro-cristalina, se interpreta como posibles depósitos asociados a flujos de bloques y cenizas, posiblemente en correspondencia con un vulcanismo coetáneo con la Formación Monteverde (Pleistoceno Inferior). Al menos 4 unidades de depósitos de debris flow/debris avalanche del Pleistoceno Medio se asocian a la Formación Nuestro Amo (Pleistoceno Medio). Sobre ellos se presentan los pórfidos andesíticos de la Formación Colima Inferior, seguidos de las ignimbritas de las formaciones Puente de Mulas y Tiribí, todas del Pleistoceno Medio, las que contienen niveles ignimbríticos hiperconcentrados e intercalaciones fluviales con espesores decrecientes. Un pliegue de propagación, que afecta a estas ignimbritas, es considerado indicio de la existencia de una tectónica de cabalgamiento de tipo piel delgada con vergencia al SW, activa al menos desde el Pleistoceno Medio. Gran parte del basculamiento de las rocas expuestas a lo largo de la Ruta 27, su tipo de fracturamiento, fallamiento y plegamiento, y la existencia de algunos altos estructurales, se podría explicar por un sistema de corrimientos con componente de rumbo.

Palabras clave: Ruta 27, Volcano-estratigrafía, tectónica, Valle Central occidental, Hoja Río Grande, Costa Rica.

\section{INTRODUCCIÓN}

Desde hace varias décadas se tenía planificada la construcción de la carretera Ciudad ColonCaldera. En 1994 se le dio un fuerte impulso, para nuevamente sufrir retrasos a inicios del presente siglo. Esta nueva carretera agilizaría el paso hacia el Pacífico costarricense, dado que las dos rutas que existían eran prácticamente las mismas utilizadas desde la Colonia, la carretera de San José-EsparzaPuntarenas (Carretera Interamericana Norte, Ruta Nacional 1, tomando la Ruta Nacional 17) o la carretera San José-Atenas-Orotina (Carretera Interamericana Norte, Ruta Nacional 1, tomando la Ruta Nacional 3). Ambas rutas son serpenteantes, angostas, de fuertes pendientes y de una vía en cada sentido, por lo que no permiten un rápido flujo vehicular. La denominada Ruta 27 inició su construcción a finales del siglo XX, pero no fue hasta el 2010, en que finalmente se pudo inaugurar.

Dicha carretera, concebida para un mayor y más rápido flujo, debe poseer un trazado con curvas más amplias y pendientes menores. En un sector montañoso como el de los montes del Aguacate y en un país en donde no se suelen construir túneles, ello implica que los cortes de la carretera deben ser muy profundos para mantener estas condiciones. Con el objeto de mitigar el riesgo que implica la alta pendiente de los taludes, se debió recurrir a obras de "terraceo" y estabilización, con un incremento substancial en los costos de estabilización y de expropiación de terrenos.

Independientemente de las obras de ingeniería y su diseño, así como de la geopolítica y otros menesteres fuera de los objetivos del presente trabajo, los nuevos cortes de carretera permitieron observar con todo lujo de detalle una estratigrafía y estructura, que hasta ahora se encontraba mayormente oculta $\mathrm{y}$, en consecuencia, no del todo clara para este sector del Valle Central occidental y las estribaciones de los Montes del Aguacate. Por lo tanto, el objetivo principal de este estudio es analizar la estratigrafía, estructura y tectónica de la parte oeste del Valle Central. 


\section{ANTECEDENTES}

Dengo (1962) identificó la sucesión de rocas volcánicas que posteriormente se denominaría Grupo Aguacate. Castillo (1969) en la Hoja Abra y parte de la Hoja Río Grande estableció los primeros antecedentes estratigráficos Denyer \& Arias (1991), detallaron la estratigrafía, diferenciando cinco unidades, tanto de ambiente marino como volcánico.

Tournon (1984), Appel (1994) y Appel et al. (1994) aportaron los primeros antecedentes petroquímicos de las rocas volcánicas en los Montes del Aguacate e incluyen dataciones radiométricas que les permiten ubicarlas en el Plioceno superior. Marshall et al. (2003) y Pérez et al. (2006), realizaron análisis geoquímicos y dataciones radiométricas de las ignimbritas en parte de la Hoja Río Grande.

Méndez \& Hidalgo (2004) describieron la unidad debris avalanche del Coyol. Alvarado \& Gans (2012) compilaron las dataciones radiométricas de la hoja Río Grande y publican resultados inéditos.

\section{METODOLOGÍA}

Los trabajos de investigación geológica realizados incluyen la búsqueda y estudio de la literatura existente, levantamientos y descripción de cortes geológicos de carretera de la Ruta 27 y sitios vecinos, análisis de fotografías aéreas e imágenes satelitales, mapas y modelos de elevación digital, descripción de secciones delgadas y análisis de las estructuras principales. Para la geología en los alrededores del poblado de Turrúcares, se contó con trabajo de campo por parte de los autores, y con un mapa geológico inédito realizado por el ICE (1980).

Las ubicaciones de las estaciones geológicas fueron determinadas con GPS y referidas a puntos geográficos oficiales de los mapas del Instituto Geográfico Nacional, o identificadas con los nombres no oficiales (p. ej., peaje de San Rafael), o con los kilómetros demarcados en la Ruta 27, escritas con mayúscula por corresponder con una localidad (p.ej., km 42+300). Todas las localidades se encuentran en la hoja topográfica
Río Grande, a excepción de las que se especifica. Las coordenadas corresponden con la proyección WGS-84 Lambert Norte, con excepción de las figuras regionales donde también se incluyen las coordenadas geográficas. Se indica la coordenada norte seguida de la coordenada este.

Adicionalmente, la información analizada en este trabajo, incluye una base histórica de menos de 20 años de registro sistemático de los sismos ocurridos en la región (Red Sismológica Nacional). La mayoría de los sismos con una profundidad menor a $20 \mathrm{~km}$, ocurridos en la hoja Río Grande, a partir del año 1992 hasta 2010, están clasificaron en función de 3 parámetros fundamentales: la profundidad a la que se registra el sismo, el número de estaciones que lo registraron el sismo, las cuales deben ser como mínimo 4 y el valor RMS, el cual varía dependiendo de la profundidad del sismo y el número de estaciones, sin embargo, este último que se ha mantenido como valido varía entre 0,2 y 0,9 .

Se aplicaron métodos analíticos para extraer información acerca de la ubicación los quiebres en la pendiente (knickpoints) ubicados a lo largo de cauces de los ríos principales siguiendo las técnicas de Horton (1999), Whipple \& Tucker (2002), Tucker \& Whipple (2002) y Whipple \& Meade (2004).

\section{MARCO TECTÓNICO REGIONAL}

El istmo centroamericano ocupa una zona de deformación compleja que responde a la interacción de cuatro placas tectónicas (Caribe, Coco, Nazca y Suramericana) y la microplaca de Panamá (Sak et al., 2009), ver figura 1. La deformación en el antearco al sur de América Central se debe a la subducción rápida de la placa de Coco bajo la placa Caribe y el bloque Panamá (Corrigan et al., 1990; Gardner et al., 1992; Kolarsky et al., 1995; Marshall et al., 2000; Fisher et al., 1998, 2004).

A lo largo de la Fosa Mesoamericana de Costa Rica, la tasa de convergencia relativa aumenta hacia el sur, en el segmento de Nicoya es de $\sim 8,5 \mathrm{~cm} /$ año mientras para el segmento de Osa 9,1 cm/año (Dixon, 1993; DeMets, 2001). Al sur de Quepos, la convergencia Coco-Caribe es de 


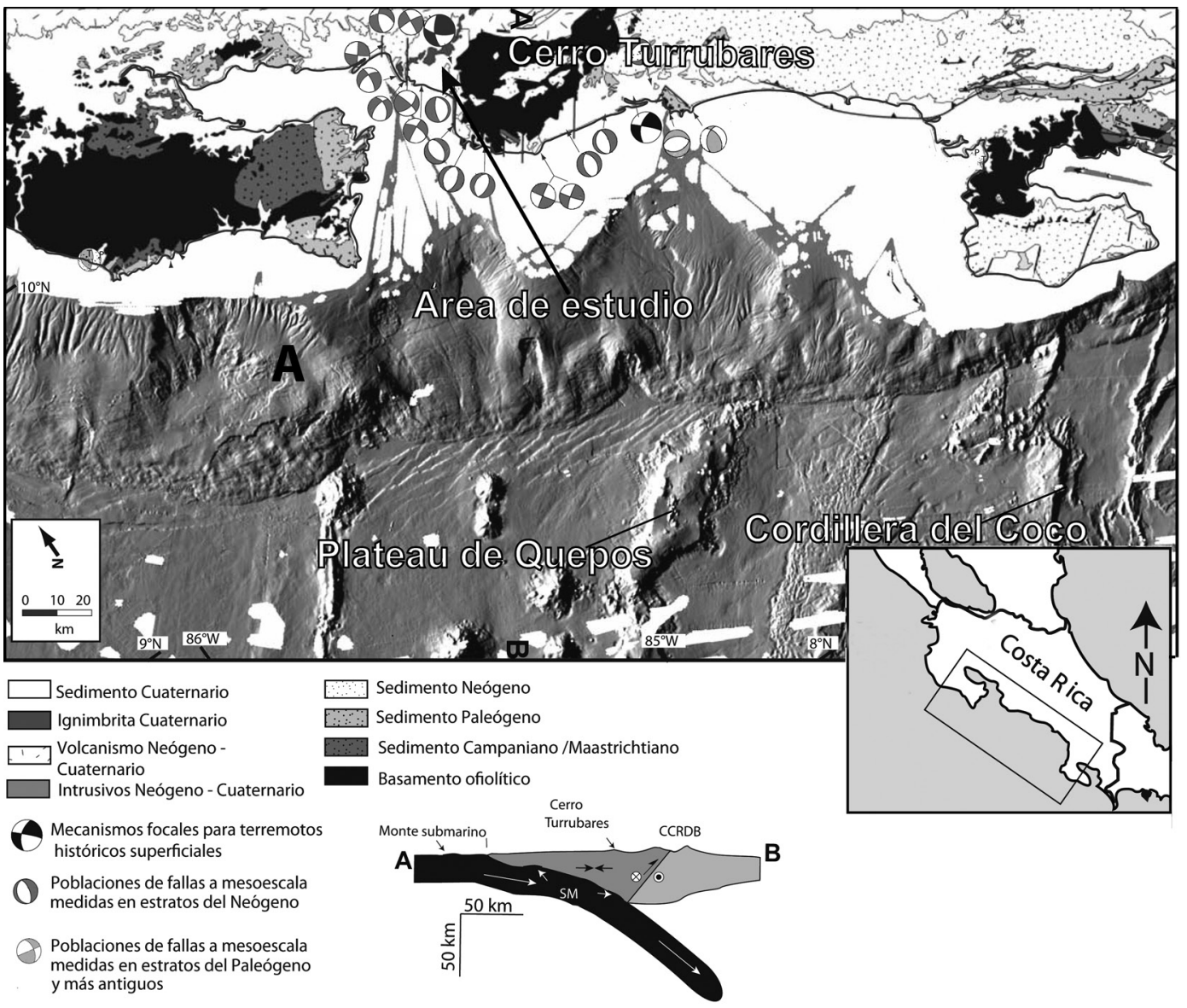

Fig. 1: Figura de ubicación regional, marco tectónico general del Istmo de América Central con las características tectónicas más importantes, modificado de Sak et al. (2009). El mapa muestra la batimetría en la región de la trinchera en América Central (Ranero et al., 2003), así como la geología de la zona del antearco (Sak et al., 2009), la distribución de las poblaciones de fallas a mesoescala de Marshall et al. (2000), Fisher et al. (2004) y Sak et al. (2009) y los mecanismos focales de terremotos de placa superior de Montero (1999) y Pacheco et al. (2006). Los mecanismos de los planos de falla representan los ejes de acortamiento y extensión de las poblaciones de falla mesoescala. Las estrías y morfologías de movimiento varían en función de la litología.

hasta $4 \mathrm{~cm} /$ año, esta mayor velocidad origina el desarrollo de una faja plegada y corrida en la Fila Costeña (Sitchler et al., 2007).

El cartografiado de la placa del Coco, mediante batimetría de alta resolución, revela una morfología áspera caracterizada por serranías y montes submarinos, que en gran parte corresponde con la cordillera del Coco (Kimura et al., 1997; Vannucchi et al., 2001, 2003). La rugosidad batimétrica de la placa del Coco cambia al sureste, donde se ubican una serie de montes sub- marinos cónicos, con una orientación oblicua de bajo ángulo relativo al vector de convergencia, los efectos de la subducción de la corteza rugosa se limitan a estrechas regiones a lo largo del margen (Fisher et al., 1998). Los montes submarinos exhiben bases amplias $(\sim 15-20 \mathrm{~km})$ y se elevan $>1,5$ $\mathrm{km}$ sobre el fondo del océano (von Huene et al., 1995, 2000).

La subducción (underthrusting) de la litosfera oceánica irregular, tiene un fuerte impacto en la morfología y la estructura del antearco, donde 
los máximos batimétricos entran en la trinchera y el eje de esta se desvía hacia el arco. Los montes submarinos en el antearco, presentan un sistema de fallas activas de alto ángulo en el margen oriental de la faja plegada y corrida de traspaís (Fisher et al., 1998; Marshall et al., 2000), en esta región se ubica el cerro Turrubares, el cual corresponde a un monte submarino acrecionado (Arias, 2003). La magnitud y distribución de la elevación durante el Cuaternario de la costa Pacifica sugiere que sólo puede ser debida al empuje de este monte submarino (Gardner et al., 1992.; Fisher et al., 1998; Gardner et al., 2001; Sak et al., 2004)

\section{GEOMORFOLOGÍA}

La zona de estudio constituye una región tectónica intra-montaña limitada al oeste por el cerro Turrubares y al este por el valle Central. A partir del análisis de imágenes satelitales, fotografías aéreas y cartografiado digital, se ha elaborado un mapa geomorfológico (Fig. 2), ya que el delimitar las unidades morfológicas ayuda a definir con mayor detalle las unidades litológicas presentes en el área.

\section{Unidad montañosa prominente}

Corresponde con los relieves positivos propios de los Montes del Aguacate, los cuales sobresalen sobre las áreas adyacentes, debido a que corresponden con relictos volcánicos constituidos por rocas del Plioceno. Las morfo-estructuras presentan formas agudas y pendientes abruptas, algún producto del fuerte tectonismo y de la alteración hidrotermal, que favorece los deslizamientos.

\section{Unidad de transición}

Se refiere a los sectores intermontanos ubicados entre las unidades morfológicas montañosas. Se extiende desde el frente montañoso del Aguacate hasta alcanzar el nivel base de erosión local, por lo general, corresponde con el río Grande de Tárcoles. En estas zonas de relieves importantes, se originan geoformas de acumulación, tales como depósitos producto de remociones en masa por colapso de edificios volcánicos (identificadas como depósitos de debris avalanches), abanicos aluviales y coluviales, en algunos casos afectados por la tectónica cuaternaria. Todavía se logran reconocer algunas lomas aisladas de la morfología hummocky dejada por los depósitos de debris avalanche. La litología predominante es muy variada, tanto textural como composicionalmente, dependiendo del área de procedencia.

\section{Unidad de planicie intermontaña}

Se ubica al este del área, contigua a la unidad de transición. Es una zona importante donde se origina la acumulación de materiales de depositación rápida. Se destacan los depósitos

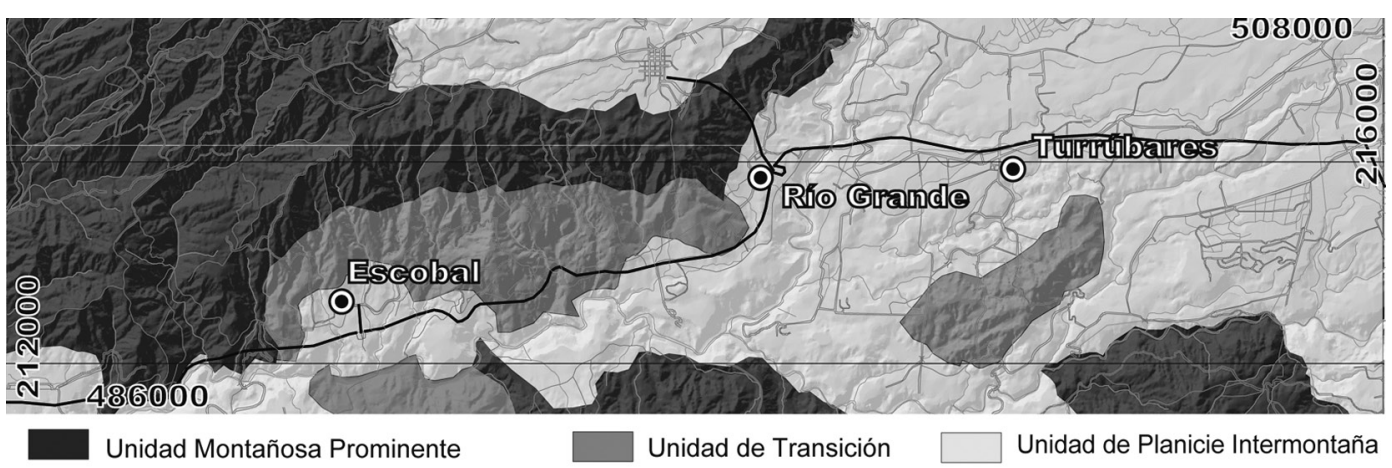

Fig. 2: Mapa geomorfológico de la zona de estudio. 
epivolcánicos del tipo debris flow/debris avalanche, con un considerable desarrollo areal, y las ignimbritas con un área reducida y limitada al occidente al cañón del río Grande de Tárcoles. La morfología característica de cada unidad estratigráfica facilita su trazado. Sin embargo, estas formaciones son depósitos cuaternarios y dificulta trazar con precisión las estructuras tectónicas presentes en el área.

\section{VOLCANO-ESTRATIGRAFÍA}

A continuación se describirán las principales unidades (Fig. 3), que se presentan en el mapa geológico (Fig. 4), iniciando de la unidad más antigua a la más joven.

\section{Formación Peña Negra y Formación Turrúcares}

Estas unidades sedimentarias afloran dentro del área, pero no a lo largo de la carretera, por lo tanto, se mencionan brevemente y no fueron estudiadas. Estas formaciones, aunque son claramente diferentes entre sí, sin embargo, para fines prácticos del presente trabajo, serán tomadas en cuenta por su importancia composicional y la relación que esta tiene en cuanto a la deformación presente en la zona.

La Formación Peña Negra fue definida por Denyer \& Arias (1991) como una secuencia de areniscas medias y finas, lutitas y areniscas finas con niveles concrecionales, intercalaciones de estratos delgados de tobas. Hacia la parte superior, las areniscas poseen mucha influencia volcánica y se vuelven de grano medio a grueso, con intercalaciones guijarrosas y estratos de caliza aislados. Su edad es miocena media (Fig. 3).

La Formación Turrúcares fue definida por Castillo (1969). Según Denyer \& Arias (1991), consiste de estratificaciones decimétricas a métricas de areniscas bioclásticas y volcanoclásticas, con capas de conglomerado ocasionales y

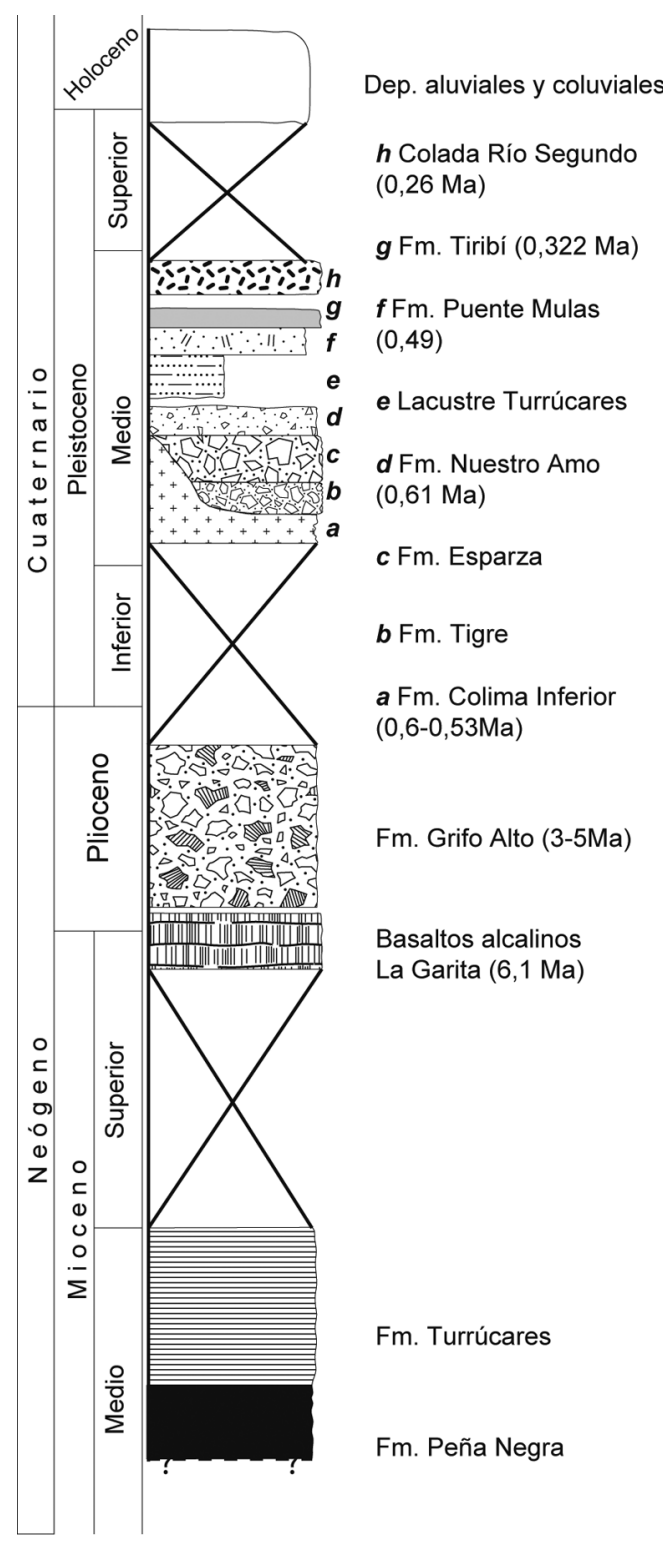

Fig. 3: Columna estratigráfica regional.

tobas intercaladas, culminando con areniscas que contienen corales arrecifales. Su edad es del Mioceno inferior cuspidal a Mioceno Superior alto (Fig. 3). 


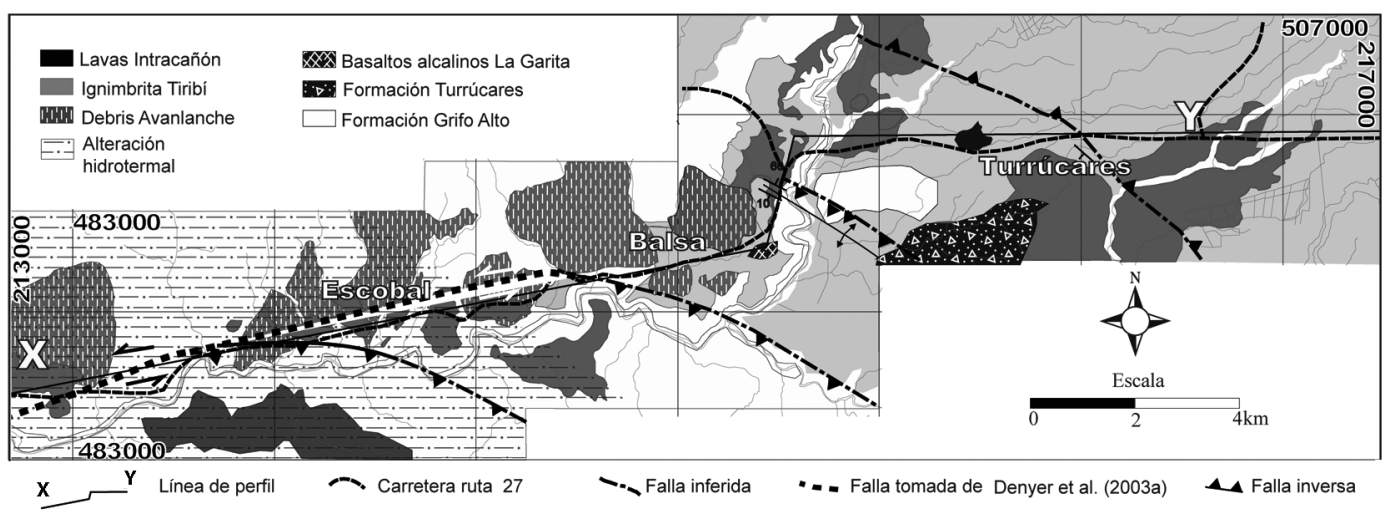

Fig. 4: Mapa Geológico del área aledaña a la ruta 27.

\section{Basaltos alcalinos La Garita}

Weyl (1969) describe por primera vez un basalto alcalino aflorando en el puente de La Garita. Recientes dataciones aportan edades de 5,52 $\pm 0,08 \mathrm{Ma}$ (Marshall et al., 2003) y en $6,47 \pm 0,21 \mathrm{Ma}$ (Gazel et al., 2009) y en 6,10 \pm 0,15 Ma (Alvarado \& Gans, 2012) (Fig. 3). En las cercanías de la localidad de Pan de Azúcar (214588/496423), se observaron basaltos porfiríticos, ricos en fenocristales de clinopiroxenos y olivinos, intruídos por filones de grano más fino, muy similares a las lavas alcalinas (basanitas, traquibasaltos y basaltos alcalinos) localizadas en el mencionado tajo, hoy día abandonado, contiguo al histórico puente La Garita.

\section{Formación Grifo Alto}

Dengo (1962) describió, en la quebrada Concepción, andesitas augíticas e hipersténicasaugíticas, coladas de basaltos iddingsíticos y abundantes brechas o aglomerados en la parte inferior, brechas andesíticas y tobas en la parte media, y tobas andesíticas y conglomerados andesíticos de matriz tobácea en la parte superior de esta formación. Sin embargo, no señaló la presencia de abundantes diques, que si fueron obser- vados por Appel (1990). Denyer \& Arias (1991), definieron la Formación Grifo Alto para aquellas rocas volcánicas no basculadas y del Plioceno, expuestas en los montes del Aguacate.

A lo largo de la Ruta 27, sin embargo, la Formación Grifo Alto aflora formando una sucesión inclinada $\left(\mathrm{N} 40^{\circ} \mathrm{W} / 30^{\circ}\right)$, constituida predominantemente por brechas volcánicas de diversos tipos, como las que se encuentran a la entrada de la localidad de Balsa (214329/496075), que están constituidas por fragmentos de pómez y de lavas, y depósitos aluvionales. Subordinadamente, contiene algunas coladas de lava.

La petrografía de una de estas lavas (muestra C-19: 213866/493685) corresponde con una andesita pórfiritica compuesta por grandes listones (hasta 1,3 cm de largo) de megafenocristales de plagioclasa $(13 \%)$, idiomórficas con golfos de corrosión, en una matriz intergranular de microlitos de plagioclasa, minerales opacos (1\%, mayoritariamente magnetita), así como calcita y algo de clorita secundarias. Es notoria la ausencia de piroxenos.

Se observa gran cantidad de mesobrechas volcánicas, coladas de lava y diques/sills, en algunos sectores con una profusa alteración propilítica (212200/487200 hasta 211361/483700). Claramente, los cortes de la carretera dejan entrever la estructura interna de un antiguo estratovol- 
cán, dada la concentración de cuerpos hipoabisales y la zonas con fuerte alteración hidrotermal ( $\mathrm{p}$. ej. quebradas Salitral y Concepción).

En el km 39+200 (213240/491100), se presentan coladas de lava muy meteorizadas y tectonizadas, con dique que buzan $\mathrm{S} 45^{\circ} \mathrm{W} / 15^{\circ}$. Cerca de allí, en el km 39+800 (212931/490853) se observan depósitos epivolcánicos (depósitos de flujos hiperconcentrados) representados por niveles pobremente estratificados, con fragmentos de 2 $\mathrm{cm}$ o menos y bloques casuales de hasta $25 \mathrm{~cm}$, el afloramiento presenta mala selección. Los estratos presentan un buzamiento aproximado de $15^{\circ} \%$ $\mathrm{SE}$, mientras que el dique que los intruye tiene un rumbo $\mathrm{N} 70^{\circ} \mathrm{E}$, buzando $60^{\circ} \mathrm{NW}$ (Fig. 4).

En el afloramiento ubicado en el $\mathrm{km} 47$ (211338/484572) se observa una zona de profusa alteración hidrotermal con fuerte olor sulfurado $\left(\mathrm{H}_{2} \mathrm{~S}\right)$, con rocas de colores café, anaranjados y grises con tonos azulados, en donde todavía se logra reconocer la roca madre, lavas algo basculadas y quizás rocas piroclásticas con textura perlítica, cortadas por fallas y fracturas con rumbo predominante $\mathrm{N} 15-25^{\circ} \mathrm{E}$, y unas pocas con rumbo $\mathrm{N} 55^{\circ} \mathrm{E}$. Esta zona, pudo haber sido parte de un acuífero geotermal fósil en ebullición o de fase vapor, donde las fracturas posiblemente fueron utilizadas en el pasado como conductos preferenciales (chimeneas) para el transporte de fluidos ácido-sulfatados, en donde la transformación del $\mathrm{H}_{2} \mathrm{~S}$ en $\mathrm{H}_{2} \mathrm{SO}_{4}$, y quizás la presencia de $\mathrm{HCl}$, causó lixiviación ácida y alteración argilítica, lo que se produce generalmente entre 100 y $300{ }^{\circ} \mathrm{C}$, dando como resultado una roca con un carácter poroso y un residuo silíceo. Durante los meses de enero y febrero del 2012, el afloramiento mencionado se cubrió por florescencias y masas de minerales amarillento-verdosos y blanquecinos que, posiblemente, corresponden a melanterita $\left(\mathrm{Fe}\left[\mathrm{SO}_{4}\right] \cdot 7 \mathrm{H}_{2} \mathrm{O}\right)$, de color verde pálido con matices blanquecinos, que se vuelven amarillentos por alteración. Se forma a partir de aguas sulfatadas muy saturadas y en un ambiente enrarecido de oxígeno, en yacimientos piritíferos alterados, donde la marcasita (también $\mathrm{FeS}_{2}$ ) se suele disgregar con más facilidad que la pirita, con la consecuente formación de sulfatos ferrosos y ácido sulfúrico, formando melanterita.
En otros sectores (p.ej., $\mathrm{km} \mathrm{44,}$ $212402 / 487330$ ) se presentan al menos tres unidades de brechas monomícticas, constituidas por $35-40 \%$ de bloques de lava grises, subangulares a subredondeados, desde $4 \mathrm{~cm}$ hasta 2 $\mathrm{m}$ de diámetro (predominantemente entre $5 \mathrm{~cm}$ y $35 \mathrm{~cm}$ ), con gradación inversa tosca, en una matriz vitro-cristalina blanco-amarillenta. El depósito se interpreta como un flujo de bloques y cenizas. La petrografía de uno de los bloques (muestra C-22: 212404/487230) corresponde con una andesita porfirítica vidriosa, compuesta por fenocristales de plagioclasa (30\%), clinopiroxenos $(3 \%)$, ortopiroxenos $(3 \%)$ y opacos $(3 \%)$, en una matriz intersertal de microlitos de plagioclasa, piroxenos, minerales opacos (magnetita) y vidrio café. Posee glomerofenocristales de plagioclasa, piroxenos y magnetita.

\section{Formación Colima Inferior}

Williams (1952) la llama como Lavas Intracañón. Fernández (1969), cambia a nombres geográficos designándola como Formación Colima. Echandi (1981) divide a la Formación Colima en Miembro Colima Inferior, Ignimbritas Puente de Mulas y Miembro Colima Superior.

La mayoría de las rocas expuestas se asocian a una secuencia espesa (al menos $160 \mathrm{~m}$ ) de lavas, rocas piroclásticas y epiclásticas, con edades de 0,75-0,59 Ma (Alvarado \& Gans, 2012). Corresponde con coladas andesíticas porfiríticas, vesiculares $(10 \%)$, ricas en megafenocristales de plagioclasa, correlacionables con Colima Inferior, las cuales se observaron en la coordenada 216355/500548. La petrografía de una colada (muestra C-13: 216355/500548) cubierta por 3 depósitos de debris flows/avalanche, corresponde con un pórfido andesítico, compuesto por grandes listones (hasta $1 \mathrm{~cm}$ de largo) de megafenocristales de plagioclasa $(25 \%)$, clinopiroxenos $(3 \%)$, trazas de posibles fenocristales de olivinos y ortopiroxenos $(0,5 \%)$ y opacos $(2 \%)$, en una matriz intersertal de microlitos de plagioclasa, clinopiroxenos, minerales opacos (magnetita) y vidrio.

Un único afloramiento anómalo de andesitas afíricas, las cuales no concuerdan con las lavas 
descritas antes y que por ese motivo se atribuyen más bien a la Formación Colima Superior, aflora bajo la ignimbrita de Tiribí cerca del poblado de Turrubares (fuera del área de estudio de la Fig. 4) una localidad bastante alejada de las lavas de Colima Superior (Alvarado \& Gans, 2012). Su estudio en detalle se dejará para trabajos posteriores.

\section{Formación Nuestro Amo}

Méndez \& Hidalgo (2004) describieron en la zona de estudio una mesobrecha con bloques de lava, tobas y brechas volcánicas de diferente composición, desde basaltos hasta andesitas, de grano grueso hasta fino, sanas e hidrotermalizadas, contacto flotante hasta puntual, a veces con estructura imbricada, en una matriz volcaniclástica color café a rojiza. Para Alvarado \& Gans (2012) la Unidad Coyol puede ser el equivalente de la Formación Nuestro Amo (Echandi, 1981) y la Formación Tivives (Madrigal, 1970) sería su equivalente distal. Esta última aflora, conforme nos acercamos a Esparza (p. ej., 211272/482947), bajo los depósitos aluviales de la Formación Tigre.

Cerca del peaje de ciudad Colón (hoja Abra, 218890/510369, sentido San José-Caldera, después de cruzar el río Virilla), al menos dos eventos que parecer de depósitos de debris flows (lahares), se presentan intercalados en un paleosuelo rojizo. La unidad superior, de unos $15 \mathrm{~m}$ de espesor, presenta bloques de lava $(4-100 \mathrm{~cm}$ de diámetro, normalmente $15-20 \mathrm{~cm}$ ) algo más frescos, con estructura compacta y masiva, incluidos en una matriz café claro rica en cristales de plagioclasa piroxeno y hornblenda. Cerca de allí (215769/509042), se observa que la unidad superior posee megabloques (métricos), algunos de hasta $12 \mathrm{~m}$ de diámetro, con estructura deformada y con inyección de matriz dentro de los bloques (diques sedimentarios), estructura en mosaico, bloques de lava fracturados, bloques de paleosuelos incorporados y deformados, sobreyaciendo igualmente a otro depósito más alterado a través de un paleosuelo. La matriz suele representar entre el 60 y el $80 \%$. En ciertos sectores todavía se preservan las morfologías de "hummocks". Las estructuras de estos depósitos se interpretan como de debris avalanche, aunque en ciertos sectores, poseen aspecto de un depósito de debris flow, lo que puede explicarse por una transformación de debris avanlanche a debris flow por incorporación local de agua (Fig. 2).

Similarmente, entre el km 20 y el km 23, cerca del Coyol (216536/507988; 216535/506162; 216485/505705), aflora un depósito clástico muy alterado con fragmentos de lava (10\%) de distintas litologías, meteorizados, de tamaños centimétricos y decimétricos, en una matriz de ceniza alterada. En algunos sectores (p.ej. km 23, 216484/505622) se observan dos o más unidades de espesor métrico, muy meteorizadas, que están plegadas y presentan niveles erosivos entre las fracciones finas en contacto entre ellas debido al movimiento de un flujo sobre el infrayacente. El llano plano-ondulado, sobre el cual se asienta el poblado de Escobal, está en su mayor parte compuesto por esta unidad.

Localmente, esta formación se encuentra subyaciendo a la Formación Tiribí (216302/508833), y sobreyaciendo a la Formación Colima Inferior (216315/500700). Alvarado \& Gans (2012) le confieren una edad de $\sim 0,61$ Ma.

\section{Lacustre de Turrúcares}

Sandoval (1966) describe la sucesión de sedimentos que conforma el lacustre de Turrúcares como sigue: unidad ácida (basal) formada por más de $30 \mathrm{~m}$ de sedimentos piroclásticos ácidos; unidad de diatomita compuesta por estratos de diatomita de variado espesor, generalmente 2 a 3 pies $(0,6$ a $0,9 \mathrm{~m})$, intercalados con estratos muy delgados (2 $\mathrm{cm})$ de sedimentos piroclásticos; sobre ésta unidad aparece un manto de sedimentos piroclásticos ácidos de aproximadamente $15 \mathrm{~m}$ de espesor formado por intercalaciones de estratos de cenizas, arenas y tobas de variado espesor. Brenes (1967), indica que en el área de San Miguel de Turrúcares el lacustre se encuentra constituyendo restos de cerros de diatomita que se explotan como tajos. De acuerdo con Sandoval (1966), la cuenca de sedimentación en la que se formó el lacustre de Turrúcares alcanzaba una superficie de aproximadamente $558 \mathrm{~m}^{2}$. En di- 
cho trabajo fue posible observar cerca de la población de San Miguel de Turrúcares, una secuencia de depósitos lacustres constituidos por capas de arcillas, diatomita, tobitas, areniscas pumíceas, con un espesor aproximado de $50 \mathrm{~m}$.

Alvarado \& Gans (2012) deducen por correlaciones regionales, que puede tener una edad entre 0,53 y $0,32 \mathrm{Ma}$, dado que parece que sobreyace a la Formación Nuestro Amo e infrayace a la Formación Tiribí.

\section{Formación Puente de Mulas}

Al oriente de Río Grande, en el km 28+500 (216580/499777), se observa una buena parte de la estratigrafía del Valle Central occidental, particularmente la Formación Puente de Mulas, dispuesta entre las formaciones Tiribí y Nuestro Amo. Bajo la Formación Tiribí y separada de ésta por un paleosuelo de algunos metros de espesor, que contiene bloques de lava, se presenta una ignimibrita que posee una parte superior masiva, pero no soldada, con escorias negras y una parte inferior con estructura prismática bien desarrollada, con pocos líticos y mucha matriz vítreo-clástica, color gris oscuro. Esta ignimbrita, que sobreyace a un depósito de debris avalanche (Formación Nuestro Amo) y se encuentra separada por un paleosuelo, está datada en el piso del Valle Central en 0,500,49 Ma (Alvarado \& Gans, 2012).

\section{Formaciones Tigre y Esparza}

Denyer et al. (2003a) definieron la Formación Tigre en los afloramientos de la calle El Tigre, e indican que está constituida por conglomerados y arenitas volcánicos, con clastos centimétricos de lavas e ignimbritas, así como de pómez gris y escorias, en una matriz crema hasta grisácea y arenosa, que representa el 60\% de la roca. La Formación Esparza, por su parte, representa el tope de la meseta de Esparza, caracterizada por depósitos lateríticos con bloques de lava, algunos completamente silicificados, estudiada originalmente por Madrigal (1970), y después por Marshall (2000), Marshall et al. (2003) y Denyer et al. (2003a).

En la Ruta 27, se observaron afloramientos de las Formaciones Tigre y Esparta, al oeste de la quebrada Salitral (211328/483082), en donde comienzan a aflorar los sedimentos epivolcánicos (aluviones y lahares), constituyendo la gran terraza de Esparza. Esta unidad está sobreyacida localmente por las facies distales de la Formación Tiribí, llamadas localmente como Formación Orotina (p. ej. 211422/483244, hoja Barranca 211135/481259). Corresponden con depósitos fluviales, principalmente lentes de gravas, conglomerados, arenas y tobitas, con estructuras de erosión y relleno, acuñamientos laterales, tanto masivos como estratificados, correspondiendo con depósitos de debris flows, hiperconcentrados y de escorrentía superficial tranquila, producto del antiguo sistema fluvial del río Grande de Tárcoles y sus tributarios. Sus componentes suelen ser lavas de diversos tipos, guijarros de cuarzo de los Montes del Aguacate y minoritariamente ignimbritas.

Se sabe que estas formaciones sobreyacen a la Tivives (equivalente de Nuestro Amo) e infrayacen a la Tiribí, y puesto que la Formación Tigre está compuesta de clastos de ignimbritas (ver Denyer et al., 2003a; Alvarado \& Gans, 2012) debe de proceder posiblemente de la erosión de la Puente de Mulas u alguna equivalente, por ello, la edad de estas unidades estará comprendida aproximadamente entre 0,49 y $0,32 \mathrm{Ma}$.

\section{Formación Tiribí}

La ignimbrita de la Formación Tiribí, datada en $322 \pm 2$ ka (Pérez et al., 2006), se observa en varios sectores, ya sea constituyendo mesetas o bien como rellenos de paleo-canales. Presenta dos facies bien diferenciables, previamente descritas con detalle para otras localidades y para parte del área de estudio por Pérez (2000) y Pérez et al. (2006): a) la facies de brechas y de ignimbritas ricas en fiammes y bombas decimétricas (pómez vesiculares negras), color gris oscuro, típica de los alrededores de La Garita-Río Grande, y b) las 
facies bien soldadas, color gris claro, similares a un sillar, denominadas de Orotina.

Se encuentran facies con grandes escorias o bombas negras (5-15\%), decimétricas, normalmente $5-50 \mathrm{~cm}$ de diámetro; excepcionalmente de

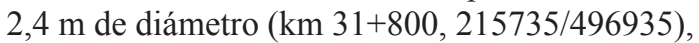
algunas con bordes vidriosos, otros verdaderos clastos de obsidianas (p.ej. 216595/508420), con líticos no juveniles (10-30\%) de hasta 20 $\mathrm{cm}$ de diámetro, representan el $20-25 \%$ del depósito, en una matriz (55-85\%) de ceniza rica en trizas de vidrio, cristales (predominantemente plag + cpx+opx) y detritos de lavas pre-existentes, color gris a gris oscuro.

Las facies soldadas, masivas, algunas con disyunción columnar, se presentan algo desvitrificadas, lo que les imprime un carácter similar a un sillar. Afloran en las partes más planas cercanas a la costa pacífica y suelen rellenar paleocanales pequeños (p. ej 216467/505629; 216170/497096; 211422/483244, hoja Barranca 211135/481259). Sus espesores varían entre 3 hasta $15 \mathrm{~m}$.

Localmente, la ignimbrita Tiribí sobreyace a la mayoría de las formaciones previas: Esparza (213077/489596), Nuestro Amo (km 28+700, 216337/498565), así como a aluviones antiguos (211422/483244) e inclusive a Colima Inferior $(\mathrm{km} 28,216419 / 500330)$ y Puente de Mulas (km 28+500, 216580/499777).

En otros sectores, se observan varias unidades de depósitos de flujos piroclásticos, separadas por tobas y por depósitos de retrabajo, que corresponden a arenas guijarrosas no consolidadas, compuestas por vidrios, pómez negra y clastos de lava (p.ej. 215036/496789). En dicha localidad, la ignimbrita inferior es un flujo de escorias y cenizas con escorias de $10 \mathrm{~cm}$ de diámetro, flotando al tope, existiendo escorias más pequeñas de 3 a $5 \mathrm{~cm}$, algunas con bandeamiento (mezcla de magma), algunos fragmentos de pómez blancos de 1 a $2 \mathrm{~cm}$ y pocos líticos en una matriz que representa el $80 \%$. Sobreyaciendo a este nivel, se presenta un depósito fluvial formado por el retrabajo de dicha ignimbrita, que se inicia con $10 \mathrm{~cm}$ de arenas guijarrosas, escorias y pómez, con algunos líticos, mal seleccionado, con laminación paralela y ondulante, y fuertes acuñamientos; algunos niveles presentan concentración de guijarros y escorias. Seguido concordantemente, se presenta una toba café con algunos niveles de escorias y particularmente reconocible por ser rica en lapilli acrecional (10 $\mathrm{cm})$. Le sigue un nivel de $22 \mathrm{~cm}$ de conglomerados guijarrosos con fragmentos de escorias centimétricas, pómez, arenas, líticos de lavas. Finalmente, previo bajo la ignimbrita superior, existe una toba de grano medio, gris, de unos 15 $\mathrm{cm}$ de espesor, seguida por el paquete espeso de arena guijarrosa mal seleccionada, pobremente estratificada, compuesta por guijarros de escoria, pómez y líticos, que presenta una laminación acuñada bien marcada.

\section{Colada de Río Segundo}

Fueron descrita y definidas por Echandi (1981) como coladas de Cebadilla y de San Antonio, como parte de la Formación Barba, aunque en dichas localidad, también afloran depósitos de debris avalanche, por lo que Alvarado \& Gans (2012) prefieren llamarlas de río Segundo, dado que allí se manifiesta sin ninguna duda como una lengua, que morfológicamente sobresale del relieve circundante.

Cerca del río Segundo (hoja Abra, 215322/509490), a unos 3,5 km al SW de Ojo de Agua, se presenta una colada andesítica-basáltica (unos $6 \mathrm{~m}$ de espesor), con vesículas estiradas paralelamente a la horizontal y algo de disyunción columnar. La colada sobreyace a un paleosuelo rico en bloques de lava, producto de la alteración de un lahar antiguo (Formación Nuestro Amo). La petrografía (muestra C-04: 215392/509418) corresponde con un basalto vesicular compuesto por fenocristales de plagioclasa (10\%) con inclusiones de minerales, clinopiroxeno (6\%), olivinos $(5 \%)$ idiomórficos, algunos iddingsitizados, ortopiroxenos $(2 \%)$ y opacos $(3 \%)$ en una matriz intergranular de microlitos de plagioclasa, piroxenos y minerales opacos (magnetita).

En efecto, estas extensas lenguas de lava, se extendieron de manera serpenteante por el piso volcánico, directamente sobre la ignimbri- 
ta Tiribí hacia el sector de La Reforma, y sobre Formación Nuestro Amo, siendo el evento efusivo más reciente del piso volcánico del Valle Central. Están datadas por ${ }^{40} \mathrm{Ar} /{ }^{39} \mathrm{Ar}$ en 0,27 0,26 Ma (Alvarado \& Gans, 2012).

\section{ANÁLISIS CUANTITATIVO DE LA TASA DE INCISIÓN SOBRE EL RÍO GRANDE DE TÁRCOLES}

Se hizo la diagramación logarítmica de la elevación con respecto a la longitud del cauce relacionando la erosión y los puntos de perturbación a lo largo del cauce del río denominados knickpoints. Estos se definen como una región escarpada a lo largo del perfil de un río que pueden variar desde una cascada a una región de alto gradiente que se extiende por varios kilómetros. (e.g., Horton, 1999; Whipple \& Tucker, 2002; Tucker \& Whipple, 2002 y Whipple \& Meade, 2004). Ver figura 5.

La línea de mayor concavidad, representa el perfil inicial del río y la de menor concavidad corresponde con el perfil de equilibrio, los distintos cambios de pendiente son la evidencia de una perturbación en los diferentes estados de erosión, el cual puede relacionarse con un rasgo tectónico o con la presencia de una litología resistente a la erosión (Whipple \& Tucker, 2002). Ver figura 6.

Se ha definido la longitud de los cauces con respecto a distancias especificas, el río Grande de Tárcoles corresponde a la distancia a lo largo del cauce entre $\mathrm{T}^{1} \mathrm{y} \mathrm{T}^{2}, \mathrm{G}^{1}$ y $\mathrm{G}^{2}$ es la distancia a lo largo del cauce del Río Grande y $\mathrm{V}^{1}$ y $\mathrm{V}^{2}$ la longitud del cauce del río Virilla (Fig. 6).

Estos son los tres ríos principales que atraviesan el área de estudio, es posible observar la curva de erosión normal del río sin variación significativa. Sin embargo, se observan cambios en la pendiente de la curva que corresponde a los knickpoints que indican los sitios en los que se generan anomalías en el cauce. El hecho de que los knickpoints, tengan altura similar en los diferentes afluentes, son un punto de apoyo para la ubicación de las estructuras tectónicas.

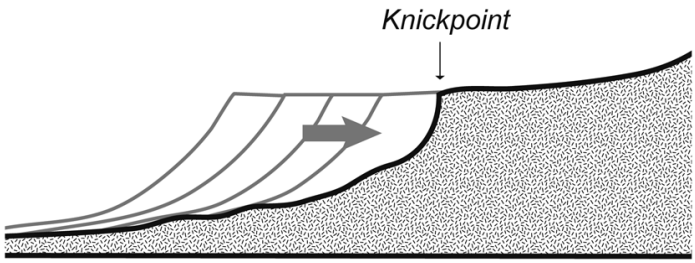

Fig. 5: Perfil esquemático del retroceso del cauce. El knickpoint define el límite móvil entre el ajuste y la porción del canal relicto. Los perfiles de color gris demuestran cómo ha migrado el perfil aguas arriba. Las flechas indican la dirección de retirada del knickpoint. Modificado de Whipple \& Tucker, (2002).

\section{SISMICIDAD EN LA HOJA RÍO GRANDE}

Los registros de eventos sísmicos localizados en la hoja Río Grande e incluidos en el presente trabajo, están basados en la información histórica documentada de sismos de baja intensidad ocurridos en esta región brindan una idea difusa sobre la ubicación de las estructuras presentes en la zona, sin embargo, arroja algunas evidencias sobre el comportamiento de las estructuras en profundidad. Montero (1999) establece los mecanismos focales para la región de tipo inverso con componente de rumbo (Fig. 1). La distribución de estos sismos se aprecia en un perfil W-E, (Fig. 7).

Se destaca el hecho de que una cantidad importante de los sismos de toda la región se generan a una profundidad bastante acotada entre los 0-10 km, dejando entrever esta profundidad como la posible zona de despegue del sistema de corrimientos regional del área. En el área mas restringida de nuestro estudio, la profundidad a la cual se generaron estos sismos no supera los $6 \mathrm{~km}$. Esto apoyaría la existencia de un nivel de despegue local somero, que de acuerdo con Montero (1999) sería de componente inversa con un movimiento sinestral.

\section{GEOLOGÍA ESTRUCTURAL}

Se ha observado una serie de zonas de falla cortando las rocas de la Formación Grifo Alto. Además se aprecian estructuras sintectónicas 

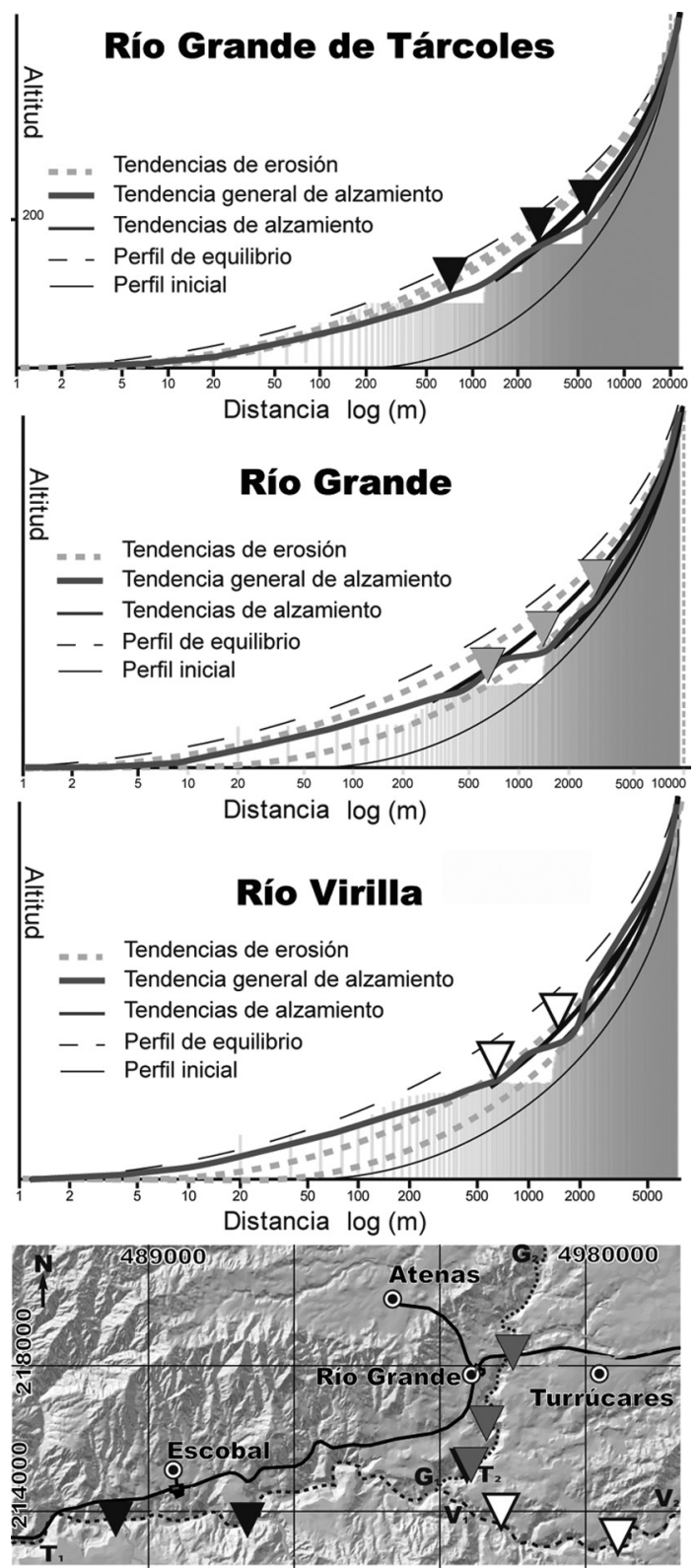

Fig. 6: Perfil de la propagación de los ríos Grande de Tárcoles, Grande y Virilla. Los triángulos indican los posibles knickpoint, para cada cauce, estos puntos se encuentran representados geográficamente en el mapa inferior. $\mathrm{T}^{1}$ y $\mathrm{T}^{2}$; es la distancia medida a lo largo del cauce del Rio Grande de Tárcoles, $\mathrm{G}^{1}$ y $\mathrm{G}^{2}$; distancia medida a lo largo del cauce del Río Grande, $\mathrm{V}^{1} \mathrm{y} \mathrm{V}^{2}$; distancia medida a lo largo del cauce del río Virilla. deformando los depósitos de ignimbrita de la Formación Tiribí y en algunos casos cortando los depósitos de debris avalanche. Las evidencias de campo sugieren, la existencia de un patrón estructural más complejo que el propuesto hasta la fecha. Se realizó un análisis metódico de los datos obtenidos in situ, para correlacionarlos con los datos obtenidos mediante el procesamiento digital de fotografías aéreas, los modelos numéricos de elevación digital de la zona y el registro sísmico histórico de la hoja Río Grande.

El análisis determinó la existencia de fallas inversas de bajo ángulo, con un estilo de deformación de piel fina (thin skinned), dado que no involucran el basamento durante deformación, la poca longitud de onda que muestran los pliegues en las secciones y porque se involucra un delgado espesor de capas (Rodgers, 1971), además un criterio indirecto estaría dado por la sismicidad de la zona ya que rara vez supera los $10 \mathrm{~km}$ de profundidad.

\section{ANÁLISIS ESTRUCTURAL}

se toma en consideración el contexto de los actuales modelos de tectónica horizontal o alóctonos para deformación en los niveles de la corteza superior, las fallas de alto ángulo se tornan horizontales en profundidad hacia un nivel de despegue principal (Coward, 1983, Erslev, 1986; Narr $\&$ Suppe, 1994). Para su estudio es necesario considerar tres factores fundamentales, estos son: la geometría de la falla principal, el comportamiento mecánico del basamento y la respuesta de la cobertura sedimentaria (Narr \& Suppe, 1994). Con respecto a la geometría, se pueden diferenciar fallas planares, ya sea con buzamiento constante o con inflexiones y fallas lístricas, cilíndricas o con curvatura variable (Erslev, 1986; Turienzo, 2005).

Referente al comportamiento mecánico, hay que tomar en consideración la deformación de las rocas del basamento, en donde se asume una disminución en el buzamiento en las fallas, el cual en nuestro caso es río arriba, generalmente asociadas a fallas de bajo ángulo, que generan 


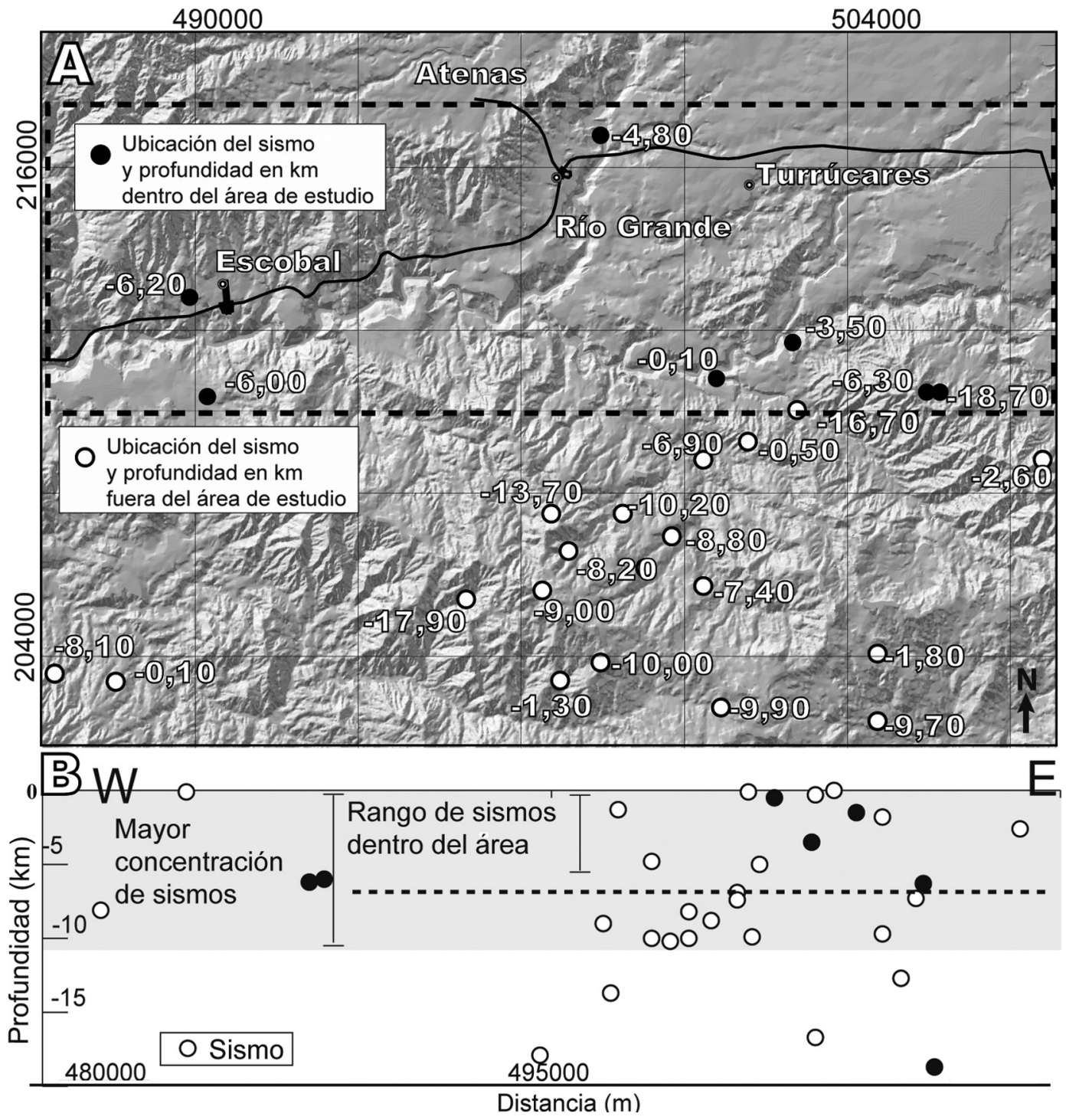

Fig. 7: A. Mapa de ubicación de los principales sismos registrados desde el año 1999 al 2002, se destaca la ubicación del sismo y la profundidad. B. Perfil de los sismos registrados, se observa como la mayoría se concentra en una profundidad menor a los 10 $\mathrm{km}$, en el área de estudio estos no superan los $6 \mathrm{~km}$ de profundidad.

un anticlinal por flexión en falla (fault-bend anticline; Narr \& Suppe, 1994, y Mitra \& Mount, 1998), y se modelan acortamientos y engrosamientos de las capas, que indican compresión, aunque puede ocurrir extensión asociada al acomodo de los bloques principales (Narr \& Suppe, 1994; Erslev 1986; 1991, Erslev \& Rogers, 1993).

Para el análisis se midieron rumbo e inclinación de los estratos en cada localidad, la orien- tación de planos fallas, estrías de falla, y ejes de pliegues. Esta información se combinó con la información obtenida de los knickpoints, con el fin de trazar con mayor precisión las fallas que atraviesan la zona de estudio. Se llegaron a definir cuatro fallas o estructuras mayores, las cuales corresponden con la zona de falla Escobal, la zona de falla Balsa, falla Río Grande y la falla Turrúcares. Asociado a la falla Balsa se determi- 
nó la posible existencia de un pliegue de orientación NW-SE y de fallas cuatro fallas principales, con dirección NW-SE, obteniéndose el mapa estructural de la figura 8 .

Las fallas propuestas Turrúcares, Río Grande, Balsa y Escobal, son paralelas entre sí Asociadas a la falla Balsa, se determinó la existencia un pliegue con eje de orientación similar a la de la falla. En una primera etapa de análisis de los datos, la interpretación se basó en el principio básico de que, la dirección y el sentido del movimiento observados sobre el plano de falla (definidos por la estría), son paralelos al esfuerzo de cizalla máximo resuelto sobre el plano de falla.

El análisis de las estrías no permitió determinar el tensor de stress, debido a que estas fueron medidas en menos de cuatro fallas, sin embargo, la dirección de empuje o transporte tectónico deducida a partir de la orientación de las fallas y ejes de pliegues asociados permite señalar que éste fue hacia el NE.

\section{Falla Turrúcares}

El análisis de los knickpoint permitió identificar un lineamiento asociado a anomalías en la red de drenaje, que permiten inferir un alzamiento de falla inversa con orientación NW-SE.

La presencia de esta estructura, se interpreta con base en anomalías en la red de drenaje y morfológicamente se manifiestan con un mayor grado de incisión en los cauces y el desarrollo de pequeños arroyos tributarios sobre el bloque elevado (Fig. 8). La interpretación de esta falla es consistente con la zona de fractura inversa observada cerca de la represa la Garita. Está cortando los depósitos volcánicos de la Formación Grifo Alto y se habría iniciado la deformación en los depósitos del Plioceno y Pleistoceno.

\section{Falla Río Grande}

En este sitio, cercano al peaje de Río Grande, en Atenas $(215,013 / 496,772)$ se encuentran los depósitos de la Formación Tiribí y posiblemente los de la Formación Puente de Mulas, las cuales presentan un plegamiento asimétrico y de tipo chevron. Su superficie axial se ubica en dirección NW-SE, se caracteriza por mostrar el flanco frontal con un buzamiento bastante elevado mientras que el flanco trasero/dorsal tiene un buzamiento más suave (Fig. 9a), indicando una vergencia hacia el NE.

Se reconocieron estructuras sintectónicas en el flanco trasero del pliegue generando estructuras en del tipo estratos de crecimiento en sobreposición (overlap), lo que sugiere que la deformación y consecuente levantamiento son más acelerados que la sedimentación (Fig. 9b). Estas estructuras indican que la falla estaba activa entre la depositación del primer flujo piroclástico y el siguiente. Sobre el flanco trasero del pliegue es posible observar pequeños grábenes en las ignimbritas, producto del acomodo tensional del pliegue progradante. La cinemática de deformación que más se ajusta con los datos obtenidos es la de pliegues por propagación de falla, asociados directamente a la presencia de una falla, tal y como se ha propuesto para otras regiones (p.e., Narr \& Suppe, 1994; Erslev \& Rogers, 1993, Fig. 9c). A partir de esta interpretación y asumiendo que la edad de las ignimbritas de la Formación Tiribí es de 0,332 $\mathrm{Ma} \pm 0.008 \mathrm{Ar}^{40} / \mathrm{Ar}^{39}$ (Pérez et al., 2006), podemos precisar esta misma edad para la falla Río Grande.

Las estimaciones geométricas y el grado de deformación observado en estas estructuras, sugieren una profundidad para esta falla menor a $1000 \mathrm{~m}$.

\section{Zona de falla Balsa}

Cerca de la entrada a Balsa (213833/493232, se localizó una zona de falla que mantiene una disposición predominante $\mathrm{N} 35^{\circ} \mathrm{W}, 70^{\circ} \mathrm{SW}$, posiblemente inversa sinestral, afectando a la unidad de debris avalanche y a la Formación Grifo Alto. Se destaca una fuerte tectónica que genera fracturas verticales con rumbos $\mathrm{N} 20^{\circ} \mathrm{W}$, con una extensa zona de alteración hidrotermal, por las cuales habrían subido los fluidos hidrotermales (e.g. $213866 / 493685, \mathrm{~N} 90^{\circ} \mathrm{E}, 70^{\circ} \mathrm{N}$ ), generando un enrejado complejo, dificultando el reconocimiento del buzamiento original. 


\section{Zona de falla Escobal}

Se localiza al extremo oeste del poblado de Escobal (212509/487023). Esta zona de falla fue observada en el campo con un rumbo predominante en dirección NW-SE (Fig. 6). En las cercanías del sitio Quebradas (212425/487243) se midió el plano en tres lugares diferentes: $\mathrm{N} 60^{\circ} \mathrm{E}$, $70^{\circ} \mathrm{N}$, a la cual no se le pudo determinar el movimiento; $\mathrm{N} 40^{\circ} \mathrm{E}, 85^{\circ} \mathrm{NW}$ de tipo dextral-inversa; $\mathrm{N} 45^{\circ} \mathrm{E}, 70^{\circ} \mathrm{NW}$ con estrías no muy claras, que parecen indicar un movimiento sinestral.

En el sector de la carretera donde se corta esta zona de falla es notoria la ausencia de deformación en los depósitos posteriores por lo que a esta falla se le podría asignar una edad del Plioceno inferior. La presencia de esta falla habría generado el desarrollo de importantes alteraciones hidrotermales existentes en la zona.

Como consecuencia de su movimiento al $\mathrm{NE}$, los sedimentos de relleno fueron acumulados en su frente orogénico, favoreciendo la formación de una cuña sedimentaria compuesta principalmente por estratos de los depósitos de debris avalanche y los rellenos coluviales y aluviales del cuaternario.

Según estas evidencias de campo se trataría de una falla inversa con componente de rumbo. Su extensión total no está definida en este trabajo, sin embargo, abarca toda el área de estudio.

\section{Zona de desgarre Tárcoles}

Denyer et al. (2003a) la denominan Falla Tárcoles y la describen con un rumbo que varía de $\mathrm{N} 40^{\circ} \mathrm{E}$ a $\mathrm{N} 55^{\circ} \mathrm{E}$. Tiene un movimiento sinestral (Denyer et al., 2003b), mientras que Marshall (2000) indica un movimiento vertical, en que el bloque NW baja con respecto al SE, lo cual deja un graben con la falla Jesús María, por donde fluyó la Formación Tivives; por ello se le llama el graben de Tivives. Está catalogada como una falla cuaternaria (Denyer et al., 2003b).

La Falla Tárcoles, descrita como una falla doble sinestral muestra una extensión considerable para Costa Rica, alrededor de 90

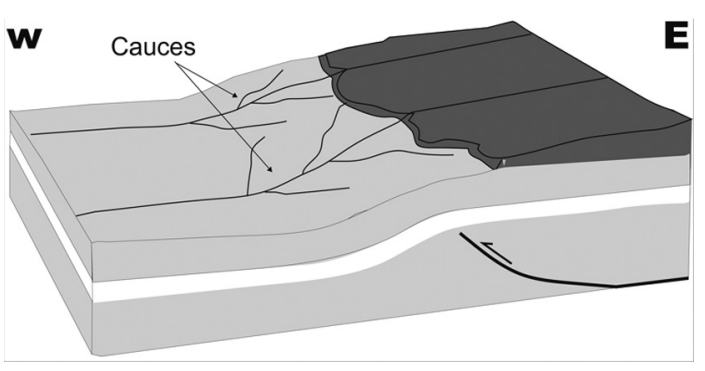

Fig. 8: Representación esquemática de una superficie de erosión generada a partir del alzamiento de una falla inversa.

km (Madrigal, 1970; Denyer et al., 2003a, b; Denyer \& Alvarado, 2007), que dentro del modelo preliminar propuesto acá, podría representar una falla de desgarre importante, dado que a partir de esta surgen los principales corrimientos de la zona de estudio. Sumado a esto, el modelo de acreción de un monte submarino estaría generando una estructura sigmoidal típicamente alargada, con fallas de desgarre situadas en los flancos laterales del mismo y con importantes fallas inversas en su frente de acreción. Sin embargo, se requiere de más investigación y trabajo de detalle para soportar mejor todo lo anterior, ya que esta se encuentra fuera del área de estudio y la interpretación que se le da es netamente teoría.

\section{Interpretación estructural}

Mediante la integración de los datos superficiales y los datos sismológicos registrados en la zona, se ha hecho una interpretación preliminar de las posibles zonas de ruptura. Los mecanismos focales indican un sistema de fallas inversas con componente de rumbo. De este modo, y teniendo en cuenta el marco tectónico regional, se ha elaborado una sección esquemática, que representa una posible interpretación del estilo estructural del sector y cuantifica el acortamiento existente en esta región en forma genérica (Fig. 10).

El acortamiento horizontal mínimo obtenido para el perfil es de $2,2 \mathrm{~km}$, equivalente a un porcentaje de acortamiento de 8,99\%.

Para las estructuras aflorantes en el área de estudio, se propone un mecanismo de evolución 

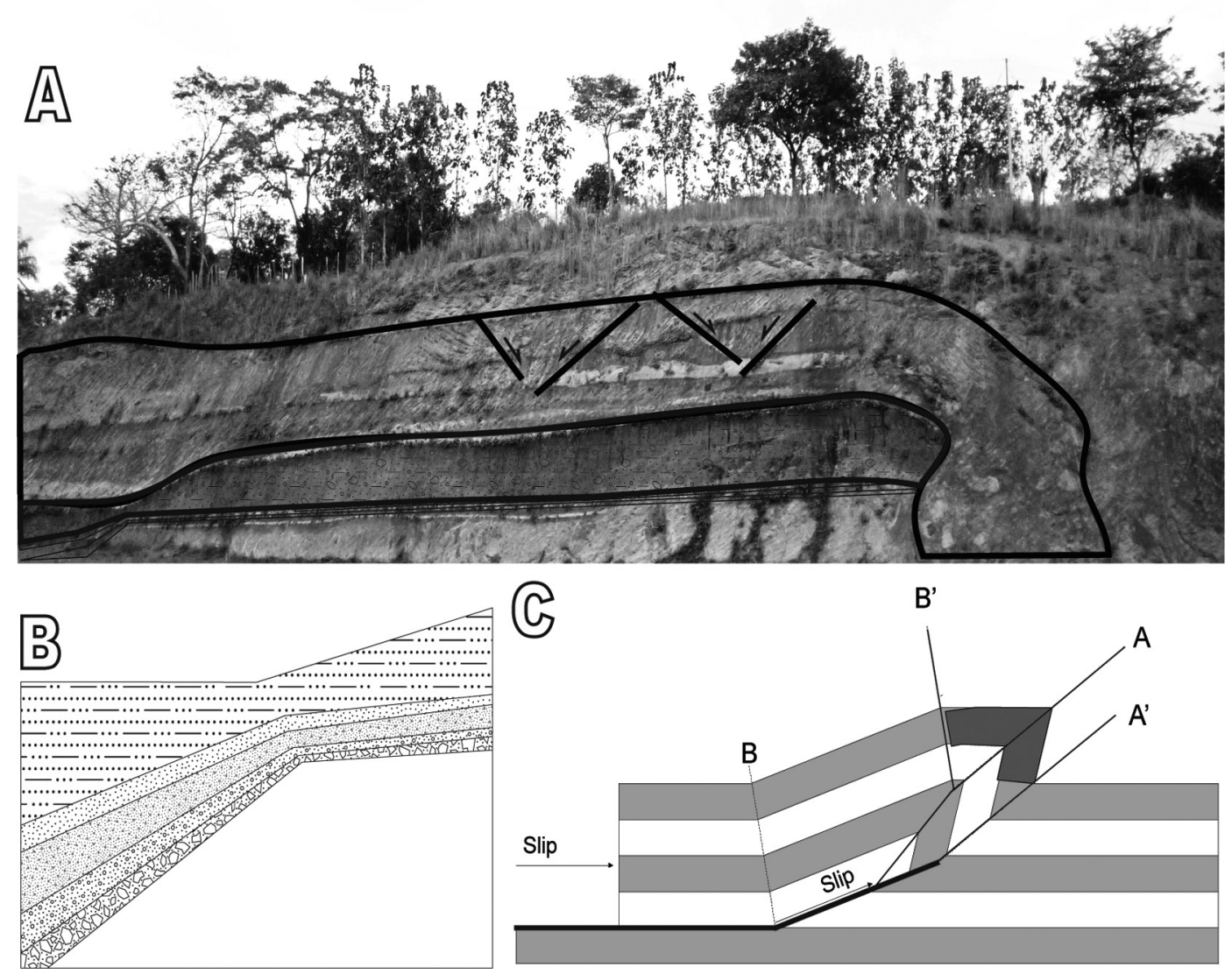

Fig. 9: A. Pliegue por propagación de falla deformando la cobertura de ignimbritas de la Formación Tiribí. Vista hacia el NW. Observar los pequeños grábenes producto del acomodo del bloque en la parte superior de la capa de ignimbritas B. Esquema mostrando estratos de crecimiento en onlap (Growth onlap), en la parte izquierda de la foto (A), que ponen en evidencia que la sedimentación fue sintectónica en condiciones de mayor rapidez de deformación que de sedimentación. C. Perfil esquemático de un pliegue por propagación de falla. El área sombreada representa la sección vista en el afloramiento.

de la deformación según una secuencia de fallas en secuencia hacia el antepaís (foreland) de suroeste a noreste, sobrepuesto a una secuencia de corrimientos con dirección al traspaís (hinterland) la cual corresponde a parte de la formación producida por las fallas de empuje frontal propuestas por Sitchler et al. (2007) Fig. 11.

Tomando en cuenta estas consideraciones, la deformación observada corresponde a una zona de piel fina (thin skinned), cuyo nivel de despegue basal sería cercano a los $2 \mathrm{~km}$ de profundidad. La estratigrafía de la zona sugiere que esta profundidad de despegue coincide con la profundidad de la Formación Peña Negra, constituida por materiales incompetentes como lutitas y pelitas negras.

\section{CONCLUSIONES}

El presente trabajo cumple con rescatar la estratigrafía de afloramientos que paulatinamente se han ido cubriendo con concreto lanzado, obras de estabilización y por la vegetación, y de proveer un modelo estructural, diferente a los previamente propuestos, aspectos que podrán afinarse y corroborarse con posteriores trabajos de campo.

La geología de la Ruta 27 permite definir, por primera vezcon detalle, una geología del extremo occidental del Valle Central y su correlación con la meseta de Orotina, que solía en su mayor parte estar reportada en perforaciones (p.ej. Echandi, 1981), como lo son las formaciones Nuestro Amo 
y Puente de Mulas, y el observar las relaciones estratigráficas con Colima Inferior. De igual modo, permitió ver la estructura interna del antiguo eje volcánico de los Montes del Aguacate, con sus diques y profusa alteración hidrotermal, y los depósitos epivolcánicos laterales. La propuesta inicial de Méndez \& Hidalgo (2004) de que la Unidad Coyol podía ser un depósito de debris avalanche y en parte la existencia de depósitos de debris flows, quedó comprobada y enmarcada en lo que se denomina Formación Nuestro Amo, constituida por lo menos por cuatro unidades de flujo volcaniclástico. Todavía se requiere de un mayor detalle geológico en los Montes del Aguacate y de algunas estructuras circulares, observadas en las fotografías aéreas, pero ubicadas fuera del área de estudio.

El modelo estructural propuesto difiere con respecto al de los trabajos previos, en los que las fallas eran principalmente dextrales (rumbo NW$\mathrm{SE}$ ) o sinestrales (rumbo NE-SW). El movimiento sinestral paralelo al sistema es consistente con la cinemática de movimiento reconocida en la desembocadura del Tárcoles. En dicha interpretación es necesario considerar que para la región de estudio el ángulo de convergencia entre las placas Cocos y Caribe, es cercano a $0^{\circ}$ (LaFemina et al., 2009) (Fig. 11a). Esto es un factor importante para el régimen de deformación dentro de una placa subdu- cida ya que el esfuerzo normal actúa en estos casos contra un orógeno ocasionando acortamiento y engrosamiento de la corteza (Scheuber et al., 1994) (Fig 11b).

Por tal motivo, se propone que las fallas de rumbo, trazadas en trabajos anteriores (p.e., Denyer et al., 2003a, b; Denyer \& Alvarado, 2007), poseen una fuerte componente inversa a modo de corrimientos. Estos se habrían originado durante el Cenozoico, cuando comenzó la deformación en el antearco interno y donde se exponen tres grandes fallas de empuje frontal que forman parte de la faja plegada y corrida que propone Sitchler et al. (2007), en secuencia hacia el traspaís (hinterland), de la cual forma parte la Falla Turrúcares.

Aunque el comienzo de la deformación no está establecido de forma precisa, los Montes del Aguacate están constituidos por rocas del Plioceno (Alvarado \& Gans, 2012), sobre las cuales se generan los principales corrimientos que cortan en superficie. Estas sobreyacen a un basamento ígneo y sedimentario del Cretácico Superior al Eoceno, que no aflora en el área, y rocas sedimentarias del Oligo-Mioceno, que afloran en las vecindades del área de la Ruta 27. Están cubiertas lateralmente por rocas volcánicas y volcaniclásticas del Cuaternario, las cuales se hallan deformadas. De acuerdo con lo anterior, se propone que la defor-

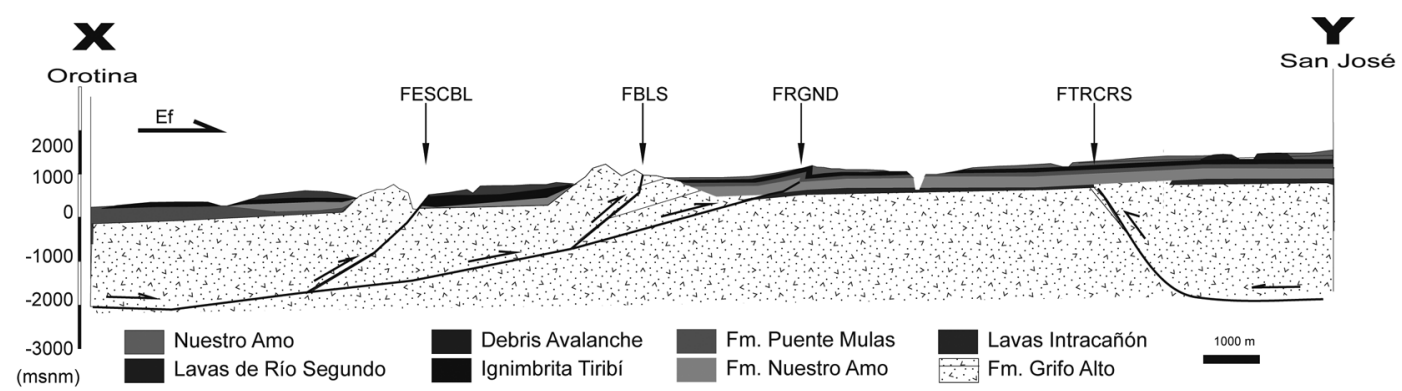

Fig. 10: Perfil esquemático de la ruta 27, de orientación SW-NE, mostrando dos fallas convergentes: Uno más antiguo con vergencia al SW y otro más reciente con vergencia al NE, o sea, hacia el antepaís. FSCBL: falla Escobal; FBLS: falla Balsa; FRNGD: falla Río Grande; FTRCRS: falla Turrúcares. 
mación se pudo originar a finales del Plioceno y haber continuado hasta la actualidad.

La deformación provocada por la acreción del cerro Turrubares, en lo que hoy se denomina el promontorio de Herradura, sería la responsable de la reactivación de las estructuras pre-existentes asociadas a los sistemas de fallas con vergencia suroccidental, así como de la generación de nuevas estructuras con una vergencia nororiental. Esta estructura, con altos topográficos, estaría asociado a un pop-up con una geometría típicamente sigmoidal y alargada (Fig. 12).

Esta deformación posiblemente no migró de manera significativa hacia el norte, donde se halla la zona de Atenas, debido a que debió chocar contra el eje volcánico del Aguacate, los cuales tienen una importante propilitización y silicificación (Laguna, 1984; Alvarado \& Gans, 2012), atribuyéndole una mayor dureza y menor deformación dúctil. Por lo tanto, afecta la región al SE de la zona de desgarre de Tárcoles, esta se debe a que en esta región se encuentran las unidades estratigráficas con menor dureza y mayor ductilidad, como por ejemplo la formación Peña Negra.

Las primeras estructuras en formase en el área de estudio, serian los corrimientos de Escobal y Balsa, ya que estos están directamente relacionado con la zona de desgarre conocida como falla Tárcoles. Se establece que la deformación migra de Suroeste a Noreste hacia el antepaís (foreland). Esta deformación, se vincula al empuje proveniente de estructuras profundas en el sector oriental del área de estudio. Estas primeras estructuras se encuentran afectadas por los fluidos hidrotermales y cortan únicamente los depósitos más antiguos de la Formación. Grifo Alto. Además están asociadas a la acreción del monte submarino denominado del bloque Herradura al suroeste de la región e interactuaron con la cobertura de rocas cenozoicas migrando a una deformación de piel fina en la cual nos concentramos en este artículo.

Se puede así proponer dividir la región en dos dominios estructurales predominantes; (a) el
Oriental, que corresponde al sector donde se propone la deformación de piel fina la cual migra en una secuencia progresiva hacia el NE donde se ubica el antepaís y (b) el Occidental el cual involucra una deformación en sentido contrario, la cual estaría migrando hacia el hinterland, esta deformación inicialmente estaría ligada a los corrimientos asociados a la falla Turrúcares y por ende a la faja plegada y corrida propuesta por Sitchler et al. (2007).

El estilo de deformación de piel fina, presumiblemente tendría un nivel de despegue en

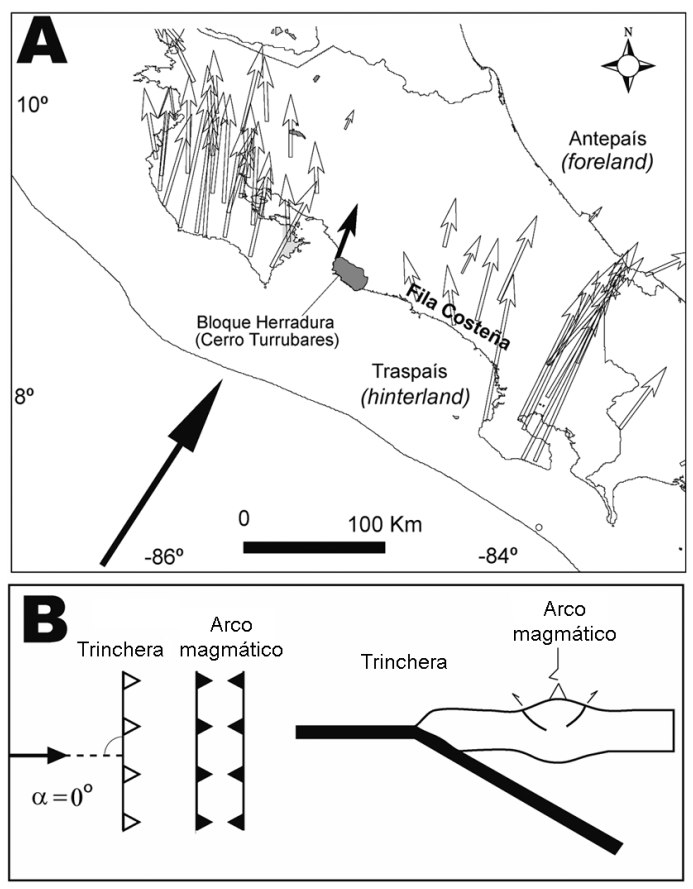

Fig. 11. A. Mapa de Costa Rica, con los principales vectores de convergencia, las flechas oscuras muestran el ángulo de convergencia entre las placas del coco y Caribe con un ángulo cercano a $0^{\circ}$ en el área de estudio (modificado de Lafemina et al., 2009). B. modelo esquemático cuando la oblicuidad es de $0^{\circ}$, el esfuerzo normal actúa como un orógeno ocasionando acortamiento y engrosamiento de la corteza (modificado de Scheuber et al., 1994). 


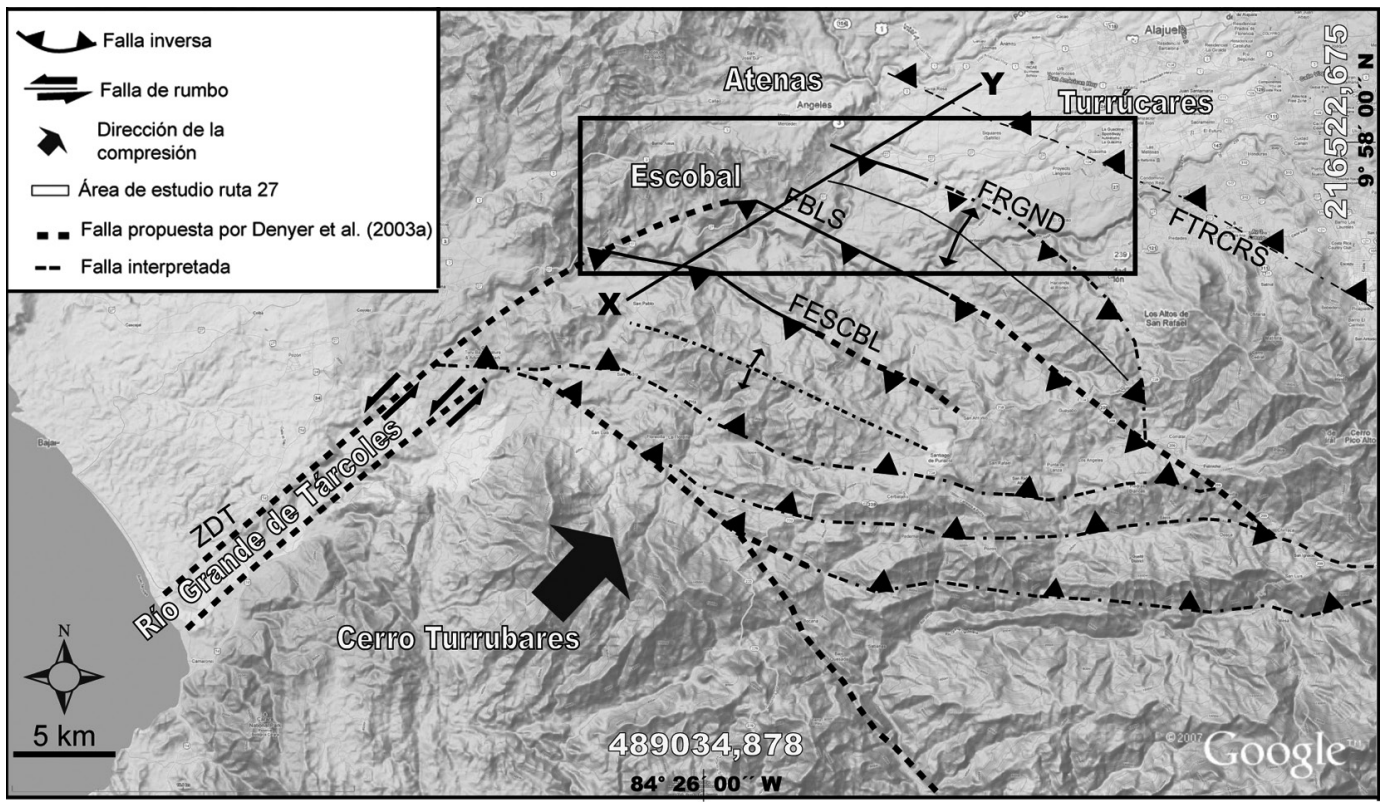

Fig. 12: Pop-up, muestra la deformación producida por la acreción del cerro Turrubares contra la costa Pacifica central. Las trazas de las fallas marcadas con líneas discontinuas, están basadas en Denyer et al. (2003b). Las demás fallas en líneas continuas, se trazan con respecto a la interpretación de imágenes satelitales. ZDT: zona de desgarre de Tárcoles; FSCBL: falla Escobal; FBLS falla Balsa; FRNGD: falla Río Grande; FTRCRS: falla Turrúcares.

la Formación Peña Negra, lo que genera el desarrollo de los principales sobrecorrimientos de la región, de este a oeste son: Escobal, Balsa y Río Grande. Estos se asume que poseen en su parte frontal, un ángulo de corte de entre $60^{\circ} \mathrm{y}$ $80^{\circ}$. La deformación debió de avanzar hacia el nororiente, por lo que las estructuras en este sector son relativamente más recientes y altera los depósitos de ignimbritas con edades de 0,3 y 0,4 Ma, pertenecientes a la Formación Tiribí y a la Formación Puente de Mulas, ya sea cortándolos o formando pliegues.

\section{AGRADECIMIENTOS}

La presente investigación se inició como parte del trabajo de campo en el curso de Vulcanología de nivel de cuarto año de bachillerato en Geología de la Universidad de Costa Rica, del I Semestre del 2010. La CNE colaboró con las giras posteriores con el fin de que se pudiera definir mejor el contexto tectónico, particularmente gracias a la desinteresada colaboración de Lidier Esquivel y Katherina Blanco Pocasangre. La RSN aportó los datos sismológicos. El presente trabajo es una contribución al proyecto Fortalecimiento de la investigación en Estratigrafía y Tectónica, 830-B0-242, del Centro de Investigaciones en Ciencias Geológicas de la Universidad de Costa Rica. Un especial agradecimiento a los revisores externos de este trabajo por sus valiosos comentarios y observaciones; Reinaldo Charrier, investigador del Departamento de Geología de la FCFM de la Universidad de Chile, Andrés Folguera, investigador del Departamento de Ciencias Geológicas de la FCEN de la Universidad de Buenos Aires, y a Percy Denyer investigador de la Escuela Centroamericana de Geología de la Universidad de Costa Rica. 


\section{REFERENCIAS}

ALVARADO, G.E. \& GANS, P.B., 2012: Síntesis geocronológica del magmatismo, metamorfismo y metalogenia de Costa Rica, América Central.- Rev. Geol. Amér. Central, 46: 7-122.

APPEL, H., 1990: Geochemie und K/ArDatierung an Magmatiten in Costa Rica, Zentralamerika.- 153 págs. Univ. Mainz, Alemania [Tesis de Diploma].

APPEL, H., WÖRNER, G., ALVARADO, G.E., RUNDLE, C. \& KUSSMAUL, S., 1994: Age relations in igneous rocks from Costa Rica.- Profil 7: 63-69.

ARIAS, O., 2003: Redefinición de la Formación Tulín (Mastrichtiano-Eoceno Inferior) del Pacífico Central de Costa Rica.- Rev. Geol. Amér. Central, 28: 47-68.

BARKHAUSEN, U., RANERO, C., VON HUENE, R., CANDE, S. \& ROESER H., 2001: Revised tectonic boundaries in the Cocos Plate off Costa Rica: Implications for the segmentation of the convergent margin and for plate tectonic models.- J. Geophys. 106(B9): 19207-19220.

CASTILLO, R., 1969: Geología de los mapas básicos Abra y partes de Río Grande, Costa Rica. 40 págs +1 mapa. MEIC, San José.

CORRIGAN, J., MANN, P. \& INGLE, J.C., 1990: Forearc response to subduction of the Cocos Ridge, Panama-Costa Rica.Geol. Soc. Am. Bull. 102: 628-653.

COWARD, M.P., 1983: Thrust tectonics, thin skinned or thick skinned, and the continuation of thrusts to deep in the crust.- J. Struct. Geol. 5(2): 113-123.
DECELLES P.G. \& GILES K.A., 2003: Foreland basin systems.- Basin Res. 8: 105-123.

DENGO, G., 1962: Tectonic-igneous sequence in Costa Rica.- En: ENGEL, A.E.J., JAMES, H.J. \& LEONARD, B.F. (eds): A volume to honor A.F. Budington.- Geol. Soc. Amer. Spec. Vol.: 133-161.

DENYER, P. \& ARIAS, O., 1991: Estratigrafía de la región Central de Costa Rica.- Rev. Geol. Amér. Central, 12: 1-59.

DENYER, P. \& ALVARADO, G.E., 2007: Mapa Geológico de Costa Rica 2007.- Escala 1: 400 000, Librería Francesa S.A., San José.

DENYER, P., AGUILAR, T. \& ALVARADO, G.E., 2003a: Geología y estratigrafía de la Hoja Barranca, Costa Rica.- Rev. Geol. Amér. Central, 29: 105-125.

DENYER, P., MONTERO, W. \& ALVARADO, G.E., 2003b: Atlas tectónico de Costa Rica.81 pags., Ed. Univ. Costa Rica, San José.

DIXON, T.H., 1993: GPS measurements of relative motion of the Cocos and Caribbean plates and strain accumulation across the Middle America Trench.- Geophys. Res. Letters, 20: 2167-2170: DOI: 10.1029/93GL02415.

DEMETS, C., 2001: A new estimate for present-day Cocos-Caribbean plate motion: Implications for slip along the Central American volcanic arc.- Geophys. Res. Letters, 28: 4043-4046: DOI: 10.1029/2001GL013518.

ECHANDI, E., 1981: Unidades volcánicas de la vertiente norte de la cuenca del río Virilla.123 págs +1 mapa. Univ. de Costa Rica, San José [Tesis Lic.]. 
ERSLEV, E., 1986: Basement balancing of Rocky Mountain foreland uplifts.- Geology, 14(3): 259-262.

ERSLEV, E. \& ROGERS, J., 1993: Basementcover geometry of Laramide faultpropagation folds.- En: SCHMIDT, C.J., CHASE, R.B., y ERSLEV, E.A. (eds): Laramide Basement Deformation in the Rocky Mountain Foreland of the Western United Stated.- Boulder, Colorado, Geol. Soc. Amer. Spec. Paper, 280: 125-146.

FISHER, D.M., GARDNER, T.W., MARSHALL, J.S., SAK, P. \& PROTTI, M., 1998: Effect of subducting seafloor roughness on forearc kinematics, Pacific coast, Costa Rica.- Geology, 26: 467-470.

FISHER, D.M., GARDNER, T.W., MARSHALL, J.S. \& MONTERO, W., 1994: Kinematics associated with late Cenozoic deformation in central Costa Rica: Western boundary of the Panama microplate.- Geology, 22: 263266.

FISHER, D.M., GARDNER, T.W., SAK, P.B., SANCHEZ, J.D., MURPHY, K., AND VANNUCCHI, P., 2004. Active thrusting in the inner forearc of an erosive convergent margin, Pacific coast, Costa Rica.- Tectonics, 23 TC2007. DOI: $10.1029 / 2002$ TC001464.

GARDNER, T.W., VERDONCK, D., PINTER, N.M., SLINGERLAND, R., FURLONG, K.P., BULLARD, T.F. \& WELLS, S.G., 1992: Quaternary uplift astride the aseismic Cocos Ridge, Pacific coast, Costa Rica.- Geol. Soc. Am. Bull. 104: 219-232.

GARDNER, T.W., MARSHALL, J., MERRITTS, D., BEE, B., BURGETTE, R., BURTON, E., COOKE, J.,
KEHRWALD, N., PROTTI, M., FISHER, D. \& SAK, P., 2001: Holocene forearc deformation in response to seamount subduction, Peninsula de Nicoya, Costa Rica.- Geology, 29: 151-154.

GAZEL, E., CARR, M.J., HOERNLE, K., FEIGENSON, M.D., SZYMANSKI, D., HAUFF, F. \& VAN DER BOGAARD, P., 2009: Galapagos-OIB signature in southern Central America: Mantle refertilization by arc-hot spot interaction.- Geochemistry Geophysics Geosystems, 10 (32), Q02S11 doi:10.1029/2008GC002246.

HORTON, B. K. 1999: Erosional control on the geometry and kinematics of thrust belt development in the central Andes.- Tectonics, 18: 1292-1304.

KIMURA, G., SILVER, E.A. \& BLUM, P. (eds.), 1997: Proceedings of the Ocean Drilling Program, Initial Report 170.- College Station TX Ocean Drilling Program, doi:10.2973/odp. proc.ir.170.app.1997

KOLARSKY, R.A., MANN, P., \& MONTERO, W., 1995: Island arc response to shallow subduction of the Cocos Ridge, Costa Rica.- En: MANN, P. (ed.): Geologic and Tectonic development of the Caribbean plate boundary in southern Central America.- Geol. Soc. Amer. Spec. Paper, 295: 235-262.

LAFEMINA, P., 2009: Fore-arc motion and Cocos Ridge collision in Central America.Geochem. Geophys. Geosystem, 10(57). DOI:10.1029/2008GC002181.

LAGUNA, J., 1984: Efectos de alteración hidrotermal y meteorización en vulcanitas del Grupo Aguacate, Costa Rica.- Rev. Geol. Amér. Central, 1: 1-17. 
MADRIGAL, R., 1970: Geología del mapa básico Barranca, Costa Rica.- 55 págs. Dirección de Geología, Minas y Petróleo. San José [Inf. interno].

MAKAY M.E. \& MOORE, G.F., 1990: Variation in deformation of the south Panama accretionary prism: Response to oblique subduction and trench sediment variation.Tectonics, 9: 683-698.

MANN P. \& KOLARSKY R.A., 1995: East Panama deformed belt: Structure, age, and neotectonic signifi cance.- En: MANN, P. (ed.): Geologic and tectonic development of the Caribbean plate boundary in southern Central America.- Geol. Soc. Amer. Spec. Paper, 295: 111-130.

MARSHALL, J.S., 2000: Active tectonics and Quaternary landscape evolution across the western Panamablock, Costa Rica, Central America.- xiii + 304 págs. The Pennsylvania State Univ., Pennsylvania [Tesis Ph.D.].

MARSHALL, J.S., FISHER, D.M. \& GARDNER T.W., 2000: Central Costa Rica deformed belt: Kinematics of diffuse faulting across the western Panama block.- Tectonics, 19: 468-492.

MARSHALL, J.S., IDLEMAN, B.D., GARDNER, T.W. \& FISHER, D.M., 2003: Landscape evolution within a retreating volcanic arc, Costa Rica, Central America.- Geology, 31 (5): 419-422.

MÉNDEZ, J. \& HIDALGO, P.J., 2004: Descripción geológica del depósito de debris avalanche El Coyol, Formación Barva, Costa Rica.Rev. Geol. Amér. Central, 30: 41-58.

MITRA S. \& MOUNT, V. 1998: Foreland basement-involved structures.- Amer. Assoc. Petrol. Geol. Bull. 82(1): 70-109.
MONTERO, W., 1999: El terremoto del 4 de Marzo 1924 (Ms 7.0): ¿Un gran temblor interplaca relacinado al límite incipiente entre la Placa Caribe y la Microplaca de Panamá?.- Rev. Geol. Amér. Central, 22: 25-62.

MONTERO, W., 2001: Neotectónica de la Región Central de Costa Rica: Frontera oeste de la microplaca de Panamá.- Rev. Geol. Amér. Central, 24: 29-56.

NARR, W., \& SUPPE, J., 1994: Kinematics of basement-involved compressive structures.Amer. J. Sci. 294: 802-806. DOI:10.2475/ ajs.294.7.802.

PACHECO, J.F., QUINTERO, R., VEGA, F, SEGURA, J., JIMÉNEZ, W., \& GONZÁLEZ, V., 2006: The Mw 6.4 Damas, Costa Rica, earthquake of 20 November 2004: Aftershocks and slip distribution.- Bull. Seismological Soc. Amer. 96: 1332-1343.

PÉREZ, W., 2000: Vulcanología y petroquímica del evento ignimbrítico del Pleistoceno Medio (0,33 M.a.) del Valle Central de Costa Rica.- xvi + 192 págs. Univ. de Costa Rica, San José [Tesis Lic.].

PÉREZ, W., ALVARADO, G.E. \& GANS, P.B., 2006: The 322 ka Tiribí Tuff: stratigraphy, geochrology and mechanisms of deposition of the largest and most recent ignimbrite in the Valle Central, Costa Rica.- Bull. Volcanol. 69: 25-40.

RODGERS, J., 1971: The Taconic Orogeny.Geol. Soc. Am. Bull. 82(5): 1141-1178.

RANERO, C.R., PHIPPS MORGAN, J., MCINTOSH, K., AND REICHERT, C., 2003: Bending-related faulting and mantle serpentinization at the Middle America Trench.- Nature, 425: 367-373. DOI: 10.1038/nature01961. 
SAK, P.B., FISHER, D.M. \& GARDNER, T.W., 2004: Effects of subducting seafloor roughness on upper plate vertical tectonism: Osa Peninsula, Costa Rica.- Tectonics, TC1017. DOI:10.1029/2002TC001474.

SAK, P.B., FISHER, D.M., GARDNER, T.W., MARSHALL, J. S. \& LAFEMINA, P., 2009: Rough crust subduction, forearc kinematics, and Quaternary uplift rates, Costa Rican segment of the Middle American Trench.- Geol. Soc. Am. Bull. 121: 992-1012.

SITCHLER, J.C., FISHER, D.M., GARDNER, T.W. \& PROTTI, J.M., 2007 : Constraints on inner forearc deformation from balanced cross sections, Fila Costeña thrust belt, Costa Rica.- Tectonics, 26, TC6012. DOI:10.1029/2006TC001949

SILVER, E.A., REED, D.L., TAGUDIN, J.E., \& HEIL, D.J., 1990: Implications of the north and south Panama thrust belts for the origin of the Panama orocline.- Tectonics, 9: 261-281.

SCHEUBER, E., BOGDANIC, T., JENSEN, A. \& REUTTER, K.J., 1994 : Tectonic development of the North Chilean Andes in relation to plate convergence and magmatism since the Jurassic.- En: REUTTER, K.J., SCHEUBER, E., \& WIGGER, P., (eds): Tectonics of the Southern Central Andes.- SpringerVerlag, Berlin: 121-139.

TOURNON, J., 1972: Présence de basaltes alcalíns récents au Costa Rica (Amérique Centrale).- Bull. Volcanol. 36: 140-147.

TOURNON, J., 1984: Magmatismes du Mesozoique a l'Actuel en Amerique Centrale: L'example de Costa Rica, des Ophiolites aux Andesites.- 335 págs. Univ. Curie, París [Tesis Ph.D.].
TUCKER, G.E. \& WHIPPLE K.X., 2002: Topographic outcomes predicted by stream erosion models: Sensitivity analysis and intermodel comparison.- J. Geophys. Res. 107(B9): 1-16.

TURIENZO, M.M. \& DIMIERI, L.V., 2005: Interpretación de la estructura del frente montañoso en la zona del río Diamante, Mendoza.- Rev. Asoc. Geol. Argent. 60(2): 336-352.

VANNUCCHI, P., SCHOLL, D.W., MESCHEDE, M., \& MCDOUGALL-REID, K., 2001: Tectonic erosion and consequent collapse of the Pacific margin of Costa Rica: Combined implications from ODP Leg 170, seismic offshore data, and regional geology of the Nicoya Península.- Tectonics, 20: 649-668. DOI: 10.1029/2000TC001223.

VANNUCCHI, P., RANERO, C.R., GALEOTTI, S., STRAUB, S.M., SCHOLL, D.W., \& MCDOUGALL-REID, K., 2003: Fast rates of subduction erosion along the Costa Rica Pacific margin: Implications for nonsteady rates of crustal recycling at subduction zones.- J. Geophys. Res. 108: 2511. DOI: 10.1029/2002JB002207.

VILLEGAS, A., 1997: Geodinámica de la Cordillera de Tilarán, relación entre la volcanología y la tectónica.- $\mathrm{v}+182$ págs + 2 mapas. Univ. de Costa Rica, San José [Tesis Lic.].

VON HUENE, R., BIALAS, J., FLUEH, E., CROPP, B., CSERNOK, T., FABEL, E., HOFFMANN, J., EMEIS, K., HOLLER, P., JESCHKE, G., LEANDRO, M., PERÉZ-FERNANDÉZ, C., CHAVARRIA, S.J., FLOREZ, H.A., ESCOBEDO, Z.D., LEÓN, R. \& BARRIOS, L.O., 1995: Morphotectonics of the Pacific convergent margin of Costa Rica.- En: MANN, P. (ed.): Geologic and 
Tectonic development of the Caribbean plate boundary in southern Central America.- Geol. Soc. Amer. Spec. Paper, 295: 291-307.

VON HUENE, R., RANERO, C., WEINREBE, W., \& HINZ, K., 2000: Quaternary convergent margin tectonics of Costa Rica: segmentation of the Cocos Plate and Central American volcanism.- Tectonics, 9: 314-334.
WHIPPLE, K.X. \&. MEADE, B.J., 2004: Controls on the strength of coupling among climate, erosion, and deformation in two-sided, frictional orogenic wedges at steady state.J. Geophys. Res. 109(F01011): 1-24.

WHIPPLE, K.X., \& TUCKER, G.E., 2002: Implications of sediment-flux-dependent river incision models for landscape evolution.- J. Geophys. Res. 107(B2): 1-20. 